\title{
ESTUDO DO TEMPO DE TRATAMENTO DE CASOS TRATADOS ORTODONTICAMENTE COM EXTRAÇÕES DE DOIS PRÉ-MOLARES SUPERIORES COMPARADOS AOS DE EXTRAÇÕES DE QUATRO PRÉ-MOLARES
}

Dissertação apresentada à Faculdade de Odontologia de Bauru, da Universidade de São Paulo, como parte dos requisitos para a obtenção do título de Mestre em Odontologia, área de Ortodontia.

( Edição Revisada) 


\section{ESTUDO DO TEMPO DE TRATAMENTO DE CASOS TRATADOS ORTODONTICAMENTE COM EXTRAÇÕES DE DOIS PRÉ-MOLARES SUPERIORES COMPARADOS AOS DE EXTRAÇÕES DE QUATRO PRÉ-MOLARES}

Dissertação apresentada à Faculdade de Odontologia de Bauru, da Universidade de São Paulo, como parte dos requisitos para a obtenção do título de Mestre em Odontologia, área de Ortodontia.

Orientador: Prof. Dr. Guilherme Janson 
Maria, Fabio Rogério Torres.

M337e Estudo do Tempo de Tratamento de casos tratados ortodonticamente com extrações de dois pré-molares superiores comparados aos de extrações de quatro prémolares / Fabio R.T.Maria. -- Bauru, 2003.

111 p. : il. ; $30 \mathrm{~cm}$.

Dissertação. (Mestrado) -- Faculdade de Odontologia de Bauru. USP.

Orientador: Prof. Dr. Guilherme Janson.

Autorizo, exclusivamente para fins acadêmicos e científicos, a reprodução parcial desta tese, por processos fotocopiadores e outros meios eletrônicos.

Assinatura:

Comitê de Ética da FOB

$N^{0}$ do Protocolo: 2042002

Data: 25/04/2002 


\section{Universidade de São Paulo \\ Faculdade de Odontologia de Bauru}

Al. Dr. Octávio Pinheiro Brisolla, 9-75 - Bauru-SP - CEP 17012-901 - C.P. 73 PABX (0XX14)235-8000 - FAX (0XX14)223-4679

Pós-Graduação

e-mail: posgrad@fob.usp.br - Fone: (0XX14)235-8223

\section{FOLHA DE APROVAÇÃO}

Dissertação apresentada e defendida por FÁBIO ROGÉRIO TORRES MARIA

e aprovada pela Comissão Julgadora em 05 de fevereiro de 2003.

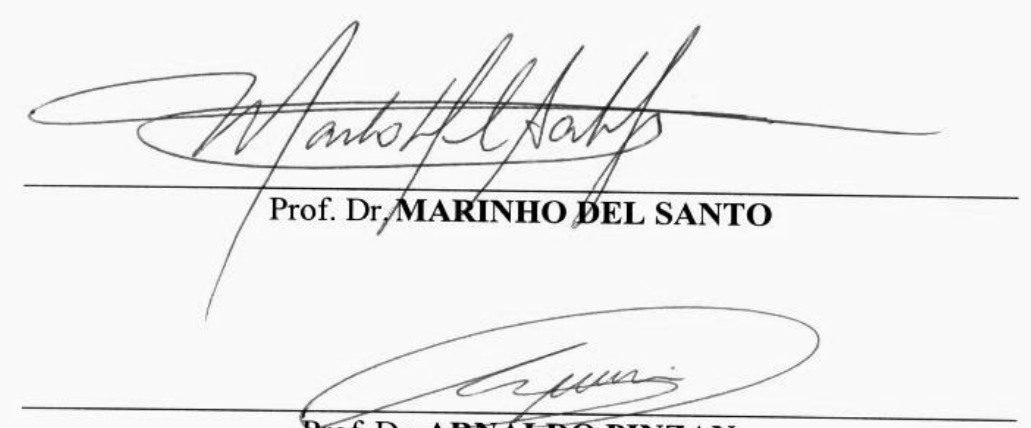

Prof.Dr. ARNALDO PINZAN

Faculdade de Odontologia de Bauru

\section{Prof. Dr. GUILHERME DOS REIS PEREIRA JANSON}

Presidente da Banca

Faculdade de Odontologia de Bauru - USP

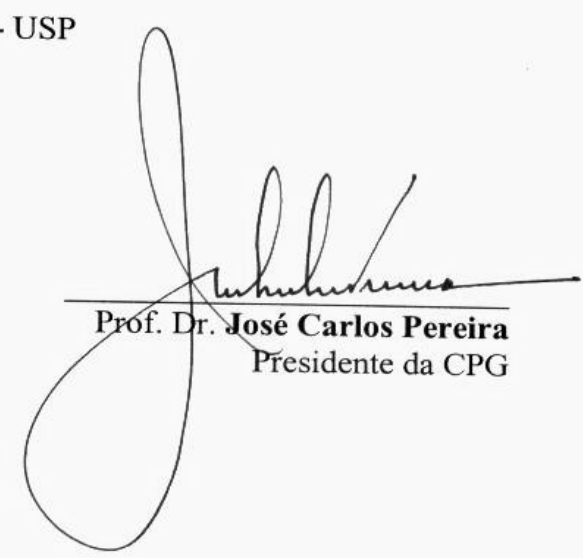




\section{FABIO ROGÉRIO TORRES MARIA}

30 de março de 1970

Nascimento

Mandaguari - Paraná

$1990-1994$

Curso de Graduação em Odontologia Universidade Estadual de Londrina - UELLondrina PR

$1995-1998$

Curso de Pós-Graduação em Ortodontia, ao nível de Especialização, na Universidade Estadual de Londrina - UEL-Londrina

$2001-2002$

Curso de Pós-Graduação em Odontologia, na área de Ortodontia, ao nível de Mestrado, na Faculdade de Odontologia de Bauru, da Universidade de São Paulo.(Minter FOB/UEL)

Associações SPRO-Sociedade Paranaense de Ortodontia. ABO - Associação Brasileira de Odontologia. 


\section{Dedico este trabalho}

A Deus, por nos proporcionar a dádiva de viver, nos orientar nos momentos dificeis, nos impulsionar em nossas buscas, além de nos proporcionar saúde e proteção em todos os momentos;

Aos meus pais, Oswaldo e Ana Maria, pelo esforço e dedicação que sempre demonstraram em cada passo de minha vida, permitindo-me, a partir de muito amor, carinho e incentivo, que pudesse alcançar todos os meus objetivos;

Às minhas irmãs Isabela e Fabiane, por estarem sempre ao meu lado, incentivando-me a cada novo desafio;

Ao meu sobrinho João Vitor e ao meu afilhado Lucca, que são verdadeiros símbolos do amor presente em nossa família;

Às queridas Ondina e Isabelinha, que representam a extensão de nossa família, e que sempre nos deram muito amor;

Minha eterna gratidão! 
Agradecimento especial:

Ao Professor Doutor Guilherme Janson, orientador e incentivador deste trabalho, que através de sua enorme vivência cientifica, pôde direcionar-me na condução desta pesquisa, sempre objetivando alcançar o melhor resultado possível; 
Meus sinceros agradecimentos:

À Professora Doutora Maria Fidela de Lima Navarro e ao Professor Newton E. de Moraes, exemplos dedicação e coragem, sem os quais este projeto não teria sido possível;

Aos Professores da Disciplina de Ortodontia da Faculdade de Odontologia de Bauru, da Universidade de São Paulo, que fizeram parte deste Mestrado Interinstitucional, Professor Doutor Marcos Roberto de Freitas e Professor Doutor José Fernando Castanha Henriques, pelos conhecimentos transmitidos, pela convivência e por toda a dedicação neste projeto; 
Agradeço ainda:

À Faculdade de Odontologia de Bauru, da Universidade de São Paulo, e à Universidade Estadual de Londrina, responsáveis pelo Mestrado Interinstitucional;

A todos os Professores que fizeram parte deste projeto e que foram responsáveis pela fase de créditos ministrados nas áreas básicas;

Aos funcionários do Departamento de Ortodontia, Daniel Francisco Rascão Selmo, Luís Sérgio Vieira, Maria José dos Santos Formenti, Teresa Cristina Alves Camaforte Ducatti e Vera Lúcia Rodrigues Purgato, pela presteza com que sempre me atenderam;

Ao secretario geral do Mestrado Interinstitucional, em Londrina, Ricardo, pela enorme dedicação ao curso;

Às bibliotecárias da Faculdade de Odontologia de Bauru, da Universidade de São Paulo, em nome das Sras. Cybele de Asumpção Fontes, Rita Paglione e Valéria Cristina Trindade Ferraz, pela orientação bibliográfica;

A todos os meus colegas de mestrado, em especial a Mauro Busato, João Tadeu Amin Graciano, Ricardo Zampieri, e Marcos Cyrino, pelo companheirismo;

A disciplina de Ortodontia da Faculdade de Odontologia de Bauru, da Universidade de São Paulo, por ter fornecido a amostra de pacientes com má oclusão de Classe II completa;

Aos professores Doutor Tieo Takahashi e Professor Doutor Walter Rino, por sempre me incentivarem em meu crescimento acadêmico 
Ao Coordenador do Curso de Odontologia da Universidade Paranaense, Prof. Márcio Gramma Hoeppner, por ter permitido a minha ausência para realizar o Curso de Mestrado;

Aos grandes amigos, e professores da Universidade Paranaense, Ricardo Takahashi, Lauri Dalmagro Filho, Ricardo Sampaio de Souza e Ernesto Roberto Neto, por suprirem a minha ausência durante o Curso de Mestrado;

À Nine, pelo enorme empenho na execução da digitação, formatação e impressão deste trabalho $e$

A todos que direta ou indiretamente contribuíram para a elaboração deste trabalho, minha mais sincera gratidão. 


\section{SUMÁRIO}

LISTA DE FIGURAS ................................................................................. ix

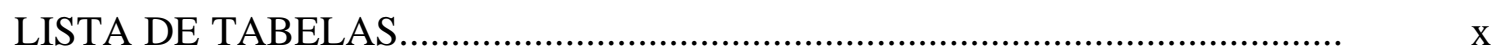

RESUMO

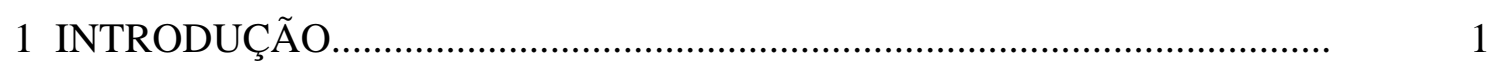

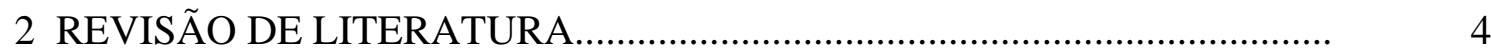

2.1 As extrações em Ortodontia.................................................................

2.2 Cooperação em Ortodontia........................................................................ 20

$2.3 \mathrm{O}$ tempo de tratamento em Ortodontia......................................................

3 PROPOSIÇÃO

4 MATERIAL E MÉTODOS................................................................... 47

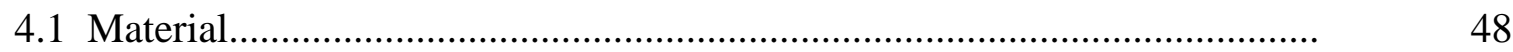

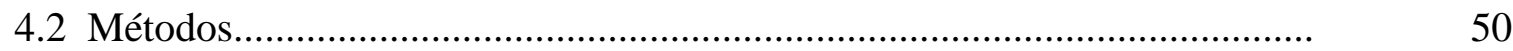

5 RESULTADOS

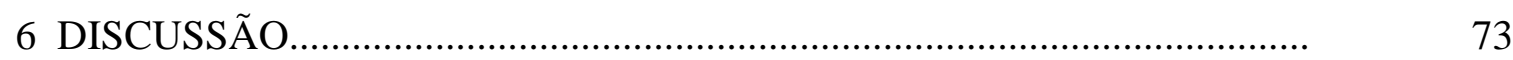

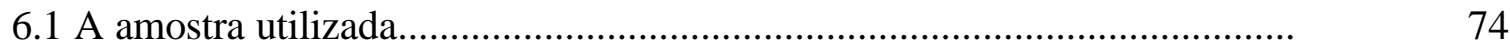

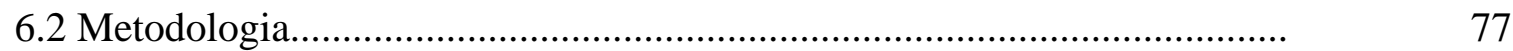

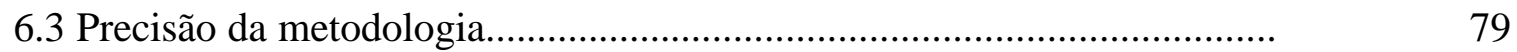

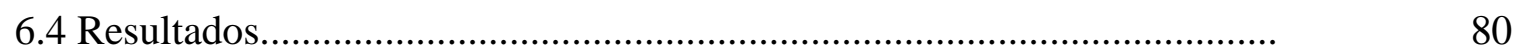

7 CONCLUSÕES............................................................................

REFERÊNCIAS BIBLIOGRÁFICAS ………................................................ 97

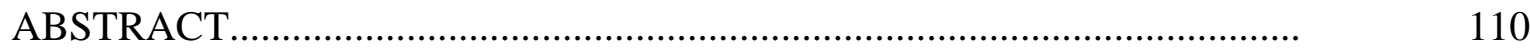

APÊNDICE. 


\section{LISTA DE FIGURAS}

FIGURA 1 - Valores médios para o tempo total de tratamento entre os dois grupos estudados

FIGURA 2 - Valores médios para o tempo total de tratamento entre os três grupos estudados após redivisão da amostra

FIGURA 3 - Valores médios do número de quebras do aparelho em cada grupo.

FIGURA 4 - Valores médios da variável Cooperação em cada grupo.

FIGURA 5 - Porcentagem dos escores de Cooperação em cada grupo. 


\section{LISTA DE TABELAS}

TABELA 1- Apresentação dos pesos que compõem o Índice de Prioridade de Tratamento (IPT), proposto por GRAINGER

TABELA 2 - Cálculo do erro do método intra-examinador. Diferença entre a primeira e a segunda mensuração, sendo o erro casual 63 (Dahlberg) e o erro sistemático (teste " $t$ " pareado)....

TABELA 3 - Cálculo do erro do método intra-examinador, para a variável não paramétrica cooperação. Diferença entre a primeira e a segunda mensuração, utilizando-se o teste Kappa.

TABELA 4- Médias e desvios padrão das variáveis estudadas, considerandose somente 2 grupos, de acordo com o número de extrações, 64 submetidas ao teste " $\mathrm{t}$ " para amostras independentes.

TABELA 5 - Valores médios e desvio padrão das variáveis relacionadas à características da amostra, submetidas à Análise de Variância (ANOVA) entre os 3 grupos

TABELA 6 - Valores médios e desvio padrão das variáveis relacionadas ao tempo total de tratamento e suas fases, submetidas à Análise de Variância (ANOVA) entre os 3 grupos.

TABELA 7 - Valores médios e desvio padrão das variáveis relacionadas ao número de ativações, faltas e quebras, submetidas à Análise de Variância (ANOVA) entre os 3 grupos..

TABELA 8 -Comparação entre os grupos para a variável cooperação, estabelecida por escores não paramétricos

TABELA 9 - Correlação de Pearson para algumas das variáveis analisadas para a amostra total $(\mathrm{N}=121)$, em relação ao tempo total de tratamento (TT)

TABELA 10 - Correlação de Spearman entre as variáveis tempo de tratamento (TT), Faltas e Quebras, com a variável não paramétrica cooperação (Coop), para a amostra total $(\mathrm{N}=121)$ e para os 3 grupos isoladamente. 
TABELA 11 - Correlação de Pearson para algumas das variáveis analisadas, para a amostra total e para os 3 grupos.

TABELA 12 - Quantidade e percentual de valores de IPT final igual a zero (IPT (f) $=0$ ), de acordo com cada grupo tratado (3 70 grupos)

TABELA 13 - Quantidade e percentual de valores de IPT final igual a zero (IPT $(f)=0)$, de acordo com cada grupo tratado, quando a amostra foi 70 subdividida em 2 grupos ( 2 e 4 extrações).

TABELA 14- Distribuição dos scores de cooperação em cada grupo analisado

TABELA 15 - Distribuição do tipo de ancoragem planejada inicialmente, para cada grupo estudado.

TABELA 16 - Distribuição da quantidade de apinhamento ântero-inferior inicial (em $\mathrm{mm}$ ) para cada grupo.

TABELA 17 - Valor médio, valor mínimo, valor máximo e desvio padrão (em meses), para a variável replanejamento (RP). 
RESUMO 


\section{RESUMO}

O propósito do presente estudo foi o de comparar os tempos de tratamento ortodôntico de casos apresentando inicialmente más oclusões de Classe II bilaterais completas, e que foram tratados com diferentes protocolos de extrações de pré-molares, com duas extrações de pré-molares superiores ou com extrações de quatro pré-molares. Para esta comparação, foram selecionados 121 pacientes , divididos em dois grupos, de acordo com os critérios de extrações. O grupo 1 , submetido a apenas duas extrações, foi constituído de 73 pacientes ( 30 do gênero feminino e 43 do gênero masculino), com idade média de 13,73 anos, enquanto o grupo 2, com quatro extrações, constituiu-se de 48 pacientes (21 do gênero feminino e 27 do gênero masculino), apresentando idade média de 13,03 anos. Observou-se que o grupo 1 apresentava uma grande porcentagem de $\operatorname{casos}(32,87 \%)$ que haviam sido iniciados com planejamento sem extrações, as quais só foram realizadas após um replanejamento. Desta forma, para evitar distorções nos resultados ,o grupo 1 foi redividido em 2 subgrupos, A e B, submetidos a extrações imediatas ou tardias de dois pré-molares, respectivamente. Foram avaliadas adicionalmente ao tempo de tratamento de cada grupo, o nível de cooperação desses pacientes, além do número de faltas e número de quebras do aparelho. Os valores foram submetidos a testes estatísticos comparativos entre os grupos e de correlação entre algumas variáveis. Os resultados demonstraram que o tempo total de tratamento para o grupo planejado e tratado desde o início com duas extrações de prémolares, apresentou-se significantemente menor que o grupo tratado com quatro extrações, que apresentou um tempo de tratamento bastante semelhante ao grupo submetido a extrações somente após um replanejamento. Além disso, constatou-se uma correlação estatisticamente significante entre o tempo total de tratamento com os níveis de cooperação, número de quebras e número de faltas dos pacientes durante o tratamento. Portanto, pode-se esperar uma menor duração do tratamento ortodôntico da má oclusão de Classe II completa, quando opta-se pelo protocolo de duas extrações superiores, ao invés de quatro extrações. 
1 INTRODUÇÃO 


\section{INTRODUÇÃO}

Dentre as várias formas de tratamento da má oclusão de Classe II, temos as alternativas de extrações de quatro pré-molares ou de dois prémolares superiores. O Tratamento com quatro extrações depende enormemente da colaboração do paciente, torna as exigências mecânicas muito maiores e já se demonstrou que conseqüentemente a probabilidade de sucesso na obtenção de resultados oclusais satisfatórios é maior quando se utiliza o protocolo de extrações de dois pré-molares superiores ${ }^{22}$. Assim, a decisão de se extrair dentes ou não, e o número de dentes a serem extraídos, pode influenciar o resultado final, incluindo a estética, a oclusão, a satisfação dos pacientes e seus familiares, assim como também a duração do tratamento ${ }^{108,145}$. Esta escolha pode também afetar todo o processo do tratamento, como o número de consultas necessárias, custos para o paciente e para o profissional, assim como riscos de efeitos adversos provenientes de tratamentos acentuadamente prolongados ${ }^{2,104}$.Com relação à duração destes tratamentos, especula-se que o tempo de tratamento no protocolo com quatro extrações seja maior que o de apenas duas extrações, devido à essa maior dificuldade mecânica. Desta forma, um maior número de informações científicas que possam ser relacionadas à variabilidade da duração destes tratamentos podem ser bastante benéficas para uma maior previsibilidade inicial destes casos, podendo o ortodontista fornecer mais subsídios aos pacientes e seus pais quando estes demonstram uma preocupação bastante comum de por quanto tempo deverão ser submetidos a estas terapias ${ }^{10,48}$. Para uma maior previsibilidade da duração destes tratamentos, torna-se imprescindível considerarmos não só o protocolo 
de extrações, mas também a influência da cooperação dos pacientes nos resultados finais e no tempo despendido para que tais resultados sejam alcançados ${ }^{90}$. Os principais fatores associados ao quesito cooperação, passam pelo nível de motivação destes pacientes em seguir à risca o uso de dispositivos mecânicos auxiliares, tais como aparelhos extrabucais e elásticos, além do número de faltas às consultas e do número de quebras do aparelho ${ }^{108,123}$. Um outro fator a ser considerado quando se avalia a duração de um tratamento ortodôntico, é o número de fases em que se planeja a execução desta terapia, assim como também a necessidade de se modificar o planejamento inicial devido à falta de cooperação dos pacientes, forçando estes casos a um replanejamento. Portanto, com a finalidade de investigar estas especulações, decidiu-se realizar essa pesquisa, de caráter retrospectivo, comparando-se os tempos de tratamento de pacientes apresentando má oclusão de Classe II completa bilateral ${ }^{1}$, tratados com mecânica edgewise simplificada, utilizandose protocolos de duas ou de quatro extrações de pré-molares, além de considerar a possível relevância de algumas variáveis, tais como a cooperação, o número de faltas e de quebras na duração desses tratamentos. 
2 REVISÃO DE LITERATURA 


\section{REVISÃO DA LITERATURA}

Em qualquer abordagem que se faça sobre a duração de um tratamento ortodôntico, é indiscutível que algumas variáveis que sabidamente poderão influenciá-la, devem obrigatoriamente ser levadas em consideração. Desta maneira, objetivando uma melhor compreensão, a revisão da literatura foi desenvolvida de forma a fornecer informações sobre os protocolos de tratamento que envolvam extrações dentárias de uma forma geral, e principalmente direcionados para a correção da má oclusão de Classe II. A seguir, abordou-se a importância da cooperação em ortodontia e os vários fatores a ela associados. Por fim, revisou-se especificamente o tempo de tratamento ortodôntico e suas variáveis.

\subsection{As extrações dentárias em Ortodontia}

Desde o século XVIII, Bourdet recomendava a extração de prémolares, com finalidade estética para aliviar o apinhamento dos dentes anteriores ${ }^{24}$.

John Hunter (1771), em seu livro "História natural dos dentes" descreve a correção da protrusão dentária com a extração de pré-molares. Fox, um pouco mais tarde (1803), defendia a extração de dentes decíduos como prevenção de possíveis posicionamentos incorretos com a erupção dos dentes permanentes, 
procedimento contestado por Delabarre, em sua obra "Odontologia" (1815), que considerava a importância destes dentes como mantenedores de espaço ${ }^{24}$.

Em 1841, Defoulon considerava que, antes de procedimentos extracionistas, deve-se estimular o crescimento ósseo através da expansão, mesmo com apinhamento. Maclean (1857) orienta a extração de primeiros molares permanentes para favorecer o alinhamento dos dentes, embora Farrer, em 1888, alerte que a extração indiscriminada pode criar problemas ${ }^{24}$.

Nessa linha de pensamento, Edward Angle, considera, na $6^{\text {a }}$ edição de seu livro, ser difícil uma generalização de indicações das extrações, por considerar bastante abrangentes as variáveis. Mais tarde, Angle se contrapõe intensamente ao critério extracionista, defendendo a partir daí o conceito de desenvolvimento funcional: os dentes deveriam ser colocados em suas posições corretas, alinhados, nivelados e articulados entre si, para que a função pudesse estimular o crescimento das bases ósseas, conseguindo-se assim, espaço para todos os dentes. Começava aí a filosofia expansionista, que buscava: 1 - uma estética facial e dentária; 2 - saúde periodontal; 3 - função ideal e 4 - estabilidade. Segundo Angle, estes resultados só poderiam ser alcançados com a manutenção de todos os dentes ${ }^{24,117}$.

Como discípulo de Angle, TWEED ${ }^{139}$, ao aplic ar os princípios básicos da técnica de arco de canto, idealizada por Angle, no tratamento das más oclusões de Classe II, divisão 1, sem extração, começou a se frustrar com os aspectos clínicos dos resultados obtidos, normalmente com biprotrusões e 
perfis faciais antiestéticos. A partir de 1936, passou a contrariar seu mestre, admitindo extrações de quatro primeiros pré-molares, para obter um melhor posicionamento dos incisivos em suas inclinações axiais corretas, e em 1941, idealizou e passou a preconizar o preparo de ancoragem, que associado às extrações mudou completamente os princípios da mecânica expansionista $24,117,140$

GRIEVE ${ }^{62}$, em 1944, corroborando as idéias de Tweed, observou também que a maioria de seus casos tratados ortodonticamente através dos princípios expansionistas tinham sofrido recidiva. Relatou que em 1926 procedeu seu primeiro caso com a extração de 4 pré-molares, que lhe permitiram uma verticalização e intrusão dos incisivos inferiores, conseguindo a correção do plano oclusal, e um melhor resultado da estética facial. Segundo o autor, sempre que a extração de 4 dentes for indicada, normalmente os dentes de escolha são os primeiros pré-molares, a menos que outras limitações, tais como perdas de outros elementos estejam presentes. Porém, ao final, conclui que em alguns casos mais discrepantes, nem mesmo a extração de quatro elementos dentários (até mesmo molares) é suficiente para um correto relacionamento maxilo-mandibular.

A partir da década de 50, com o advento rotineiro da cefalometria, TWEED $^{141}$, passa a basear rotineiramente seu diagnóstico no triângulo de Tweed, baseado em valores normativos para os ângulos FMA, IMPA e FMIA, como guias diagnósticos para a posição axial dos incisivos inferiores dentro de suas bases ósseas e a partir daí indicar ou não a necessidade de extrações para correção cefalométrica $^{45,115}$. 
DEWEL $^{38}$, em 1956, prescreve que para se tratar a má oclusão de Classe II com extrações, os pré-molares inferiores deveriam ser previamente extraídos com subseqüente preparo de ancoragem posterior inferior e verticalização ântero-inferior. Os pré-molares superiores só seriam extraídos após o estabelecimento de uma rígida ancoragem mandibular ${ }^{139}$, para só então ser iniciada a mecânica de Classe II. Segundo o autor, na fase de preparo de ancoragem, usaria-se elástico de Classe III e ou ganchos J para controle ânteroinferior.

Já MOORE ${ }^{88}$, em1959, defende que um conhecimento básico sobre o crescimento facial e a influência do gênero e da idade são fundamentais para o crescimento e o planejamento da correção desta má-oclusão. Por fim, defende que as extrações dentárias devem sempre ser consideradas como uma alternativa, nos casos com espaços insuficientes para as necessidades de movimentação dentária, com complemento de aparelhos extrabucais tipo Kloehn $^{76}$ para um redirecionamento do crescimento maxilar, mesmo que as extrações sejam inevitáveis.

Seguindo os mesmos objetivos da filosofia de Tweed ${ }^{139,140,141}$, JARABAK $^{69}$, em 1960, faz pequenas considerações que acredita pertinentes em relação às modificações da técnica original proposta por Tweed. A primeira exceção se refere à prescrição de fios iniciais redondos e mais resilientes para a incorporação de movimentações dentárias de segunda ordem, contrapondo-se aos fios retangulares menos resilientes. A segunda exceção seria a movimentação em massa dos dentes maxilares para a redução da relação molar de Classe II. Acredita serem estas modificações importantes na redução do 
tempo de tratamento e principalmente por se enquadrarem mais efetivamente dentro de um contexto biológico.

TULLEY; CAMPBELL ${ }^{137}$, em 1965, afirmam que o apinhamento é uma das principais indicações de extrações no arco inferior em tratamentos apresentando má oclusão de Classe II divisão 1. Afirmam que a protrusão dos incisivos inferiores para a correção deste apinhamento, levaria a uma recidiva pela ação contrária do lábio. Porém, SALZMANN ${ }^{117}$, em 1966, adverte que a protrusão dos incisivos inferiores devem servir de guia, mas não são aceitos como critério invariável para a extração.

Para GRABER ${ }^{54}$, em 1969, quando o paciente não apresenta mais crescimento e possui um bom arco inferior, o tratamento deveria ser realizado com extrações de 2 primeiros pré-molares superiores, ou com distalização de molares. Com a presença de um apinhamento inferior considerável, a extração de dois primeiros ou dois segundos pré-molares inferiores poderão ser realizados. Considera ainda que a interpretação cefalométrica não deve ser levado tão à risca. Assim, em muitos casos é possível se evitar a extração inferior e retração anterior, aceitando-se uma posição de incisivos inferiores um pouco mais anteriorizada ${ }^{55,57}$.

A decisão de se extrair ou não dentes como parte do tratamento ortodôntico pode influenciar o resultado final, incluindo o perfil facial, a estética, a oclusão, a satisfação do paciente, assim como a duração do tratamento. Este procedimento pode também afetar todo o processo de 
tratamento, como o número de consultas necessárias, custos para o paciente e para o profissional, assim como possíveis riscos de efeitos adversos provenientes de procedimentos cirúrgicos ${ }^{145}$.

Desta maneira, o ortodontista se depara, com grande freqüência, com casos considerados limítrofes, ou borderline ${ }^{15,19,37,133,}$, no que se refere à decisão ou não de se extrair dentes com finalidade ortodôntica.

Segundo $\mathrm{CASE}^{26}$, as principais indicações de extração nos casos de má oclusão de Classe II divisão 1 são: 1- protrusão do lábio superior, com a mandíbula bem posicionada e; 2 - casos de protrusão superior acompanhada de retrusão mandibular. Evidencia ainda que o foco principal deve ser a obtenção de um perfil facial harmônico, quando a decisão incorpora extrações. Considera que estas estariam contra-indicadas quando os dentes inferiores estivessem retruídos (ângulo mento labial aumentado) e os superiores estivessem bem posicionados ou levemente vestibularizados.

Com a preocupação de estabelecer alguns guias de conduta em relação aos casos limítrofes no que se refere à decisão ou não de extrações dentárias como parte do planejamento, SWAIN $^{133}$, em 1971, enfatiza que o diagnóstico e a escolha da melhor das alternativas é mais um processo de eliminação de possibilidades, em casos considerados moderados, que aqueles casos mais severos onde as opções para as possíveis correções são bastante restritivas. Defende que estes casos limítrofes deveriam ser observadas por um determinado período, e que uma avaliação dos possíveis prognósticos e suas 
relações com as alternativas de escolha fossem bastante ponderadas ${ }^{14,20,114}$, principalmente em relação à estabilidade e aos resultados finais.

Em 1995, BISHARA; CUMMINS; JAKOBSEN ${ }^{19}$, compararam as características dentofaciais pré-tratamento de 91 casos tratados ortodonticamente, com ou sem extrações, para que fosse possível identificar quais parâmetros influenciam na decisão de se fazer extração. $O$ grupo com extrações de quatro primeiros pré-molares apresentava uma maior discrepância de modelo em ambos os arcos, lábios superiores e inferiores nos homens, e somente o lábio inferior nas mulheres mais protruído. A posição dos lábios foi nesse grupo determinante para a decisão das extrações. Esta preocupação do impacto das extrações no perfil facial faz parte de vários outros trabalhos relacionados à quantidade de retração dos incis ivos superiores e seu efeito sobre os lábios ${ }^{17,20,41,131}$, ângulo nasolabial ${ }^{152}$, aspectos relacionados ao tamanho e forma do nariz ${ }^{105}$, além do impacto das extrações sobre o sorriso e o corredor bucal ${ }^{71}$.

Com relação a possíveis impactos das extrações sobre o desenvolvimento de disfunções temporomandibulares, MC LAUGHLIN; BENNET $^{86}$, em 1995, procuraram através de uma revisão da literatura investigar se há realmente fundamentação científica no dilema que associa o desenvolvimento de disfunções têmporo-madibulares às extrações de prémolares. Aqueles que defendem esta associação, como Witzig e Spahl, afirmam que isto ocorre por um colapso da dimensão vertical, sobrecorreção do sobressaliência com impacto sobre o perfil facial, o surgimento de contatos prematuros anteriores, e ainda um deslocamento distal da mandíbula e dos 
côndilos. Porém, a grande maioria dos trabalhos científicos ${ }^{15,81}$ não suportam estas afirmações, principalmente por não haver uma maior incidência destas disfunções em pacientes não tratados ortodonticamente ou tratados sem extrações. Além disso, parece ser evidente que se algum destes efeitos indesejáveis, seja no perfil facial, na acentuação sobremordida e no aparecimento de contatos prematuros realmente acontecem, parecem ser resultados diretos de erros de diagnósticos ou erros de mecânica.

Muitos trabalhos científicos ${ }^{95,97,147}$ demonstram que durante o processo de diagnóstico e plano de tratamento, a frequiência de extrações dentárias não segue uma prevalência estável, parecendo ser mais um processo intensamente baseado em opiniões pessoais, vinculado a experiências anteriores, sem grande respaldo científico para fundamentar esta decisão. Por este motivo, RIBAREVSKI et al. ${ }^{99}$, em 1996, se propuseram a avaliar a confiabilidade intra e interexaminador das decisões de extrações dentárias como parte do planejamento ortodôntico. Para isto foram avaliados 60 pacientes, apresentando má oclusão de Classe II divisão 1, com idades entre 11 e 14 anos, tendo pelo menos $6 \mathrm{~mm}$ de sobressaliência. Os planejamentos foram reavaliados por duas vezes, com intervalos de 1 mês entre elas, por 10 ortodontistas que replanejaram todos os casos novamente, e registraram suas decisões em relação às extrações. Com os resultados obtidos, concluem estarem os ortodontis tas baseando suas decisões de extrações em critérios individuais, não aplicados universalmente, reforçando a afirmação que os planejamentos ortodônticos têm se baseado em níveis bastante frágeis de evidências científicas. 
Quando a decisão tende para a extração, há ainda que se decidir qual dente seria preferencial, de acordo com benefícios mecânicos que poderiam promover. Desta forma a escolha do dente a ser extraído deve, segundo DEWEL $^{37}$, ser cuidadosamente analisada. Esta análise deve ser guiada pelo grau de discrepâncias entre a massa dentária e a óssea, além da quantidade de espaço a ser fechado após o correto posicionamento dos incisivos inferiores. Em casos de apinhamento severo, a escolha é quase sempre por primeiros prémolares, praticamente não havendo espaços remanescentes. Já em casos limítrofes, há freqüentemente uma maior demanda de espaço que o necessário, espaço este que deve ser fechado com mesialização do segmento posterior $51,142,143$. Por isso, o autor acredita que a extração de segundos prémolares $^{35,65,129}$, aumentando a ancoragem anterior de 6 para 8 dentes, facilitaria este fechamento de espaços com uma mesialização mais favorável do segmento posterior, evitando-se uma retroinclinação exagerada ântero-inferior, além de favorecer a correção da chave molar, e até mesmo uma rotação anti-horária da mandíbula ${ }^{151}$.

Em relação à má oclusão de Classe II divisão 2, com pacientes em fase de crescimento, seja no final da dentadura mista ou no início da tardia, vários estudos 16,30,107,151 alegam que as extrações de pré-molares deveriam ser evitados sempre que possível. O protocolo de tratamento sem extrações provavelmente contribuiria para a correção da má oclusão sem tendências indesejáveis de achatamento do perfil fácil e aumento da sobremordida. 
Em contrapartida, em pacientes adultos, sem crescimento, a ausência de manifestação de crescimento mandibular, exige um maior esforço mecânico para a correção da chave molar, com manutenção ou distalização dos molares superiores $^{8,66}$.

Para GRABER $^{55}$, em uma má oclusão de Classe II divisão 1, a extração de quatro pré-molares pode não ser a melhor escolha, por exigir um maior controle mecânico de ancoragem, um maior controle da sobremordida, e um maior controle de torque dos incisivos superiores e inferiores, potencializando possíveis respostas iatrogênicas ${ }^{104}$. Em uma avaliação de 150 pacientes, observou que dois terços desses pacientes tinham arcos inferiores normais, apresentando apenas discrepâncias sagitais com o arco superior. Isto, segundo Graber, reforça a impressão que a extração no arco inferior pode muitas vezes ser evitada.

Uma opção para estas correções, seria a extração de somente dois prémolares superiores ${ }^{22,55,75,78,81,118}$ para redução da sobressalência excessiva e correção da chave de caninos, facilitando a extensão das movimentações mecânicas, finalizando com os molares em Classe II.

Comparando os resultados oclusais do tratamento da Classe II, com protocolos de extrações de dois pré-molares superiores com o protocolo de extrações de dois pré-molares superiores e dois pré-molares inferiores, BRAMBILLA $^{22}$, avaliou 131 pacientes, sendo 81 casos tratados com duas extrações superiores e 50 casos tratados com quatro extrações de pré-molares. 
Para a verificação do melhor resultado oclusal, utilizou o índice de prioridade de tratamento $(\text { IPT })^{58}$, nas fases pré e pós-tratamento. Os resultados demonstraram que o grupo 1, com apenas duas extrações superiores, apresentou melhores resultados oclusais que os do grupo 2. Portanto, conclue que, sempre que for possível se evitar extrações inferiores, a correção da má oclusão de Classe II completa com duas extrações somente na maxila parecem conduzir a resultados oclusais mais satisfatórios.

Considerando-se casos que necessitem previamente de extrações maxilares, e que já apresentem caninos impactados, ALTMAN et al. ${ }^{5}$, propõem que a possibilidade de extrações dos caninos em substituição aos prémolares deveriam ser cuidadosamente analisados como uma alternativa ao tratamento. Baseiam-se principalmente nos riscos de insucesso no tracionamento destes caninos, possibilidade de seqüelas pós-operatórias, anquilose e a proximidade de outras raízes adjacentes, que poderiam acarretar perdas ósseas, reabsorções e problemas periodontais. Atestam ainda que, com frequiência, a escolha pelo tracionamento prolonga o tempo de tratamento. Assim, defendem que sempre que o prognóstico for incerto no que se refere ao tracionamento, as extrações de pré-molares devem ser evitadas ou pelo menos adiadas até análise mais precisa dos riscos.

Nestes casos de extrações atípicas, parece evidente a possibilidade de discrepâncias de tamanho dentário aparecerem. Porém, mesmo em extrações consideradas clássicas, como a de pré molares, estas discrepâncias podem surgir ${ }^{73}$. Partindo-se desta premissa, SAATÇI; YUKAY ${ }^{111}$, em 1997, conduziram um estudo em que avaliaram as documentações pré-tratamento de 
50 pacientes que não apresentavam discrepâncias de Bolton, e que tiveram todos os diâmetros mésio-distais mensurados e digitalizados. A seguir, diferentes hipóteses de extrações foram consideradas digitalmente (extrações de quatro primeiros pré-molares, extrações de quatro segundos pré-molares e extrações de dois primeiros pré-molares superiores e dois segundos prémolares inferiores), e novamente avaliadas pela análise de Bolton. Os resultados demonstraram que surpreendentemente, somente com as extrações de quatro primeiros pré-molares criou-se uma discrepância de Bolton estatisticamente significante, enquanto que as menores faixas de discrepâncias foram encontradas nas extrações de quatro segundos pré-molares.

Quando a alternativa para a correção de má oclusão de Classe II não prioriza a extração dentária, os benefícios do crescimento mandibular são muito bem vindos ${ }^{64,88}$, além da possibilidade de redirecionarmos o crescimento da maxila com aparelhos extrabucais ${ }^{76}$, ou até mesmo os usando para a distalização dos molares superiores ${ }^{8}$.

Uma outra alternativa para esta mecânica distalizadora são os dispositivos intrabucais baseados em molas e ancoragens acrílicas no palato, como o utilizado RUNGE et al. ${ }^{110}$,em 1999, e KELES;SAYINSU ${ }^{72}$, em 2000. Os resultados demonstraram que a distalização dos molares realmente aconteceu, sem a necessidade de cooperação dos pacientes, porém outros efeitos negativos desta mecânica aconteceram e devem ser ressaltados. Demonstraram que a perda de ancoragem, com mesialização e angulação dos pré-molares, além da projeção dos incisivos superiores, com aumento da sobressaliência, e ainda o aumento da altura facial anterior, são efeitos 
colaterais a serem esperados e associados a esta distalização. Concluem ser questionável a classificação deste aparelho como um dispositivo que elimine a necessidade de cooperação dos pacientes.

Os efeitos indesejáveis destes distalizadores intrabucais, tornam seu uso bastante restritivo. Uma opção que parece ser bastante efetiva, seria a alternativa de ancoragem absoluta, que elimina a necessidade de reforço de ancoragem com aparelhos removíveis baseado em implantes ósteo-integrados, como o proposto por BLOCK; HOFFMAN ${ }^{21}$. Estes implantes ${ }^{27,59,132}$ demonstraram ser bastante eficientes para promover ancoragem absoluta dos molares quando da retração da bateria anterior ou distalização posterior.

No arco inferior, vários autores concordam que sempre que possível as extrações deveriam ser evitadas ${ }^{10,16,55,57,81}$. Uma opção para a correção do apinhamento inferior ${ }^{68}$ nestes casos seria o desgaste interproximal, ou stripping. Porém, enquanto este procedimento aumenta sua popularidade em casos exibindo um apinhamento anterior moderado, ROCCO ${ }^{106}$, em 1971, adverte que este procedimento deveria ser considerado apenas como um auxílio na eliminação de apinhamentos leves para a obtenção de um resultado mais estético, e não como uma alternativa primária para um adequado alinhamento dos dentes. Reforça ainda que a indicação mais pertinente se refira à presença de discrepâncias de tamanho dentário.

Para SHERIDAN ${ }^{120,121}$, respectivamente em 1985 e 1987, ganhos de espaço de até $6,4 \mathrm{~mm}$ na região posterior ( 8 superfícies de $0,8 \mathrm{~mm}$ ) e de 2,5 
mm na região anterior ( 5 superficies de $0,5 \mathrm{~mm}$ ) podem ser alcançados por este procedimento, podendo segundo o autor evitar extrações dentárias ou expansões indesejáveis em muitos casos. Conclue ser indefensável nos dias atuais, a manutenção de todo o volume de esmalte interproximal em casos em que seja necessário ganho de espaço.

As irregularidades provocadas pelo stripping, no esmalte, mesmo após o uso de lixas de polimento, são consideradas por RADLANSK; JAGER ${ }^{98}$, em 1988, um efeito iatrogênico a ser considerado, pela tendência de um maior acúmulo de placa bacteriana e de provável surgimento de cáries interproximais.

Em 1990, SHERIDAN; CRAIN ${ }^{122}$, investigando uma amostra de 20 pacientes que haviam sido submetidos a stripping, entre 2 e 5 anos anteriores à avaliação, demonstraram que os índices de aparecimento de cáries não foram significantemente maiores que em superfícies não desgastadas, embora haja uma maior tendência de acúmulo de placa bacteriana.

CAPELLI; CARDOSO; ROSEMBACH ${ }^{25}$, em 1999, são um pouco mais conservadores, limitando suas intervenções por desgaste interproximal em $5 \mathrm{~mm}$, alertando que este procedimento deveria ser indicado em pacientes que tivessem uma boa higiene bucal e um baixo risco de cárie, pelo maior acúmulo de placa bacteriana deixada pelas irregularidades criadas no esmalte. 
Muito se especula sobre uma maior ou menor estabilidade póstratamento, dependente do protocolo de tratamento escolhido, seja com ou sem extração. MILLS ${ }^{87}$, avaliou 56 casos onde os incisivos inferiores foram vestibularizados pelo menos 5 graus durante o tratamento ortodôntico sem extrações. Baseado nos resultados, o autor afirma ser possível se vestibularizar os incisivos inferiores dentro de certos limites ${ }^{7}$

LITTLE; WALLEN; RIEDEL ${ }^{80}$, avaliando pacientes tratados com extrações de quatro pré-molares, com pelo menos 10 anos pós-tratamento, consideraram que a longo prazo, o comportamento do alinhamento ânteroinferior é variável e imprevisível, não se correlacionando com a quantidade de apinhamento inicial, idade, gênero e tempo de contenção.Estes resultados foram compatíveis com várias investigações ${ }^{17,52,82,94,104,116,118,124}$ demonstrando a instabilidade desta região, sejam em terapias com ou sem extrações.

Em 1991, OLIVEIRA JUNIOR et al. $^{93}$, também avaliando a estabilidade pós tratamento de casos tratados com extrações de quatro prémolares, constataram uma maior tendência de recidiva no apinhamento ânteroinferior, em jovens com padrão vertical de crescimento, com algum envolvimento hereditário neste apinhamento. 


\subsection{Cooperação em Ortodontia}

Parece bastante evidente que uma má oclusão severa chega a significar uma desvantagem para seu portador, tanto funcionalmente quanto esteticamente, podendo afetar suas relações interpessoais e sua própria autoestima. Para Mc GREGOR ${ }^{84}$,uma boa aparência dentofacial é desejada praticamente por todas as pessoas, tanto para si como para seus filhos. Esta aparência está altamente relacionada com situações de êxito e prestígio quando são considerados os aspectos sociais e culturais.

Porém, os adolescentes de um modo geral, demonstram uma grande variabilidade de desenvolvimento físico, maturidade emocional, experiências sociais, atitudes frente à autoridade e a habilidade de enfrentar responsabilidades. Por isso, segundo FELDSTEIN ${ }^{46}$, em 1959, sugestões não podem ser aplicadas genericamente. Existe uma necessidade de compreensão individual dos problemas de desenvolvimento dos adolescentes, e para isso a abordagem a cada um deles deve ser individualizada. Conclue que os pacientes deveriam ser encorajados a verbalizar seus sentimentos com relação ao tratamento, mesmo que sejam negativos, pois segundo o autor ao não suprimir estes anseios, terão uma menor necessidade de agir negativamente em relação a não cooperação ao tratamento ${ }^{49}$.

Ao enumerar fatores que considera imprescindíveis ao sucesso de um tratamento ortodôntico, SALZMANN ${ }^{115}$, em 1963, destaca a importância da formação do ortodontista em conhecimentos de crescimento e 
desenvolvimento, etiologia, diagnóstico e obviamente informações e habilidade suficientes para tratar estas más oclusões. Considera que, deve-se ter em mente, que quando insucessos acontecem, nem sempre o ortodontista ou o aparelho utilizado pode ser o culpado. Para o autor, falhas podem ocorrer devido à natureza da má oclusão e da má formação dentofacial, e ainda freqüentemente, por falta de cooperação por parte dos pacientes em seguir corretamente as instruções do ortodontista.

Destacando a importância da percepção de como a psicologia pode nos ajudar no campo da ortodontia, STORY ${ }^{130}$, em 1966, afirma ser este um assunto infelizmente ignorado ou considerado como secundário na prática ortodôntica. Descreve muitos temas relacionados a esta associação ortodontiapsicologia, como por exemplo, o nível de ansiedade dos pacientes, o grau de complacência dos pais para com o tratamento ortodôntico, além de como a criança realmente se vê em toda esta situação. Com relação à pré-adolescência e ao início da adolescência, destaca que, estas transformações súbitas, apesar de tornarem os comportamentos mais intempestivos, trazem um aliado importante de motivação, que é a vaidade e o interesse maior pela aparência. Assim, em meio a este grande número de transformações involuntárias, a ortodontia talvez seja a única oportunidade de fazer parte destas mudanças, como um ser ativo e importante para seu sucesso ${ }^{9}$.

O nível de motivação mantida pelo paciente no decorrer do tratamento, parece ser uma variável cuja flutuação afeta consideravelmente a duração e a qualidade do tratamento ortodôntico. Baseado em anos de experiências, GABRIEL $^{50}$, em 1968, especifica as características relacionadas à motivação 
que acredita serem fundamentais. Entre elas, tem-se a aceitação em relação aos procedimentos ortodônticos, higiene bucal, regularidade nas consultas, além de persistência, quantidade e correção no uso do aparelho extrabucal. Os seus achados evidenciam conclusivamente que quando o ortodontista planeja um programa de motivação de acordo com uma comunicação baseada no entendimento de cada paciente, a qualidade final pode ser consideravelmente aumentada e a duração do tratamento diminuída.

Algumas técnicas ortodônticas dependem da cooperação dos pacientes mais que outras, como dispositivos removíveis ${ }^{101}$, porém todas tendem a falhar sem sua presença. Além disso, enquanto o ortodontista é exaustivamente treinado em mecanoterapia, relativamente pouca atenção é dispensada à motivação do paciente. Antecipando-se à esta preocupação, GRABER $^{56}$, em 1971, faz algumas considerações de fundamentação psicológica para esta abordagem. Considera serem de grande importância a personalidade do ortodontista, o comportamento psico-social dos pacientes, o impacto da equipe clínica, o ambiente clinico, além da grande participação da família durante o tratamento. Acredita que o ortodontista deve ir além do aparelho, procurando entender a criança, conhecer algo de seu meio ambiente e cotidiano, além de tentar um maior contato com seus pais. Para ele, a motivação é muito mais importante que qualquer aparelho, e por isso, delicadeza, empatia, firmeza e atenção devem ser empregadas para que a criança crie uma imagem positiva e de motivação em relação ao tratamento.

O tempo de uso dos aparelhos extrabucais foi avaliado por CLEMMER; HAYES ${ }^{31}$, em 1979 em 20 pacientes adolescentes. Observaram 
que os pacientes apresentando as maiores severidades de 1má oclusão, com uma conseqüente maior demanda de uso dos extrabucais, eram os pacientes que mais freqüentemente demonstravam atitudes problemáticas em relação à cooperação. Quanto ao gênero, as meninas demonstraram maior dedicação, apresentando uma maior motivação por melhores estéticas dentofaciais. Para os autores, os ortodontistas deveriam sensibilizar seus pacientes em relação às reais condições e demandas de suas más oclusões, tentando aumentar sua apreciação pelo tratamento.

Abordando como o ortodontista deve encarar um paciente não colaborador, RUBIN ${ }^{109}$, em 1980, evidencia algumas condutas que acredita serem as mais adequadas no relacionamento com os pacientes e seus pais. Defende que atitudes como gritar, censurar, ameaçar, além de ridicularizar o paciente para melhorar sua performance, definitivamente não funcionam, criando uma relação de rivalidade entre o ortodontista e o adolescente. $\mathrm{O}$ segredo desta abordagem, segundo o autor, é transferir a responsabilidade sobre seu tratamento e seu sucesso para o próprio paciente, afinal enfatiza que cada um tem que ser responsável por sua própria saúde. Acredita que crianças a partir de 8 a 10 anos já têm condições de aceitar algumas responsabilidades, e para muitas crianças, esta seria a primeira oportunidade de serem tratadas como pessoas emergentes que são ${ }^{48}$. 
Impessoalidade , nervosismo, tensão , frieza, indiferença, são condutas consideradas extremamente indesejáveis por parte do ortodontista, que provavelmente influenciarão negativamente a atitude dos pacientes ${ }^{12}$.

Para GROSS, SAMSON ; DIERKES ${ }^{63}$, em 1985, quase sempre a não cooperação dos pacientes é classificada como uma atitude de rebeldia em relação as tratamento ortodôntico. Porém os autores procuraram salientar, a relação entre o comportamento do paciente e o ambiente que o cerca. $\mathrm{O}$ modelo comportamental proposto baseia-se fundamentalmente em fornecer inicialmente o maior número de informações possíveis, aos pacientes e seus pais, sobre os possíveis impactos positivos e/ou negativos que seu comportamento em relação ao tratamento pode acarretar. Identificados fatores do cotidiano que as crianças consideram prazeirosas (televisão, cinema, jogos), cria-se um aspecto de pacto entre pais, filhos e ortodontistas, onde negocia-se o cumprimento das exigências diárias com a concessão de algumas destas atividades.

Este modelo de gratificação também foi abordado por RICHTER et al. ${ }^{103}$, onde os autores conseguiram melhoras significativas principalmente em relação aos índices de higiene oral ${ }^{29,148}$ embora ressaltem que este controle doméstico depende fundamentalmente da participação dos pais.

Em 1992, KLAGES; SERGL; BURUCKER ${ }^{74}$, fizeram um estudo baseado em 66 contatos clínicos rotineiros entre o paciente e o ortodontista, registrados através de gravação de fitas, para a verificação da relação verbal do 
ortodontista com a possível cooperação comunicativa dos pacientes, durante as visitas ortodônticas regulares. Para os autores, um paciente cooperador assume uma posição ativa na comunicação. Isto é expresso no volume de sua fala ou no número de sentenças usadas durante a consulta. Um outro aspecto é se as respostas foram detalhadas ou não. Para a obtenção de informações, o clínico deve iniciar a conversação com o paciente, sejam sobre assuntos específicos ao tratamento, ou assuntos de extensão social, sempre respondendo em detalhes as perguntas feitas pelos pacientes, para estimulá-los ativamente a demonstrar interesse. Por fim afirmam que um comportamento encorajador desses ortodontistas tiveram uma forte correlação com a cooperação comunicativa dos pacientes $^{50}$, que diferiram significativamente de acordo com a personalidade do ortodontista.

Os ortodontistas normalmente assumem que alguns desconfortos nas ativações ortodônticas são normais e fazem parte do processo, e atribuem a falta de cooperação dos pacientes a fatores meramente comportamentais. Porém, WHITE ${ }^{149}$, observou que muitos de seus pacientes, que não eram cooperadores, escovavam seus dentes muito levemente, e reclamavam que as cerdas eram desconfortáveis para a gengiva. Isto levou o autor a estudar a tolerância à dor, e a concluir que, a falta de cooperação, pode ser, muito mais que uma característica comportamental, uma resposta a intolerância à dor, promovendo uma maior inabilidade à cooperação ${ }^{39}$.

Considerando o efeito das prostaglandinas e da diminuição do fluxo sanguíneo neste processo, WHITE $^{149}$ avaliou 93 casos em tratamento ortodôntico, submetidos ao uso de aspirinas e a um mordedor plástico apertado 
entre os dentes durante 20 a 30 minutos posteriormente às ativações. Detectou que $63 \%$ dos casos relatavam uma diminuição do desconforto, enquanto $25 \%$ não demonstraram melhoras. Por fim acredita que esta relação entre desconforto, higiene oral, cooperação e tempo de tratamento devem ser mais profundamente investigados ${ }^{149}$.

Muitas especulações são feitas sobre o perfil de um paciente cooperador $^{4,128}$, quais o fatores que teriam influência sobre seu comportamento , como mensurar através de testes psicológicos 32,33,43,44,90,126,134 estas tendências, e a partir daí, como conseguir predizer o nível de motivação e dedicação a se esperar . ALLAN; $\mathrm{HODGSON}^{4}$, consideraram que o perfil de um paciente cooperador incluiria quase sempre qualidades como ser amigável, entusiástico, responsável, confiável, trabalhador, franco e atencioso. Os pacientes não cooperadores se enquadrariam em características como, dominadores, muito inteligentes, cabeças-dura, independentes, desinteressados, temperamentais, impacientes, individualistas, auto-suficientes e intolerantes.

Em 1977, COLENATY; GABRIEL ${ }^{32}$, compararam os resultados das respostas de um teste psicológico de personalidade, baseado em um livreto contendo doze figuras, as quais deveriam ser descritas pelos pacientes de acordo com o que achassem representar, com índices de cooperação obtidos independentemente pela avaliação direta de seus desempenhos durante o tratamento. Os resultados demonstraram uma correlação entre a idade e a intensidade do ego, com pacientes cooperadores. Porém a identificação de pacientes não cooperadores demonstrou-se ligada a fatores adicionais, tais como, falta de confiança, impulsividade e/ou resistência, associada com grande 
significância estatística a pacientes mais jovens, com menos de 14 anos de idade.

Para SLAKTER et al. ${ }^{126}$, é possível mensurar precocemente o nível de cooperação dos pacientes através de perguntas sobre o comportamento dos pacientes ( OPCS - Orthodontic Patient Cooperation Scale), e os resultados obtidos em suas investigações demonstraram-se estáveis, ou seja, pacientes cooperadores aos 2 meses de tratamento, tendem a continuar cooperadores aos 6 meses, agindo os não cooperadores da mesma forma.

EL-MANGOURY $^{44}$, em 1981, avaliou 70 casos em tratamento ortodôntico ativo, submetidos a questionários psicológicos que pudessem quantificar e qualificar suas motivações. As seguintes variáveis clínicas foram registradas: uso do aparelho extrabucal, uso de elásticos, manutenção do aparelho, falta às consultas, higiene bucal e índice de placa. Os resultados demonstraram que a cooperação ortodôntica é previsível através de questionários psicológicos, embora esta cooperação não envolva uma dimensão única de dedicação, ou seja, um paciente que seja um bom higienizador não necessariamente será um bom usuário do aparelho extrabucal e vice-versa. Quanto a classificação do tipo de motivação, o desejo de aquisição de uma melhor estética dentofacial, que facilite a relação interpessoal com outras pessoas parece ser a característica que mais contribua para a predição do uso dos elásticos, dispositivos extrabucais, manutenção do aparelho e pontualidade e assiduidade às consultas. 
Quatro fatores demonstraram estar associados ao nível de cooperação dos pacientes submetidos a questionários elaborados por EGOLF; BEGOLE; UPSHAW $^{43}$, em 1990. Estavam relacionados basicamente à combinação do tipo de personalidade, motivos negativos (dor, inconveniência e disfunção) e motivos positivos (consciência geral de saúde, conhecimento dentário específico e constrangimentos bucais pessoais).

Também a partir do uso de testes de performance psicológica, CUCALON; SMITH ${ }^{33}$, em 1990, constataram que os pacientes adolescentes do gênero feminino demonstraram uma maior cooperação. Além disso, esta característica esteve associada a pacientes com maiores escores de auto-estima, satisfação, que apresentavam-se otimistas em relação ao futuro, tinham condições sócio-econômicas mais altas, além de demonstrarem um baixo grau de alienação da sociedade.

Em 1991, BRATTSTRON; INGELSSON; $\mathrm{ABERG}^{23}$, procuraram determinar as razões que levaram alguns pacientes a desistirem do tratamento antes do seu término. Constataram que $4 \%$ da amostra analisada tinham desistido prematuramente. Estes pacientes foram entrevistados, e as maiores causas apresentadas foram, falta de motivação e de informações sobre o tratamento, dificuldades com os aparelhos tais como irritações e aftas, alguns relataram já estarem satisfeitos com os resultados parciais e por último, relataram alguns problemas de relacionamento com o ortodontista. Os autores reafirmaram que os ortodontistas deveriam investir mais em conhecimentos de psicologia e treinamento para aprimorar sua comunic ação interpessoal. 
A contribuição das seguintes variáveis foram exploradas por NANDA; KIERL $^{90}$, em 1992, na tentativa de predição da cooperação dos pacientes: 1 relacionamento pai-filho; 2- características psico-sociais dos pais e das crianças; 3 - as atitudes e opiniões dos pais e dos filhos sobre a ortodontia; 4 - a percepção das crianças quanto ao seu grau de comprometimento social; 5 relacionamento dos pais e dos pacientes com o ortodontista; 6 - atitudes e anseios em relação ao tratamento ortodôntico, além de 7 - características demográficas. As variáveis relacionadas à percepção do ortodontista ao relacionamento paciente/ortodontista tiveram a mais intensa associação com a motivação dos pacientes. Assim, este relacionamento teve um impacto bastante positivo no comportamento cooperador destes pacientes.

Como a falta de cooperação dos pacientes pode acarretar tempos de tratamento muito maiores que os estimados inicialmente, $\mathrm{MACHEN}^{83}$, em 1995, alega que esta questão deve ser cuidadosamente abordada pelo ortodontista desde o início do tratamento, através da inclusão no contrato inicial relativo ao tratamento, de uma cláusula específica que defina as regras que serão seguidas caso o tempo de tratamento extrapole o prazo inicialmente acordado, principalmente pela atitude não cooperadora do paciente. Normas sobre a extensão dos honorários, ou remoção dos aparelhos, devem estar expressas, para que sejam evitados desacordos com os pais. Alerta que todo e qualquer indício de não cooperação deve ser registrado desde o início, além de comunicado oficialmente aos pais, para que haja validade legal em qualquer litígio. 
Reconhecendo a grande dependência de cooperação no uso de aparelhos extrabucais, além da deficiência de métodos psicológicos para que seja alcançado um maior engajamento e motivação no uso destes dispositivos, NORTHCUTT ${ }^{91}$, no início dos anos 70, propôs a utilização de um "timer" acoplado à tala do aparelho extrabucal para um monitoramento mais preciso de sua utilização. Este relógio eletrônico em miniatura seria sensibilizado simultaneamente por 2 dispositivos separados: um baseado em corrente elétrica e outro baseado em pressão contra o pescoço, sendo que a tração isolada da tala não teria nenhum efeito. Segundo o autor, além de um monitoramento mais adequado, principalmente dos casos de cooperação inadequada, o que poderia levar imediatamente a uma mudança de planejamento, este controle eletrônico seria um fator complementar de reforço positivo na motivação dos pacientes que também acompanhariam mais de perto a quantidade de uso dos extrabucais e seus efeitos.

Esta incorporação de dispositivos eletrônicos para a mensuração da quantidade real de uso dos aparelhos extrabucais parece ser bastante valiosa, fornecendo dados confiáveis sobre o nível de cooperação dos pacientes, como também revelando a quantidade de uso a ser requerido para que determinado movimento seja conseguido. Porém, a confiabilidade destes dispositivos foi investigada por BANKS; READ ${ }^{11}$, em 1987. Constataram que, das 13 marcas comerciais disponíveis na época, apenas 4 apresentaram índices de confiabilidade superiores a $90 \%$, enquanto as outras marcas disponíveis se mostraram bastante imprecisas. 
Devido a grande dificuldade de se monitorar o verdadeiro número de horas de uso de determinados aparelhos removíveis, SAHM;BARTSCH; WITT $^{112,113}$, em 1990, propuseram o uso de um dispositivo micro-eletrônico com um sensor magnético acoplado a um aparelho funcional tipo Bionator, para a identificação exata da cooperação destes pacientes. Os resultados demonstraram que o tempo médio de uso diário foi de 7,65 horas por dia, enquanto a média do número de horas solicitadas aos pacientes foi de 14,9 horas, determinando um índice de cooperação de 50,59\%, o que significa dizer que os pacientes usaram seus aparelhos apenas a metade do tempo que os foi solicitado. Consideraram ainda como bastante frustrante a baixa correlação entre o número verdadeiro de horas utilizadas, e o julgamento que os operadores faziam através dos questionários, do número de horas que acreditavam estar sendo usados.

Correlacionando o nível de cooperação real do uso de aparelhos ortopédicos monitorados por sensores eletrônicos iguais aos preconizados por SAHM;BARTSCH; WITT $^{112}$, com as respostas obtidas por questionários psicológicos, características vinculadas ao nível de cooperação foram correlacionadas por BARTSCH et al. ${ }^{13}$, em 1993, com: 1 - características do paciente relacionadas à obediência, sociabilidade e desempenho escolar; 2 educação familiar; 3 - grau de apoio e supervisão familiar e 4 - relacionamento profissional/paciente no que se refere às atitudes e comunicação verbal entre eles. 


\subsection{O Tempo de tratamento em Ortodontia}

Para PLATZER ${ }^{96}$, em 1968, muitas más oclusões são incompatíveis com correções rápidas, devido ao grau de severidade e à necessidade de intervenções precoces, que prolongam o tempo de tratamento mas que poderiam ser compensadas com outras vantagens tais como a possibilidade de redução das necessidades de extrações, diminuição de traumas em alguns tecidos, uma melhora estética mais precoce, além da possibilidade de um maior benefício quando o crescimento é favorável.

Uma possível interrelação entre a severidade inicial do caso e a duração do tratamento, sempre levantou muitas especulações e controvérsias. Para investigar esta suspeita, GREWE ${ }^{60}$, em 1972, examinou 66 casos tratados ortodonticamente, com idades entre 11 e 15 anos, que foram classificados quanto a sua severidade por índices de má oclusão, entre eles o IPT ${ }^{58}$ (Índice de Prioridade de Tratamento). Além disso, o grau de cooperação e a duração do tratamento foram determinados. Em seu trabalho, nenhuma correlação estatisticamente significante foi observada entre estas variáveis, assim como em outras investigações ${ }^{36,61,119}$, contrário aos achados de FINK;SMITH ${ }^{48}$

Em relação a um possível tratamento ortodôntico em adultos, que supostamente encontraria uma maior dificuldade mecânica e um maior tempo de tratamento, CHIAPPONE ${ }^{28}$, em 1976, afirma ser necessário um exame clínico mais preciso em estruturas como as articulações têmporo-mandibulares, músculos mastigatórios e cervicais e condições dentárias. Além disso, um 
correto exame da posição mandibular em relação cêntrica pode significar a diferença entre um tratamento com extração e/ou cirurgias ortognáticas em pacientes adultos. Considera ainda que uma investigação pertinente a possíveis fatores estressantes podem ser muito importantes, recomendando o uso de placas miorelaxantes pré-tratamento em alguns casos de intensa tensão muscular. Por fim conclue que a duração deste grupo de pacientes não parece ser maior, devido principalmente à excelente cooperação apresentada, obsevações confirmadas por estudos posteriores ${ }^{2,43,110}$.

Para ALEXANDER; SINCLAIR; GOATES ${ }^{2}$, em 1986, as consequiências da extração de quatro pré-molares em adultos são numerosas. Dentre elas, citam uma maior dificuldade para correção da Classe II, um maior tempo de tratamento, um maior potencial de reabsorção radicular, além da possibilidade de problemas periodontais. Alternativas mecânicas consideradas, passam desde desgastes interproximais, expansão dos arcos, além da projeção dos dentes anteriores, apesar de uma maior tendência de recidiva destas abordagens. Quanto ao tempo de tratamento, os resultados parecem bastante similares aos dos adolescentes, principalmente pelo fato de que uma maior cooperação nos adultos parecem contrabalançar as maiores dificuldades mecânicas nas movimentações dentárias. Consideram ainda que o tipo de tratamento é dependente do grau de severidade inicial da má-oclusão.

Em mais um estudo comparativo entre adultos e adolescentes, em relação à efetividade e a duração destes tratamentos, algumas variáveis relacionadas ao grau de cooperação dos pacientes foram obtidas por ROBB;SADOWSKY;SCHNEIDER ${ }^{108}$, em 1988, através dos registros 
descritivos do tratamento (número de faltas e número de quebras do aparelho). O tempo de tratamento do grupo de adolescentes foi em média de 29,4 meses, e o grupo de adultos apresentou tempo médio de 30,6 meses, diferença que não se mostrou estatisticamente significante, o mesmo ocorrendo com os escores relacionados ao grau de melhora oclusal baseados no PAR(Peer Assessment Rating). Constataram que o número de faltas e o número de quebras do aparelho responderam por $46 \%$ da variabilidade da duração do tratamento e por $24 \%$ da variabilidade da efetividade do tratamento. Com relação à correção da oclusão posterior e da sobressaliência, estas duas variáveis responderam por $46 \%$ da variabilidade da duração do tratamento, enquanto que a sobremordida e o alinhamento anterior não tiveram influência nesta variabilidade.

Comparando um grupo de adolescentes com um grupo de adultos, apresentando uma má oclusão de classe II divisão 1, DYER; HARRIS; $\mathrm{VADEN}^{42}$, em 1991, constataram que o tratamento dos adultos e dos adolescentes, ambos com extrações de pré-molares, levaram praticamente o mesmo tempo, em torno de 2,46 anos para os adolescentes e 2,56 anos para os adultos. Constataram ainda a presença de muitas seqüelas mecânicas do uso de elásticos de classe II no grupo dos adultos: extrusão de molares inferiores, extrusão de incisivos superiores e acentuação do plano oclusal.

Considerando-se alguns protocolos de extração ou não de dentes e a sua correlação com a duração do tratamento ortodôntico, ALTMAN; ARNOLD; SPECTOR $^{5}$, propõem que a possibilidade de extrações de caninos que estejam impactados, em substituição aos pré-molares que seriam extraídos, deveriam ser cuidadosamente analisados como uma alternativa ao tratamento. 
Baseiam-se principalmente nos riscos de insucesso no tracionamento destes caninos, possibilidade de sequielas pós-operatórias, anquilose e a proximidade de outras raízes adjacentes, que poderiam acarretar perdas ósseas, reabsorções e problemas periodontais. Atestam ainda que, com frequiência, a escolha pelo tracionamento prolonga o tempo de tratamento.

A grande heterogeneidade de protocolos de tratamento que se seguem ao diagnóstico, tornam bastante difíceis o estabelecimento de generalizações sobre procedimentos de tratamento e seus efeitos. Com relação ao protocolo de extrações ou não, VIG et al. ${ }^{145}$, em 1990, dispuseram-se a avaliar se existia um relacionamento entre a frequiência de extrações e a duração do tratamento. A amostra utilizada, composta de 438 pacientes provenientes de 5 clínicas diferentes, apresentou freqüência média de 54\%, com grande variação de 25 a $84 \%$. O tempo de tratamento parece ter sido influenciado pelo número de arcos tratados, pelo número de fases e pela execução ou não de extrações. Quando os casos com e sem extrações foram comparados isoladamente em cada clínica, os casos sem extrações apresentaram uma menor duração de tratamento, redução esta que variou de 2,3 a 7,4 meses, dependendo da clínica em questão, resultados semelhantes aos de VADEN;KISER ${ }^{144}$

Em relação ao tempo de tratamento entre o tratamento com extrações de quatro primeiros pré-molares comparados ao tratamento com extrações de quatro segundos molares, STAGGERS ${ }^{127}$, em 1990, detectou um tempo médio de 36,8 meses para o grupo dos pré-molares, e de 38 meses no grupo dos molares. Porém, se considerarmos que o tempo total de tratamento no grupo dos molares não levou em consideração nenhum tempo possivelmente 
necessário para um correto posicionamento dos terceiros molares, assim que irrompidos, o tempo de tratamento neste grupo pode ter sido muito maior que o indicado neste estudo.

A maioria dos pacientes ortodônticos se preocupam com o tempo que deverão usar os aparelhos fixos. Por isso, uma confiável estimativa do tempo de tratamento seria valiosa, inclusive para um gerenciamento clínico mais eficiente. Com este intuito, FINK; $\mathrm{SMITH}^{48}$, em 1992, avaliaram 118 pacientes, tratados por 6 clinicas diferentes. Destes casos, $38 \%$ se submeteram a extrações e $32 \%$ usaram aparelhos extrabucais. A média do tempo de tratamento para a amostra total foi de 23,1 meses, sendo que a mais importante variável relacionada a diferenças de duração de tratamento entre os casos foi a extração de pré-molares. O grupo sem extrações apresentou média de 21,95 meses, o grupo com extrações superiores teve média de 25 meses, e o grupo com extrações de quatro pré-molares apresentaram média de 26,18 meses. Este resultado demonstrou que para cada pré-molar extraído acrescentou-se 0,9 meses na duração do tratamento. Após o número de extrações, a variável de maior correlação em relação ao tempo de tratamento foi o número de consultas perdidas, refletindo de certo modo uma forma de não cooperação. Por fim, valores maiores do ANB e do índice de severidade de Salzmann também apresentaram uma tendência de levar a um maior tempo de tratamento, enquanto que o aumento no ângulo do plano mandibular diminuiu o tempo de tratamento em quase 0,3 meses para cada grau.

RICHMOND; ANDREWS; ROBERTS ${ }^{102}$, em 1993, avaliando 1110 pacientes tratados ortodonticamente verificaram que $74 \%$ dos casos foram 
terminados em até 2 anos, enquanto que $25 \%$ dos casos levaram mais que 2 anos. Os casos que apresentaram os melhores resultados finais foram submetidos a tratamento com aparelhagem fixa em ambos os arcos, com extrações de primeiros pré-molares superiores e segundos pré-molares inferiores, embora tenham levado um tempo mais longo de tratamento quando comparados aos tratados com aparelhos fixos somente em um dos arcos com extrações de dois pré-molares superiores.

Partindo de uma amostra de 100 pacientes tratados ortodonticamente, DE SATURNO ${ }^{36}$, em 1994, procurou estabelecer possíveis influencias da severidade inicial dos casos, da adoção ou não de extrações no tratamento, e ainda estudar a possível influência sócio-econômica e cultural dos pacientes com a duração do tratamento ortodôntico. Dentre os casos tratados com extrações, $64 \%$ foram submetidos a extrações de quatro pré-molares e $18 \%$ tiveram extrações de dois pré-molares superiores isoladamente. O tempo médio de tratamento para o grupo sem extrações foi de 22,59 meses, enquanto o grupo com quatro extrações levou em média 27,07 meses. O grupo com somente duas extrações apresentou um valor médio intermediário de 25,28 meses. Concluem que os casos sem extrações foram 4,5 meses em média mais rápidos que os casos com quatro extrações e que a duração do tratamento apresentou uma maior correlação com a conduta do paciente ( por exemplo, a sua regularidade às consultas) do que com a decisão de realizar extrações ou não.

O'BRIEN et al. ${ }^{92}$, em 1995, constataram em um estudo com 250 casos tratados ortodonticamente, com ou sem extrações, apresentando uma 
sobressaliência mínima de 5mm, uma associação positiva muito importante entre a duração do tratamento,com a severidade inicial, extrações e número de fases, embora ressaltem que aqueles pacientes submetidos a extrações apresentavam índices de má-oclusão mais severos. Com relação à cooperação, as variáveis que tiveram a maior correlação com o tempo foram o número de consertos do aparelho, juntamente com a porcentagem de consultas atendidas. Por fim sugerem que os resultados finais e a quantidade de melhora não tiveram relação com o método terapêutico escolhido.

Com relação à correção da má oclusão de Classe II divisão 2, com sobremordida profunda, tanto LITT; NIELSEN ${ }^{79}$, como TAYLOR; KERR ${ }^{136}$, consideraram ser este tipo má oclusão, um fator de aumento da duração do tratamento, principalmente quando o caso foi conduzido com extrações (48 meses) ${ }^{79}$.

Comparando-se o tempo de tratamento entre aparelhos fixos e móveis, MYRBERG; THILANDER ${ }^{89}$, não constatataram diferenças significativas , sendo que cerca de 42,4\% dos casos duraram até 1 ano, 35,5\% duraram de 1 a 2 anos, 17,4\% levaram de 2 a 3 anos, e apenas 4,7\% dos casos foram submetidos a 3 ou mais anos de tratamento. Com relação aos resultados finais, segundo a opinião dos autores, $91,0 \%$ dos casos foram avaliados como bons ou aceitáveis, sendo os demais categorizados como regulares, deficientes ou sem efeito. Quanto à estabilidade, 52,4\% dos casos revisados não apresentavam recidivas, $19,7 \%$ apresentavam-na moderadamente, enquanto que 4,2\% as apresentavam em níveis acentuados. Finalmente, 14,8\% dos casos 
apresentavam um resultado muito melhor que os encontrados nos registros finais do tratamento.

Cento e cinquienta pacientes submetidos a tratamentos ortodônticos com aparelhos removíveis, sejam funcionais, extrabucais ou placas superiores, foram avaliados por JOHN;KEER;BUCHANAN ${ }^{70}$, para a verificação dos fatores que poderiam influenciar o resultado e a duração do tratamento. As melhoras oclusais, mensuradas pelo índice PAR (Peer Assessment Rating), foram maiores, em média, no gênero feminino. Além disso, 66\% da variabilidade do tempo de tratamento pode ser explicada no grupo usando aparelhos funcionais ou extrabucais pelo escore inicial do PAR e pelo número de aparelhos usados. No grupo que usou placas removíveis, 56\% da variabilidade do tempo de tratamento foi explicado também pelo número de aparelhos usados separadamente.

A suspeita que pacientes tratados por estudantes de pós-graduação durante seu treinamento poderiam ter alguma desvantagem na qualidade dos resultados, além de poderem ser submetidos a tempos de tratamentos mais longos levaram Mc GUINESS; Mc DONALD ${ }^{85}$, em 1998, a avaliarem 2 grupos de 30 pacientes, o primeiro grupo tratado do início ao fim pelo mesmo operador, e o segundo grupo cujo tratamento foi finalizado por um segundo operador. O tempo médio do grupo com apenas um operador foi de 17,67 meses, enquanto que a média para o segundo grupo foi de 26,1 meses. Isto significa um acréscimo médio de 8,43 meses nos pacientes que foram submetidos à mudança de operador. 
Em 1999, uma avaliação dos possíveis fatores que podem afetar a duração do tratamento ortodôntico foi realizado por BECKWITH et. al. ${ }^{10}$, a partir da investigação de 140 casos ortodônticos finalizados, que apresentaram um tempo médio de tratamento de 28,6 meses, variando entre 23,4 e 33,4 meses. Os resultados demonstraram que mais da metade da variação do tempo de tratamento foi explicado por seis variáveis; três relacionadas primariamente à cooperação dos pacientes, duas relacionadas à modalidade de tratamento, e a última relacionada a diferentes clínicas que executaram os tratamentos. Consultas perdidas, quebra de braquetes/bandas e higiene bucal deficiente, representaram as variáveis de cooperação que contribuíram para um maior tempo de tratamento. Quanto à modalidade de tratamento, a prescrição do uso de aparelhos extrabucais e o tratamento em mais de uma fase, também levaram a um maior tempo ativo de tratamento, assim como os achados anteriores de SUBICH $^{125}$.

Partindo-se da suposição que diferenças friccionais e de contato na interface da canaleta do braquete com o arco metálico utilizado, pode ter influência na mecânica empregada e por conseguinte na duração do tratamento ortodôntico, AMDITIS; SMITH ${ }^{6}$,em 2000, conduziram um estudo em que compararam 2 grupos de 32 pacientes tratados com mecânica edgewise, usando canaletas 0.018 " e 0.022 " respectivamente. O grupo 1 , com canaletes 0.018 ", apresentou um tempo médio de tratamento de 20,2 meses, enquanto o $2^{\circ}$ grupo com canaletas 0.022"apresentou tempo médio de 21,7 meses. Esta diferença de 1,5 meses se apresentou estatisticamente significante, embora não seja clinicamente significante. Há de se ressaltar quem em ambos os grupos a freqüência de extrações foi de aproximadamente de $80 \%$, embora o grupo 1 tenha apresentado uma maior frequiência de extrações de dois pré-molares 
superiores $(18,8 \%)$ e uma menor freqüência de quatro pré-molares $(56,3 \%)$ quando comparados ao grupo 2, com 9,4\% de freqüência de duas extrações de pré-molares superiores, e $62,5 \%$ de freqüências de quatro primeiros prémolares.

Um grupo tratado com extrações de pré-molares precocemente na dentadura mista, por meio de extração seriada, e posteriormente tratado ortodonticamente na dentadura permanente, foi comparada por WAGNER; $\mathrm{BERG}^{146}$, em 2000, a outro grupo de pacientes submetidos simultaneamente à extrações de pré-molares e tratamento ortodôntico na dentadura permanente. Os resultados demonstraram que o grupo 1, submetidos à extração seriada, apresentou um tempo de tratamento significativamente menor quando comparado ao grupo 2, embora o número de consultas e o tempo total de tratamento quando incluída a fase preliminar de observação da extração seriada tenha sido significativamente maior.

Segundo WRIGHT ${ }^{150}$, todos ortodontistas tem casos que levaram muito mais tempo de tratamento que o estimado inicialmente, e isto acaba sendo frustrante para os pais, pacientes e também para os profissionais. Os cincos principais motivos alegados pelo autor para esta maior demanda de tempo são: braquetes soltos, bandas soltas, posição incorreta das bandas, muitas trocas de arcos e distalização dos molares superiores. Algumas soluções, como o uso de aparelhos pré-ajustados, fios superelásticos nitinol e distalização de molares com molas distatizadoras intrabucais são propostos pelo autor como alternativas de redução do tempo de cadeira e do tempo final de tratamento. 
Em uma investigação de 500 pacientes tratados ortodonticamente em sua clínica, SHIA ${ }^{123}$, procurou avaliar o tempo de tratamento real de seus casos e esta relação com o tempo que havia previamente estimado para finalizá-los. Observou que mais de 50\% de seus pacientes necessitaram de mais tempo que o estimado (média de 3 meses de acréscimo), e que os pacientes que tiveram seus tempos de tratamento verdadeiramente extrapolados, demonstraram um acréscimo de duração em torno de $25 \%$. Enumerou a seguir os principais fatores contribuidores destas intercorrências: 1) cooperação deficiente (a qual considerou o fator mais importante); 2) faltas às consultas; 3) quebras do aparelho; 4) necessidade de replanejamentos (principalmente nos casos considerados "borderline"); 5) prognóstico equivocado; 6) extrações prévias com espaços já fechados; 7) ausência congênita de dentes; 8) tratamentos iniciados muito cedo; 9) transferência de casos; 10) algumas mordidas abertas; 11) alguns dentes impactados e 12) algumas disfunções musculares. Conclui ser imprescindível uma precisa predição da duração do tratamento e dos principais fatores que possam afetá-las para que sejam alcançados todos os objetivos do tratamento.

Avaliando 92 casos tratados ortodonticamente com aparelhagem fixa pré-ajustada, com braquetes simples providos de aletas de rotação, $\mathrm{ALGER}^{3}$, procurou determinar o tempo de tratamento destes casos e a sua possível correlação com o intervalo entre as consultas, assim como também com o número mínimo de ativações. Desta amostra, 37 casos (40\%) não foram submetidos a extrações, e 55 casos (60\%) foram submetidos a extrações diversas. Em 3 casos foram realizadas disjunção maxilar e em outros 4 casos havia a presença de dentes impactados. Com relação à mecânica, foram utilizados basicamente arcos .018" nitinol para alinhamento e nivelamento e 
arcos retangulares $.018 \times .025$ " de aço para o final do nivelamento, retração e finalização. Os resultados demonstraram uma média para a amostra total de 22,01 meses de tratamento, com 15,9 consultas de média, com intervalo médio de 6 semanas entre as ativações. Dos 12 casos que necessitaram de mais de 30 meses de terapia, estavam os casos com as impactações, casos com grande freqüência de faltas, além da falta de cooperação no uso de aparelho extrabucal e/ou elásticos. Os casos sem extrações apresentaram um menor tempo de tratamento (19,1 meses), comparados aos submetidos a extrações (23,7 meses).

Abordou neste mesmo estudo ${ }^{3}$, um caso apresentando biprotrusão , que teve que se submeter a extrações de 4 pré molares, e que obteve o maior tempo de toda a amostra (46 meses). Porém, ressalta que o caso só foi submetido a extrações de pré-molares após 2 anos de tratamento, após um replanejamento. Comparando-se os casos com duas e quatro extrações de prémolares, as duas extrações apresentaram uma média de 22 meses enquanto as quatro extrações levaram entre 24 e 25 meses de tratamento. Conclui, não ter havido um aumento significante na duração dos tratamentos, apesar da menor frequiência de ativações, fato que poderia ser atribuído às novas características tecnológicas dos aparelhos, assim como uma provável ausência de necessidade de visitas a cada 3 ou 4 semanas.

Como demonstrado nessa revisão, o tratamento da Classe II pode seguir uma grande variedade de protocolos, sejam com ou sem extrações. Dentre as alternativas incluindo extrações de pré-molares, o tratamento com extrações de quatro pré-molares exige um controle mecânico e uma necessidade de cooperação dos pacientes muito maior, além de demonstrar resultados 
oclusais menos favoráveis $^{22}$, principalmente na correção sagital da Classe II, quando comparados aos casos tratados com apenas duas extrações de prémolares superiores. Além disso, vários estudos ${ }^{36,48,92,102,143}$ afirmam que protocolos com um menor número de extrações levam a um menor tempo de tratamento. Assim, com base nessas colocações, considerou-se pertinente avaliar se o protocolo com duas extrações nos tratamentos das más-oclusões de Classe II completas, além de levar a melhores resultados oclusais, também levaria a um tempo de tratamento mais curto, quando comparado ao protocolo de quatro extrações. 
3 PROPOSIÇÃO 


\section{PROPOSIÇÃO}

O objetivo da presente investigação é testar a seguinte hipótese nula: não há diferença entre os tempos de tratamento de casos de Classe II tratados com extrações de dois ou de quatro pré-molares. Para tanto serão comparados:

a. O tempo total de tratamento entre os grupos planejados e tratados desde o início com duas ou quatro extrações de pré-molares

b. O tempo total de tratamento entre o grupo planejado e tratado desde o início com duas extrações, o grupo inicialmente planejado sem extrações e depois tratado com duas extrações, e o grupo tratado com quatro extrações de pré-molares

3.3 Adicionalmente serão estudadas:

a) A possível correlação do grau de cooperação dos pacientes, com o tempo total de tratamento e

b) A possível correlação do número de faltas e de quebras do aparelho, com o tempo total de tratamento. 


\section{MATERIAL E MÉTODOS}




\section{MATERIAL E MÉTODOS}

\subsection{Material}

\subsubsection{Obtenção da amostra}

Procedeu-se à seleção da amostra, de caráter retrospectivo, a partir do arquivo da Disciplina de Ortodontia da Faculdade de Odontologia de Bauru - Universidade de São Paulo, FOB - USP.

A amostra constituiu-se de um total de 121 pacientes, selecionados a partir de um critério básico de presença de uma relação molar de Classe II completa de ambos os lados, segundo critérios de ANDREWS ${ }^{1}$, presença de dentes permanentes até os primeiros molares e ausência de anodontias ou dentes supranumerários. Desta amostra, 92\% dos casos selecionados para investigação são coincidentes com a amostra utilizada por BRAMBILLA ${ }^{22}$, o qual se caracterizou pela comparação dos resultados oclusais finais de 2 grupos, sendo um deles tratado com extrações de dois pré-molares superiores, e o outro, tratado com extrações de quatro pré-molares . Esta comparação baseou-se na avaliação do IPT inicial e final da referida amostra, segundo princípios propostos por GRAINGER ${ }^{58}$.

Estes 121 pacientes selecionados, foram divididos inicialmente em dois grupos experimentais. $\mathrm{O}$ grupo 1 foi composto por pacientes que apresentavam uma má oclusão de Classe II completa, e que foram tratados com a terapêutica utilizando extrações de dois pré-molares superiores. Este grupo foi constituído 
por 73 pacientes (30 do gênero feminino e 43 do gênero masculino), com idade média de 13,73 anos (idade mínima de 9,42 anos e máxima de 22,08 anos). O grupo 2 ficou constituído por 48 pacientes ( 21 do gênero feminino e 27 do gênero masculino), com idade média de 13,03 anos (idade mínima de 10,67 anos e máxima de 18,33 anos), com má oclusão de Classe II completa, tratados com extrações de dois pré-molares superiores e dois inferiores. Ambos os grupos foram tratados com aparelho fixo utilizando a mecânica edgewise simplificada.

Após esta divisão inicial da amostra em 2 grupos, seguindo especificamente critérios de extrações de dois pré-molares superiores ou de quatro pré-molares (dois superiores e dois inferiores), verificou-se que muitos dos casos $(32,87 \%)$ do grupo $1 \quad(\mathrm{~N}=73)$, foram submetidos às extrações de dois pré-molares somente após um replanejamento, posterior a uma tentativa inicial de terapia ortodôntica sem extrações superiores para a correção da Classe II. Assim sendo, optou-se pela redivisão deste grupo 1 inicial em dois subgrupos: o subgrupo A, tratado com a terapia de duas extrações superiores imediatas ao planejamento inicial, e o subgrupo $\mathrm{B}$, tratado com a mesma terapêutica, porém tardiamente, após um replanejamento. Procedeu-se esta nova divisão por se considerar que este fato poderia promover distorções na interpretação dos resultados que se referissem ao tempo total de tratamento e de suas várias fases. Assim sendo, esta nova divisão da amostra total, ficou distribuída da seguinte maneira:

Subgrupo 1 A : Composto por 49 pacientes (19 do gênero feminino e 30 do grupo masculino), com idade média inicial de 14,35 anos (idade mínima de 9,42 anos e máxima de 27,08 anos), tratados com a terapia de duas extrações de pré-molares superiores imediatas ao planejamento inicial. 
Subgrupo 1 B : Composto por 24 pacientes (11 do gênero feminino e 13 do gênero masculino), com idade média inicial de 13,11 anos (idade mínima de 9,42 anos e máxima de 21,50 anos), tratados com a terapia de duas extrações de pré-molares superiores somente após uma reconsideração ao planejamento inicial que não previa inicialmente extrações de dois pré-molares superiores.

Grupo 2: Este grupo se refere exatamente ao grupo 2 do primeiro critério de divisão da amostra.

\subsection{Métodos}

4.2.1 Investigação das documentações ortodônticas pré-selecionadas para a amostra, pertencentes ao arquivo da Disciplina de Ortodontia da Faculdade de Odontologia de Bauru, Universidade de São Paulo, FOB - USP.

As pastas ortodônticas foram avaliadas detalhadamente para a obtenção da maior parte dos dados relacionados ao estudo em questão.

\subsubsection{Ficha de dados cadastrais}

Destas fichas foram obtidos dados gerais relacionados ao nome completo de cada paciente, além de gênero e data de nascimento, imprescindível para a determinação exata da idade no início do tratamento ortodôntico.

\subsubsection{Ficha de Planejamento Terapêutico Inicial}

A partir da análise do planejamento inicial definido para cada caso, observou-se principalmente a decisão ou não por extrações de pré-molares 
superiores e/ou inferiores, e também se estava previsto algum tipo de ancoragem extrabucal complementar às extrações ou determinante como distalizador em casos em que se optou inicialmente pela correção da Classe II sem extrações. Anotou-se também o tipo de tração planejada (KHG ou IHG).

\subsubsection{Ficha de procedimentos terapêuticos diários}

A maior parte das variáveis analisadas neste estudo foram obtidas a partir da investigação detalhada de todos os procedimentos clínicos anotados à cada consulta, do início do tratamento até sua finalização e instalação dos dispositivos de contenção.

Os dados extraídos desta ficha foram os seguintes:

\section{1) Data do início do tratamento:}

Considerou-se neste item, a data da instalação das primeiras bandas de molares ou das primeiras colagens diretas, considerando-se as que acontecessem primeiro. Foram descartados todos os procedimentos de preenchimento de fichas, moldagens, radiografias, fotos clínicas e colocação de separadores prévios às bandagens.

\section{2) Data do final do tratamento:}

A instalação do plano de contenção ortodôntica foi considerada como a data final do tratamento.

\section{3) Determinação do tempo total de tratamento:}


Foram contados o número de meses e de dias entre as datas do início e da finalização do tratamento. O número de dias foram transformados em fração decimal em relação a um mês de 30 dias.

\section{4) Número de faltas:}

Foram consideradas todas as ausências às consultas, com ou sem justificativa.

\section{5) Número de quebras dos dispositivos ortodônticos:}

Todas as recolagens de braquetes e/ou recimentações das bandas ortodônticas provenientes de quebras acidentais foram consideradas. As recolagens realizadas para o reposicionamento voluntário das peças em uma nova altura ou angulação foram descartadas.

\section{6) Número de ativações:}

Procedeu-se à contagem do número de consultas realizadas ao longo de todo o tratamento para a obtenção do intervalo médio de tempo entre as ativações.

\section{7) Determinação da duração de cada fase do tratamento:}

Além da determinação do tempo total de tratamento, verificou-se também a duração de cada uma de suas fases. Considerou-se para isso, a terapia do arco inferior independentemente do arco superior, dividindo-se as etapas da seguinte maneira:

a) Alinhamento e Nivelamento superior e inferior:

Os critérios desta fase consideram a Retração inicial dos caninos e a terapia envolvendo todos os arcos redondos de alinhamento e nivelamento, 
tanto na maxila quanto na mandíbula, até a instalação do primeiro arco retangular prévio à retração anterior.

b) Retração da Bateria Anterior Superior e Inferior:

Finalizada a fase de alinhamento e nivelamento, considerou-se o início da retração à partir da primeira ativação do arco retangular de retração, com alças ou através de deslizamento com alastiks. A retração superior foi realizada nos 3 grupos avaliados, enquanto que a Retração inferior só existiu para o grupo 2, onde fora realizado extrações de pré-molares inferiores.

c) Finalização Superior e Inferior:

Procedida a retração completa dos dentes anteriores, superiores e/ou inferiores, considerou-se o início desta fase do tratamento. Englobaram-se nesta etapa todos os arcos retangulares ideais, arcos redondos de intercuspidação, incorporação de dobras artísticas e de finalização, assim como todos os procedimentos realizados com o intuito de uma melhor finalização em relação à chave normal dos caninos, quando estas não se apresentaram ideais no final da fase de retração.

\section{8) Análise do Relatório Final do Tratamento:}

Avaliou-se o relatório final apresentado após o término do tratamento ortodôntico fixo, para a obtenção de informações relacionadas à possíveis dificuldades encontradas durante a mecânica, principalmente no que se refere à fidelidade e cumprimento do planejamento inicial, assim como identificar, através de dados deste relatório, o nível de cooperação apresentado pelos pacientes durante todo o tratamento. Assim, baseados nestas informações, foram atribuídos scores de cooperação seguindo-se os seguintes critérios:

- Score P (0): Valor atribuído a uma cooperação considerada péssima. 
- Score R (1): Valor atribuído a uma cooperação considerada regular .

- Score B (2): Valor atribuído a uma cooperação considerada boa.

A atribuição destes scores são semelhantes aos critérios qualitativos utilizados por EL-MANGOURY ${ }^{44}$.

4.2.2 Utilização de dados obtidos em outro estudo ${ }^{22}$, estabelecendo valores para algumas variáveis relacionadas ao grau de severidade inicial dos casos e à quantidade de melhoras oclusais decorrentes dos tratamentos.

\subsubsection{1 Índice de Prioridade de Tratamento (IPT) ${ }^{58}$}

Foram utilizados neste trabalho todos os valores individuais dos 121 casos desta amostra, referentes ao IPT inicial de cada caso, ao IPT final após o tratamento, assim como o IPT corrigido durante o tratamento (IPT inicial menos o IPT final). O IPT foi calculado utilizando os modelos de gesso pré e pós-tratamento de cada paciente, conforme a Tabela 1, procedendo-se inicialmente a escolha da coluna mais apropriada desta tabela de acordo com a relação molar do modelo inicial do paciente. Como todos os casos desta amostra apresentavam uma má oclusão de Classe II completa, todos os pacientes foram selecionados na primeira coluna da Tabela 1. Dado escores a todos os itens da tabela, somou-se a esses valores a constante fornecida para cada tipo de má oclusão presente em cada coluna da tabela, sendo a soma final o valor do IPT. 
MATERIAL E MÉTODOS 55

TABELA 1 - Apresentação dos pesos que compõem o Índice de Prioridade de Tratamento (IPT), proposto por GRAINGER [GRAINGER,

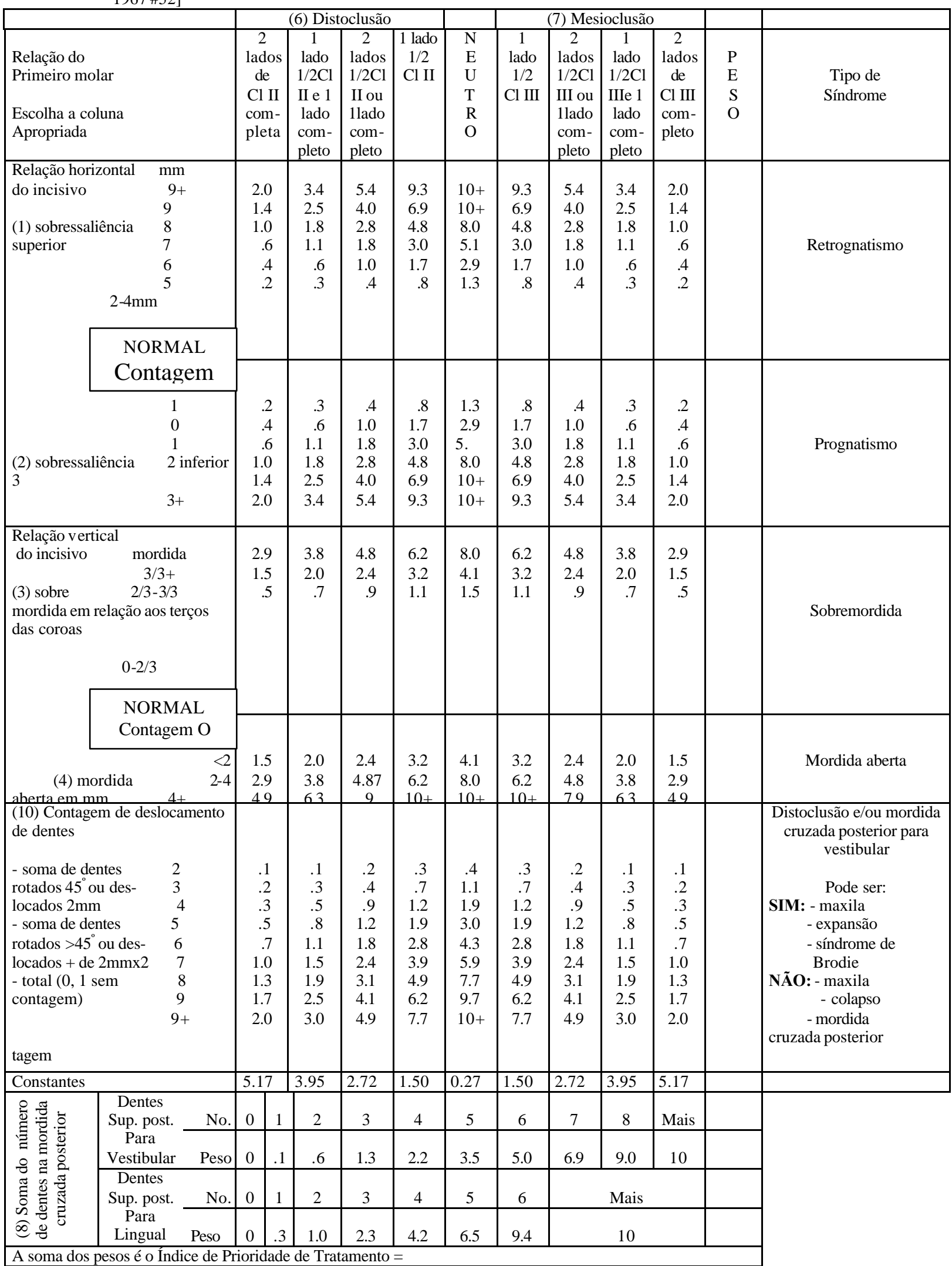


4.2.2.2 Quantidade de apinhamento ântero-inferior

Como esta amostra foi dividida basicamente se levando em consideração extrações de dois pré-molares superiores combinadas ou não à extrações inferiores, a quantidade de apinhamento na região ântero-inferior dos modelos iniciais torna-se de suma importância para se investigar a influência deste apinhamento no planejamento inicial dos casos.

O critério utilizado para medir a quantidade de apinhamento foi calculado como a diferença entre o comprimento do arco (circunferência, da face mesial do primeiro molar do lado esquerdo à face mesial do primeiro molar do lado direito, ) e a soma da largura dos dentes de mesial do primeiro molar à primeiro molar do lado oposto.

\subsubsection{Sobressaliência e Sobremordida inicial}

Os valores iniciais de subressaliência e sobremordida de cada caso individualmente foram utilizadas como características complementares de grau de severidade inicial consideradas separadamente em relação ao IPT inicial.

- Sobressaliência: mediu-se a distância da face vestibular do incisivo inferior à face lingual do incisivo superior.

- Sobremordida: mediu-se a distância vertical da incisal do incisivo inferior à projeção da incisal do incisivo superior na face vestibular do incisivo inferior. 
4.2.3 Estabelecimento de uma legenda de abreviaturas para as variáveis analisadas

Devido ao grande número de variáveis utilizadas neste estudo, optou-se pelo estabelecimento de abreviaturas correspondentes à cada variável, com o objetivo de propiciar uma maior facilidade na manipulação e tabulação destes dados.

As abreviaturas estabelecidas são as seguintes:

1) TT - Tempo total de tratamento (em meses);

2) ANS -Tempo relativo à fase de alinhamento e nivelamento superior ;

3) ANI - Tempo relativo à fase de alinhamento e nivelamento inferior ;

4) RS - Tempo relativo à fase de Retração ântero-superior (em meses);

5) RI - Tempo relativo à fase de Retração ântero-inferior (em meses);

6) FS - Tempo relativo à fase de finalização superior (em meses);

7) FI - Tempo relativo à fase de finalização inferior (em meses);

8) COOP - Abreviatura referente ao score de cooperação ;

9) ATIV - Número de ativações (consultas) realizadas no tratamento;

10) IPT (i) - Índice de prioridade de tratamento inicial de cada caso;

11) IPT (f) - Índice de prioridade de tratamento final de cada caso;

12) IPT (tto) - IPT inicial menos o IPT final;

13) SM (i) - Quantidade em milímetros da sobremordida inicial ;

14) SS (i) - Quantidade em milímetros da sobressaliência inicial ; 
15) RP - Referente à variável Replanejamento, em meses;

\subsubsection{Análise Estatística}

\subsubsection{Erro do Método}

Para a avaliação do erro intra-examinador, foram realizadas novas aferições sobre nove variáveis de 20 pacientes de ambos os grupos, selecionados aleatoriamente da amostra total. A aplicação da fórmula proposta por DAHLBERG ${ }^{34}\left(\mathrm{SE}^{2}=\right.$ somatória $\left.\mathrm{d}^{2} / 2 \mathrm{n}\right)$ permitem estimar a ordem de grandeza dos erros casuais. A obtenção dos erros sistemáticos procedeu-se pela aplicação do teste " $\mathrm{t}$ " pareado.

Com relação à variável Cooperação, não paramétrica, efetuou-se o teste Kappa para a verificação da confiabilidade da distribuição destes scores qualitativos baseados no relatório final de cada caso. 4.2.4.2 Comparação entre os dois grupos de acordo com o número de
extrações

Para esta análise estatística, utilizou-se o teste " $\mathrm{t}$ " para variáveis independentes. Para a utilização deste teste, torna-se necessário que a distribuição das variáveis seja normal, constatação esta obtida pelo teste de Kolmogorov-Smirnov, para cada uma das variáveis. Estes testes foram 
realizados com o programa Statistica ${ }^{[a]}$, com nível de significância para $p<$ 0,05 .

4.2.4.3 Comparação entre os grupos quando a amostra foi subdividida em 3 grupos ( grupo 1 subgrupo A, grupo 1 subgrupo B e grupo 2)

Inicialmente, calculou-se a média e desvio padrão de todas as variáveis analisadas, para cada um dos 3 grupos, comparadas entre si através da Análise de Variância (ANOVA) e complementada pelo teste de Tukey, para determinar o grau de similaridade dos grupos estudados através de comparações múltiplas $(\mathrm{p}<0,05)$.

Para a análise comparativa da única variável não paramétrica (cooperação), utilizou-se o teste de Kruskal-Wallis, complementada pelo teste de Dunn.

\subsubsection{Correlações entre as variáveis}

As correlações entre algumas das variáveis foram realizadas através da correlação de Pearson tanto para a amostra total quanto para cada grupo isoladamente, exceto para a variável cooperação não paramétrica, cujas correlações foram analisadas através da correlação de Spearman $(p<0,05)$.

\subsubsection{Percentuais de algumas características da amostra}

Foram calculados percentuais de algumas variáveis relevantes da amostra, tais como:

\footnotetext{
[a] Statistica for Windows - Release 4.3 B. - Copyrigth Statsoft, Inc. 1993.
} 
- Distribuição percentual do gênero masculino e feminino para a amostra; percentual de pacientes finalizados com valores de IPT = zero para cada grupo; distribuição das frequiências dos scores de cooperação em cada grupo; percentual de pacientes apresentando diferentes quantidades de apinhamento ântero-inferior inicial, de 0 a $10 \mathrm{~mm}$; distribuição do tipo de ancoragem extrabucal (KHG ou IHG) planejada inicialmente para cada grupo; percentual do número de pacientes que foram submetidos a um replanejamento. 
5 RESULTADOS 


\section{RESULTADOS}

Os resultados obtidos foram dispostos em tabelas e gráficos.

As TABELAS 2 e 3 demonstram o erro do método por meio do teste " $t$ ", da fórmula de Dahlberg ${ }^{34}$ e a porcentagem de concordância para a variável Cooperação segundo o teste Kappa.

A TABELA 4 demonstra uma análise comparativa das variáveis estudadas, através do teste "t", considerando-se os dois grupos, de acordo com as extrações ( 2 e 4 pré-molares).

As TABELAS 5, 6 e 7 mostram os valores médios e desvio-padrão de todas as variáveis analisadas, comparadas entre si através da Análise de Variância (ANOVA), considerando-se os 3 grupos.

Para a análise comparativa da única variável não paramétrica (cooperação), utilizou-se o teste de Kruskal-Wallis (TABELA 8).

As correlações entre algumas das variáveis estão demonstradas nas TABELAS 9,10 e 11. A correlação estatística utilizada foi a de Pearson, exceto na TABELA 10.

A quantidade e percentual de pacientes finalizados com valores de IPT = zero, de acordo com os grupos considerados, foram demonstradas nas tabelas 12 e 13.

Considerando-se os scores de cooperação dos pacientes, a distribuição de suas frequiências foram demonstrados na TABELA 14, enquanto que a TABELA 15 denota a distribuição do tipo de ancoragem extrabucal (KHG ou IHG) planejada inicialmente para cada grupo. 
Devido à importância da quantidade de apinhamento ântero-inferior numa decisão de extrações inferiores, a TABELA 16 apresenta a frequiência das quantidades iniciais de apinhamento de cada grupo.

A TABELA 17 demonstra todos os dados referentes à variável replanejamento, ocorrida em 32,87\% do casos tratados com extrações de 2 prémolares superiores.

TABELA 2 - Cálculo do erro do método intra-examinador. Diferença entre a primeira e a segunda mensuração, sendo o erro casual (Dahlberg) e o erro sistemático (teste "t" pareado)

\begin{tabular}{|c|c|c|c|c|c|c|}
\hline \multirow{2}{*}{ VARIÁVEL } & \multicolumn{2}{|c|}{ 1- MEDIÇÃO } & \multicolumn{2}{|c|}{ 2a MEDIÇÃO } & \multicolumn{2}{|c|}{ ERRO DO MÉTODO } \\
\hline & $\bar{X}$ & $\mathrm{dp}$ & $\bar{X}$ & $\mathrm{dp}$ & $\mathrm{p}$ & Dahlberg \\
\hline TT & 26,18 & 10,92 & 26,17 & 10,91 & 0,271 & 0,037 \\
\hline ANS & 8,34 & 4,16 & 8,49 & 4,34 & 0,416 & 0,573 \\
\hline ANI & 7,38 & 4,59 & 8,23 & 5,23 & 0,004 & 1,027 \\
\hline RS & 10,87 & 6,76 & 11,13 & 6,94 & 0,317 & 0,799 \\
\hline FS & 3,15 & 2,19 & 3,08 & 2,10 & 0,494 & 0,333 \\
\hline FI & 4,28 & 5,23 & 4,38 & 5,00 & 0,593 & 0,580 \\
\hline ATIV & 36,8 & 11,27 & 37,3 & 11,54 & 0,212 & 1,277 \\
\hline FALTAS & 1,65 & 1,46 & 1,75 & 1,41 & 0,330 & 0,324 \\
\hline Quebras & 6,60 & 8,07 & 6,40 & 7,92 & 0,599 & 1,192 \\
\hline
\end{tabular}

Diferenças estatisticamente significantes $(\mathrm{p}<0,05)$. 
TABELA 3 - Cálculo do erro do método intra-examinador, para a variável não paramétrica cooperação. Diferença entre a primeira e a segunda mensuração, utilizando-se o teste Kappa

\begin{tabular}{|c|c|c|c|}
\hline & Porcentagem & Kappa & Significância \\
\hline CONCORDÂNCIA & $80 \%$ & 0,65 & Substancial $^{\star}$ \\
\hline
\end{tabular}

* Significância de acordo com LANDIS; $\mathrm{KOCH}^{77}$ (1977)

TABELA 4 - Médias e desvios padrão das variáveis estudadas, considerando-se somente 2 grupos, de acordo com o número de extrações, submetidas ao teste " $\mathrm{t}$ " para amostras independentes

\begin{tabular}{ccccccc}
\hline \multirow{2}{*}{ Variável } & \multicolumn{2}{c}{ Grupo $1(\mathrm{~N}=73)$} & \multicolumn{2}{c}{ Grupo $2(\mathrm{~N}=48)$} & \multirow{2}{*}{ t } & p \\
\cline { 2 - 5 } & $\overline{\mathrm{X}}$ & $\mathrm{dp}$ & $\overline{\mathrm{X}}$ & $\mathrm{dp}$ & & \\
\hline TT & 26,78 & 9,35 & 28,28 & 7,54 & $-0,93$ & 0,350 \\
\hline Idade & 13,94 & 2,74 & 13,03 & 1,70 & 2,07 & 0,041 \\
\hline SS (i) & 6,79 & 3,10 & 7,58 & 2,99 & $-1,40$ & 0,163 \\
\hline Sm (i) & 4,10 & 2,92 & 3,98 & 1,28 & 0,28 & 0,783 \\
\hline IPT (i) & 8,06 & 1,65 & 8,21 & 1,09 & $-0,57$ & 0,570 \\
\hline IPT (f) & 0,72 & 0,74 & 1,91 & 1,76 & $-5,15$ & 0,000 \\
\hline IPT (tto) & 7,35 & 1,83 & 6,31 & 1,92 & 2,99 & 0,003 \\
\hline FALTAS & 1,93 & 2,22 & 2,42 & 3,37 & $-0,95$ & 0,342 \\
\hline Quebras & 6,49 & 8,78 & 2,89 & 7,25 & 2,36 & 0,019 \\
\hline ATIV & 38,85 & 13,12 & 47,37 & 15,50 & $-3,25$ & 0,001 \\
\hline ANS & 8,28 & 3,95 & 8,80 & 3,66 & $-0,73$ & 0,464 \\
\hline ANI & 10,40 & 5,96 & 8,65 & 3,57 & 1,83 & 0,069 \\
\hline
\end{tabular}

Estatisticamente significantes ( $\mathrm{p}<0,05$ ). 


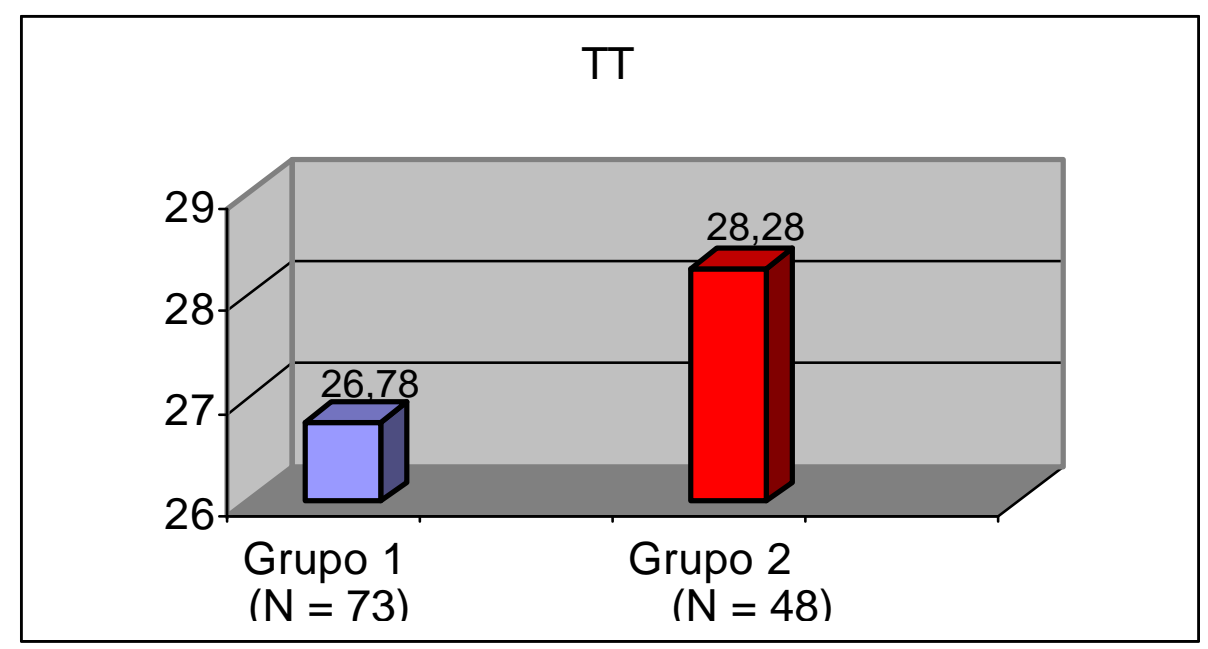

FIGURA 1 - Valores médios para o Tempo Total de Tratamento entre os dois grupos

TABELA 5 - Valores médios e desvio padrão das variáveis relacionadas à características da amostra, submetidas à Análise de Variância (ANOVA) entre os 3 grupos

\begin{tabular}{|c|c|c|c|c|c|c|c|c|}
\hline \multirow{3}{*}{ Variável } & \multicolumn{6}{|c|}{ Valores Médios e Desvio Padrão } & \multirow{2}{*}{\multicolumn{2}{|c|}{$\begin{array}{l}\text { Análise de } \\
\qquad \text { Variância }\end{array}$}} \\
\hline & \multicolumn{2}{|c|}{ Subgrupo A } & \multicolumn{2}{|c|}{ Subgrupo B } & \multicolumn{2}{|c|}{ Grupo 2} & & \\
\hline & $\bar{X}$ & $\mathrm{dp}$ & $\bar{X}$ & $\mathrm{dp}$ & $\overline{\mathrm{X}}$ & $\mathrm{dp}$ & $\mathrm{F}$ & $\mathrm{p}$ \\
\hline Idade & $14,35^{\mathrm{a}}$ & 2,79 & $13,11^{\mathrm{ab}}$ & 2,46 & $13,03^{\mathrm{b}}$ & 1,70 & 4,42 & 0,014 \\
\hline IPT(i) & 7,94 & 1,29 & 8,30 & 2,22 & 8,21 & 1,09 & 0,64 & 0,530 \\
\hline IPT(f) & $0,70^{\mathrm{a}}$ & 0,71 & $0,74^{\mathrm{a}}$ & 0,81 & $1,91^{\mathrm{b}}$ & 1,76 & 13,17 & 0,000 \\
\hline IPT(tto) & $7,24^{\mathrm{a}}$ & 1,46 & $7,56^{\mathrm{a}}$ & 2,45 & $6,31^{\mathrm{b}}$ & 1,92 & 4,69 & 0,010 \\
\hline SS(i) & 6,78 & 3,18 & 6,79 & 2,98 & 7,58 & 2,99 & 0,97 & 0,380 \\
\hline $\operatorname{SM}(\mathrm{i})$ & 3,71 & 2,95 & 4,89 & 2,74 & 3,98 & 1,28 & 2,03 & 0,136 \\
\hline
\end{tabular}

Diferenças estatisticamente significantes ( $\mathrm{p}<0,05)$, submetidas ao teste de Tukey. $\mathrm{a} / \mathrm{b}$ - Grupos com letras exponenciais iguais (Ex.: $\mathrm{X}_{1}^{\mathrm{a}} / \mathrm{X}_{2}^{\mathrm{a}}$ ) não possuem diferenças estatisticamente significantes. 
TABELA 6 - Valores médios e desvio padrão das variáveis relacionadas ao tempo total de tratamento e suas fases, submetidas à Análise de Variância (ANOVA) entre os 3 grupos

\begin{tabular}{|c|c|c|c|c|c|c|c|c|}
\hline \multirow{3}{*}{ Variável } & \multicolumn{6}{|c|}{ Valores Médios e Desvio Padrão } & \multirow{2}{*}{\multicolumn{2}{|c|}{$\begin{array}{l}\text { Análise de } \\
\text { Variância }\end{array}$}} \\
\hline & \multicolumn{2}{|c|}{ Subgrupo A } & \multicolumn{2}{|c|}{ Subgrupo B } & \multicolumn{2}{|c|}{ Grupo 2} & & \\
\hline & $\bar{X}$ & $\mathrm{dp}$ & $\bar{X}$ & $d p$ & $\bar{X}$ & $\mathrm{dp}$ & $\mathrm{F}$ & $\mathrm{p}$ \\
\hline Tempo Total (TT) & $23,52^{\mathrm{a}}$ & 5,86 & $33,44^{b}$ & 11,53 & $28,28^{\mathrm{b}}$ & 7,84 & 13,20 & 0,000 \\
\hline ANS & 7,27 & 3,15 & 9,30 & 5,15 & 8,80 & 3,66 & 1,57 & 0,212 \\
\hline ANI & $9,33^{\mathrm{ab}}$ & 5,84 & $12,58^{\mathrm{b}}$ & 5,70 & $8,65^{\mathrm{a}}$ & 3,57 & 5,13 & 0,007 \\
\hline $\mathrm{RS}$ & 9,88 & 5,75 & 12,17 & 5,30 & 12,31 & 7,16 & 2,11 & 0,126 \\
\hline FS & 3,38 & 2,35 & 5,27 & 5,65 & 4,97 & 4,29 & 2,70 & 0,071 \\
\hline FI & $5,75^{\mathrm{a}}$ & 4,83 & $10,10^{\mathrm{b}}$ & 8,90 & $5,64^{\mathrm{a}}$ & 4,94 & 5,40 & 0,005 \\
\hline
\end{tabular}

Diferenças estatisticamente significantes $(\mathrm{p}<0,05)$, submetidas ao teste de Tukey. $\mathrm{a} / \mathrm{b}$ - Grupos com letras exponenciais iguais (Ex.: $\mathrm{X}_{1}^{\mathrm{a}} / \mathrm{X}_{2}^{\mathrm{a}}$ ) não possuem diferenças estatisticamente significantes.

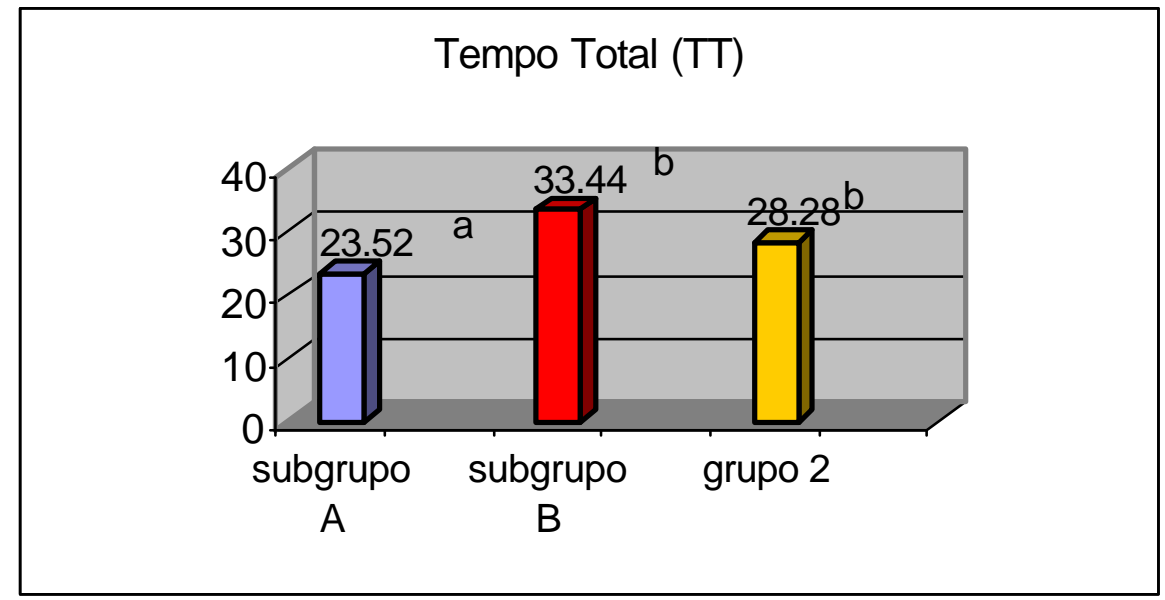

FIGURA 2 - Valores médios para o Tempo Total de Tratamento em cada grupo 
TABELA 7 - Valores médios e desvio padrão das variáveis relacionadas ao número de ativações, faltas e quebras, submetidas à Análise de Variância (ANOVA) entre os 3 grupos

\begin{tabular}{|c|c|c|c|c|c|c|c|c|}
\hline \multirow{3}{*}{ Variável } & \multicolumn{6}{|c|}{ Valores Médios e Desvio Padrão } & \multirow{2}{*}{\multicolumn{2}{|c|}{$\begin{array}{l}\text { Análise de } \\
\text { Variância }\end{array}$}} \\
\hline & \multicolumn{2}{|c|}{ Subgrupo A } & \multicolumn{2}{|c|}{ Subgrupo B } & \multicolumn{2}{|c|}{ Grupo 2} & & \\
\hline & $\overline{\mathrm{X}}$ & $\mathrm{dp}$ & $\overline{\mathrm{X}}$ & $\mathrm{dp}$ & $\overline{\mathrm{X}}$ & $\mathrm{dp}$ & $\mathrm{F}$ & $\mathrm{p}$ \\
\hline Ativações & $35,73^{\mathrm{a}}$ & 11,60 & $45,21^{\mathrm{b}}$ & 13,96 & $47,37^{\mathrm{b}}$ & 15,50 & 9,73 & 0,000 \\
\hline Faltas & 1,71 & 2,12 & 2,37 & 2,39 & 2,42 & 3,37 & 0,92 & 0,399 \\
\hline Quebras & $5,39^{\mathrm{ab}}$ & 9,15 & $8,75^{\mathrm{a}}$ & 7,65 & $2,89^{\mathrm{b}}$ & 7,25 & 4,19 & 0,017 \\
\hline
\end{tabular}

Diferenças estatisticamente significantes ( $\mathrm{p}<0,05)$, submetidas ao teste de Tukey. $\mathrm{a} / \mathrm{b}$ - Grupos com letras exponenciais iguais (Ex.: $\mathrm{X}_{1}^{\mathrm{a}} / \mathrm{X}_{2}^{\mathrm{a}}$ ) não possuem diferenças estatisticamente significantes.

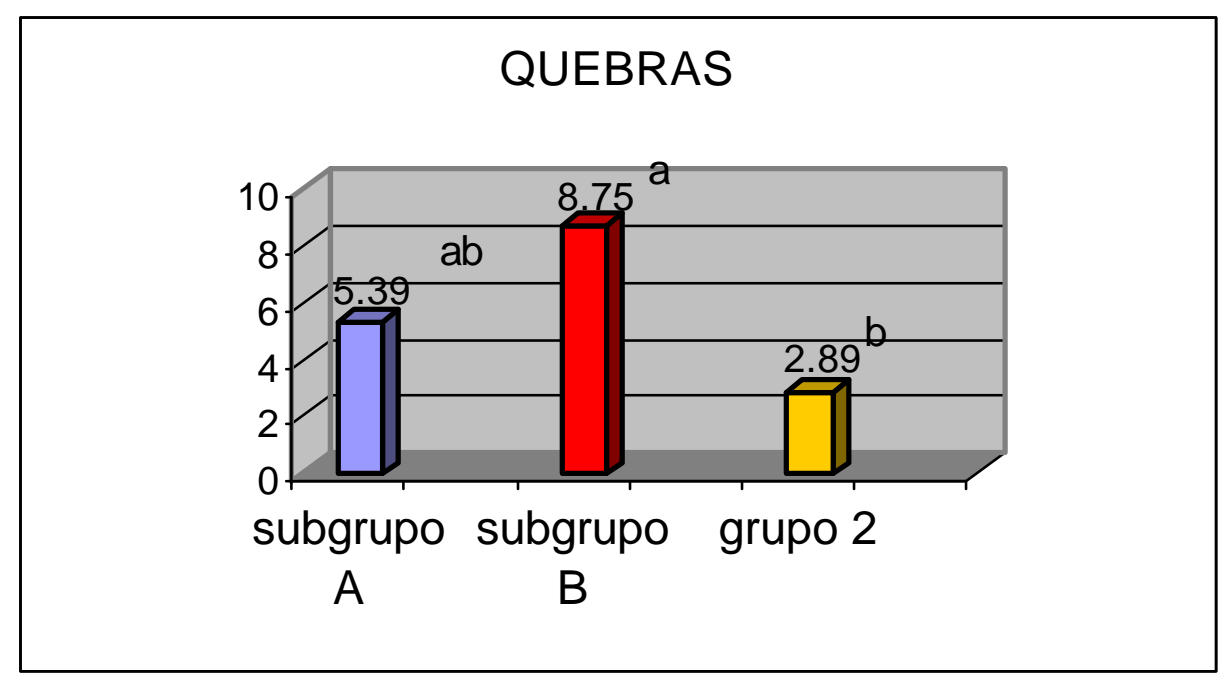

FIGURA 3 - Valores médios do número de quebras do aparelho em cada grupo 
TABELA 8- Comparação entre os grupos para a variável cooperação, estabelecida por scores não paramétricos

\begin{tabular}{cccccccc}
\hline \multirow{2}{*}{ Variável } & \multicolumn{6}{c}{ Subgrupo A $(\mathbf{N}=49)$} & \multicolumn{4}{c}{ Subgrupo B $(\mathbf{N}=\mathbf{2 4})$} & Grupo 2 $(\mathbf{N}=48)$ & H \\
\cline { 2 - 8 } & $\overline{\mathrm{X}}$ & $\mathrm{dp}$ & $\overline{\mathrm{X}}$ & $\mathrm{dp}$ & $\overline{\mathrm{X}}$ & $\mathrm{dp}$ & \\
\hline Cooperação & $1,53^{\mathrm{a}}$ & 0,68 & $0,58^{\mathrm{b}}$ & 0,58 & $1,23^{\mathrm{a}}$ & 0,80 & $23,915^{*}$ \\
\hline
\end{tabular}

*Diferenças estatisticamente significantes $(\mathrm{p}<0,05)$.

$\mathrm{a} / \mathrm{b}$ - Grupos com letras exponenciais iguais não possuem diferenças estatisticamente significantes (Teste de Dunn).

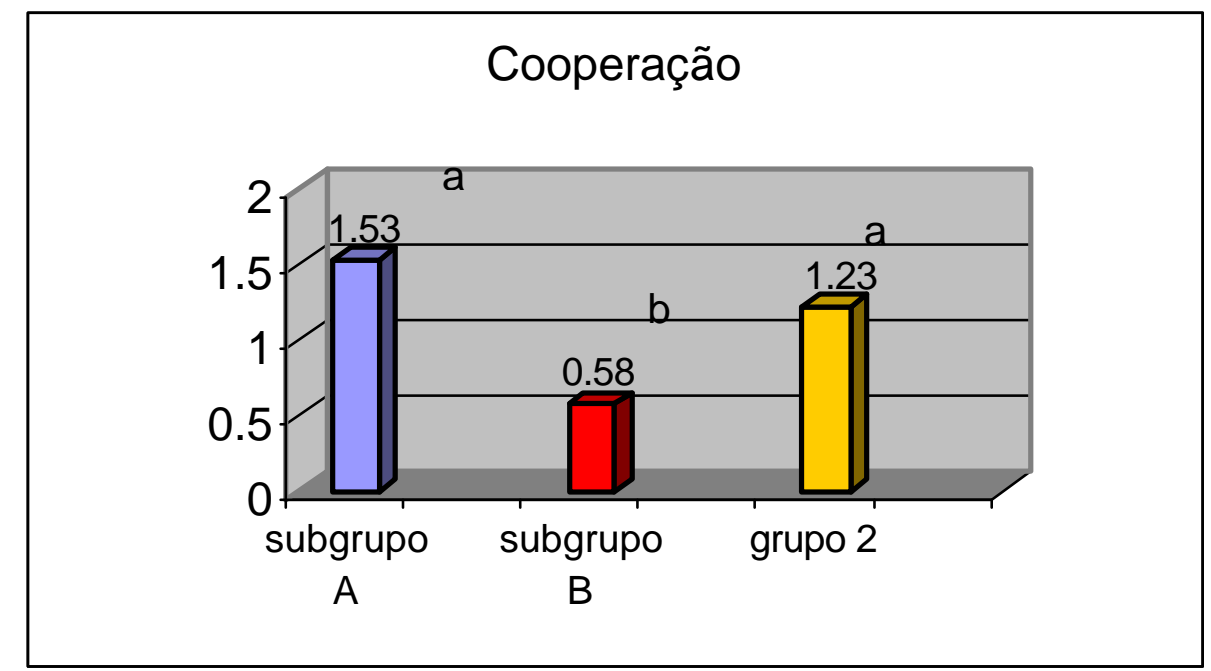

FIGURA 4 - Valores médios da variável cooperação em cada grupo 
TABELA 9 - Correlação de Pearson para algumas das variáveis analisadas para a amostra total $(\mathrm{N}=121)$, em relação ao tempo total de tratamento $(\mathrm{TT})$

\begin{tabular}{|c|c|c|}
\hline Correlação & $\mathbf{r}$ & $\mathbf{p}$ \\
\hline TT $\mathrm{x}$ idade & $-0,0091$ & 0,921 \\
\hline TT $\quad x \quad$ IPT (i) & 0,274 & 0,002 \\
\hline TT $\quad x \quad$ IPT (f) & 0,045 & 0,621 \\
\hline TT $\quad x \quad$ IPT (tto) & 0,176 & 0,053 \\
\hline TT $\quad x \quad$ SS (i) & 0,191 & 0,036 \\
\hline TT $\quad x \quad S M(i)$ & 0,105 & 0,254 \\
\hline TT $\mathrm{x}$ RP & 0,421 & 0,000 \\
\hline TT $\mathrm{x}$ ATIV & 0,607 & 0,000 \\
\hline TT $\mathrm{x}$ FALTAS & 0,402 & 0,000 \\
\hline TT x Quebras & 0,277 & 0,002 \\
\hline
\end{tabular}

Correlações estatisticamente significantes $(p<0,05)$.

TABELA 10 - Correlação de Spearman entre as variáveis tempo de tratamento (TT), Faltas e Quebras, com a variável não paramétrica cooperação (Coop), para a amostra total ( $\mathrm{N}=$ 121) e para os 3 grupos isoladamente

\begin{tabular}{lccccccccc}
\hline \multirow{2}{*}{ Correlação } & \multicolumn{2}{c}{ A. Total $(\mathbf{N}=\mathbf{1 2 1})$} & \multicolumn{2}{c}{ Subgrupo A $(\mathbf{N}=49)$} & \multicolumn{2}{c}{ Subgrupo B $(\mathbf{N}=\mathbf{2 4})$} & \multicolumn{2}{c}{ Grupo 2 $(\mathbf{N}=\mathbf{4 8})$} \\
\cline { 2 - 10 } & Spearman & $\mathrm{p}$ & Spearman & $\mathrm{p}$ & Spearman & $\mathrm{p}$ & \multicolumn{2}{c}{ Spearman } & $\mathrm{p}$ \\
\hline TT x Coop & $-0,464$ & 0,000 & $-0,464$ & 0,000 & $-0,536$ & 0,007 & $-0,281$ & 0,052 \\
\hline FALTAS x Coop & $-0,517$ & 0,000 & $-0,477$ & 0,000 & $-0,484$ & 0,016 & $-0,607$ & 0,000 \\
\hline Quebras x Coop & 0,455 & 0,000 & $-0,520$ & 0,000 & $-0,280$ & 0,184 & $-0,262$ & 0,072 \\
\hline
\end{tabular}

Correlações estatisticamente significantes $(\mathrm{p}<0,05)$. 
TABELA 11 - Correlação de Pearson para algumas das variáveis analisadas, para a amostra total e para os 3 grupos

\begin{tabular}{cccccccccc}
\hline \multirow{2}{*}{ Correlação } & \multicolumn{2}{c}{ Total $(\mathbf{N}=\mathbf{1 2 1})$} & \multicolumn{2}{c}{ Subgrupo A $(\mathbf{N}=49)$} & \multicolumn{2}{c}{ Subgrupo B $(\mathbf{N}=\mathbf{2 4})$} & \multicolumn{2}{c}{ Grupo 2(N=48) } \\
\cline { 2 - 9 } & $\mathrm{r}$ & $\mathrm{p}$ & $\mathrm{r}$ & $\mathrm{p}$ & $\mathrm{r}$ & $\mathrm{p}$ & $\mathrm{r}$ & $\mathrm{p}$ \\
\hline Quebras X SM(i) & 0,261 & 0,004 & 0,322 & 0,024 & 0,275 & 0,194 & 0,007 & 0,964 \\
\hline Quebras x ANI & 0,343 & 0,000 & 0,520 & 0,000 & 0,214 & 0,315 & $-0,098$ & 0,508 \\
\hline
\end{tabular}

Correlações estatisticamente significantes $(\mathrm{p}<0,05)$.

TABELA 12- Quantidade e percentual de valores de IPT final igual a zero (IPT $(f)=0$ ), de acordo com cada grupo tratado (3 grupos)

\begin{tabular}{ccccccc}
\hline \multirow{2}{*}{ Variável } & \multicolumn{2}{c}{ Subgrupo A $(\mathbf{N}=49)$} & \multicolumn{2}{c}{ Subgrupo B $(\mathbf{N}=\mathbf{2 4})$} & \multicolumn{2}{c}{ Grupo 2 $(\mathbf{N}=\mathbf{4 8})$} \\
\cline { 2 - 7 } & $\mathrm{N}$ & $\%$ & $\mathrm{~N}$ & $\%$ & $\mathrm{~N}$ & $\%$ \\
\hline IPT final zero & 12 & $24,50 \%$ & 09 & $37,50 \%$ & 07 & $14,60 \%$ \\
\hline
\end{tabular}

TABELA 13 - Quantidade e percentual de valores de IPT final igual a zero (IPT (f) = 0), de acordo com cada grupo tratado, quando a amostra foi subdividida em 2 grupos $(2$ e 4 extrações)

\begin{tabular}{ccccc}
\hline Variável & \multicolumn{3}{c}{ Grupo 1 $(\mathbf{N}=\mathbf{7 3})$} & \multicolumn{2}{c}{ Grupo 2 $(\mathbf{N}=\mathbf{4 8})$} \\
\cline { 2 - 5 } & $\mathrm{N}$ & $\%$ & $\mathrm{~N}$ & $\%$ \\
\hline IPT final zero & 21 & $28,76 \%$ & 7 & $14,60 \%$ \\
\hline
\end{tabular}


TABELA 14- Distribuição dos scores de cooperação em cada grupo analisado

\begin{tabular}{lccccccc}
\hline \multirow{2}{*}{ Variável } & \multirow{2}{*}{ SCORE } & \multicolumn{2}{c}{ Subgrupo A (N=49) } & \multicolumn{2}{c}{ Subgrupo B (N=24) } & \multicolumn{2}{c}{ Grupo 2 (N=48) } \\
\cline { 2 - 8 } & & $\mathrm{N}$ & $\%$ & $\mathrm{~N}$ & $\%$ & $\mathrm{~N}$ & $\%$ \\
\hline \multirow{3}{*}{ Cooperação } & 0 & 5 & $10,20 \%$ & 12 & $50,00 \%$ & 11 & $22,92 \%$ \\
\cline { 2 - 8 } & 1 & 13 & $26,53 \%$ & 11 & $45,83 \%$ & 15 & $31,25 \%$ \\
\cline { 2 - 8 } & 2 & 31 & $63,27 \%$ & 1 & $4,17 \%$ & 22 & $45,83 \%$ \\
\hline
\end{tabular}

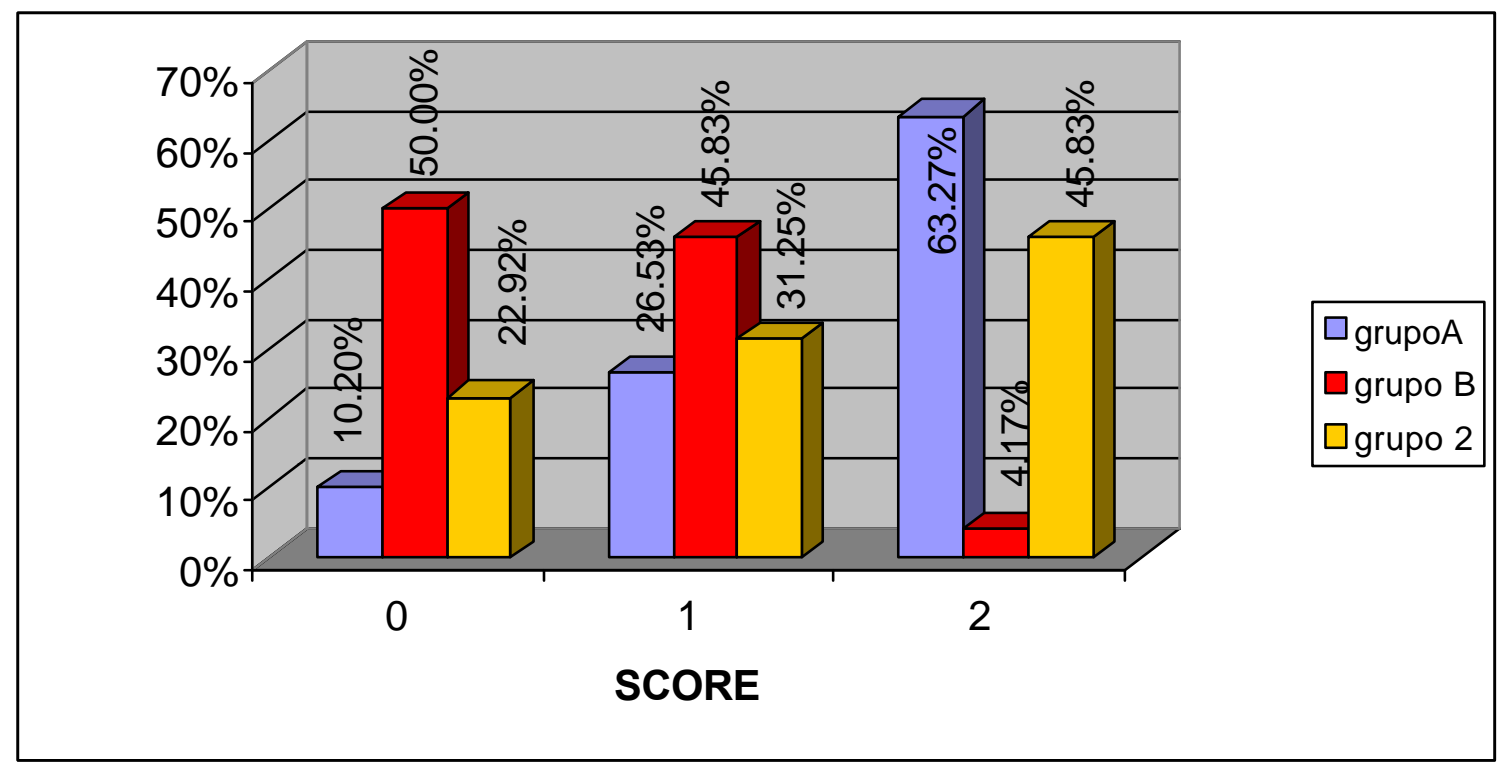

FIGURA 5 - Porcentagem em cada score 0 (P), 1 (R), 2 (B) por grupo 
TABELA 15 - Distribuição do tipo de ancoragem planejada inicialmente, para cada grupo estudado

\begin{tabular}{lcccccc}
\hline \multirow{2}{*}{ Variável } & \multicolumn{2}{c}{ Subgrupo A $(\mathbf{N}=\mathbf{4 9})$} & \multicolumn{2}{c}{ Subgrupo B $(\mathbf{N}=\mathbf{2 4})$} & \multicolumn{2}{c}{ Grupo 2 $(\mathbf{N}=\mathbf{4 8})$} \\
\cline { 2 - 7 } & $\mathrm{N}$ & $\%$ & $\mathrm{~N}$ & $\%$ & $\mathrm{~N}$ & $\%$ \\
\hline KHG & 40 & $81,63 \%$ & 15 & $62,50 \%$ & 31 & $64,28 \%$ \\
\hline IHG & 9 & $18,37 \%$ & 9 & $37,50 \%$ & 17 & $35,42 \%$ \\
\hline
\end{tabular}

TABELA 16 - Distribuição da quantidade de apinhamento ântero-inferior inicial (em mm) para cada grupo

\begin{tabular}{lcccccc}
\hline \multirow{2}{*}{ Variável } & \multicolumn{2}{c}{ Subgrupo A $(\mathbf{N}=\mathbf{4 9})$} & \multicolumn{2}{c}{ Subgrupo B $(\mathbf{N}=\mathbf{2 4})$} & \multicolumn{2}{c}{ Grupo 2 $(\mathbf{N}=\mathbf{4 8})$} \\
\cline { 2 - 8 } & $\mathrm{N}$ & $\%$ & $\mathrm{~N}$ & $\%$ & $\mathrm{~N}$ & $\%$ \\
\hline $0 \mathrm{~mm}$ & 35 & $71,43 \%$ & 18 & $75 \%$ & 14 & $29,17 \%$ \\
\hline $1 \mathrm{~mm}$ & 01 & $2,04 \%$ & 01 & $4,17 \%$ & - & - \\
\hline $2 \mathrm{~mm}$ & 05 & $10,20 \%$ & 02 & $8,33 \%$ & 01 & $2,08 \%$ \\
\hline $3 \mathrm{~mm}$ & 06 & $12,25 \%$ & 02 & $8,33 \%$ & 08 & $16,67 \%$ \\
\hline $4 \mathrm{~mm}$ & 02 & $4,08 \%$ & 01 & $4,17 \%$ & 09 & $18,75 \%$ \\
\hline $5 \mathrm{~mm}$ & - & - & - & & 06 & $12,50 \%$ \\
\hline $6 \mathrm{~mm}$ & - & - & - & & 03 & $6,25 \%$ \\
\hline $7 \mathrm{~mm}$ & - & - & - & & 03 & $6,25 \%$ \\
\hline $8 \mathrm{~mm}$ & - & - & - & & 03 & $6,25 \%$ \\
\hline $9 \mathrm{~mm}$ & - & - & - & & - & - \\
\hline $10 \mathrm{~mm}$ & - & - & - & & 01 & $2,08 \%$ \\
\hline
\end{tabular}

TABELA 17 - Valor médio, valor mínimo, valor máximo e desvio padrão (em meses), para a variável replanejamento $(\mathrm{RP})$

\begin{tabular}{lccccc}
\hline Variável & $\overline{\mathrm{X}}$ & dp & V. MAX & V. MIN & \% Replanejamento \\
\hline $\mathrm{RP}$ & 8,40 & 5,73 & 29,50 & 3,00 & 32,87 \\
\hline
\end{tabular}


6 DISCUSSÃO 


\section{DISCUSSÃO}

Com o objetivo de facilitar o entendimento dos resultados obtidos, e interpretá-los considerando todas as possíveis variáveis, serão discutidos em seqüência, a amostra utilizada, a metodologia empregada, a precisão desta metodologia e por fim, os resultados obtidos.

\subsection{A Amostra Utilizada}

O critério básico para a seleção da amostra foi que os pacientes apresentassem inicialmente uma relação molar de Classe II completa ${ }^{1.54,75}$ dos dois lados e que tivessem sido tratados com a mecânica ortodôntica fixa tipo edgewise ${ }^{54,57,88,117}$ nos dois arcos, com a extração de dois pré-molares superiores $6,22,36,54,55,57,75,81,97,102,118$, ou de dois pré-molares superiores e dois inferiores $22,55,54,57,88,117,137,142,143$. Não foram feitas exclusões de casos que por ventura tenham sido submetidas à extrações de segundos pré-molares, visto que esta ocorrência foi muito pequena, com a mesma probabilidade de ocorrência nos dois grupos, e também pelo fato de que vários trabalhos evidenciam uma maior tendência de mesialização dos molares inferiores 35,37,51,65,129,142,143,151 , o que facilitaria a mecânica e a correção da Classe II. Os casos com relação molar de Classe II que não fossem completas ou que apresentassem subdivisões ${ }^{67}$, foram eliminados da amostra para que não promovessem necessidades de mecânicas assimétricas que poderiam criar diferentes níveis de severidade ${ }^{12,36,48,60,61,108}$ da má oclusão, influenciando 
assim o principal objetivo deste estudo, que era a avaliação de qual destes protocolos de tratamento ${ }^{22}$ levaria a um menor tempo de tratamento.

Desta maneira, satisfazendo estes requisitos, a amostra constituiu-se de um total de 121 pacientes, provenientes integralmente de um outro estudo ${ }^{22,}$ composto por 131 pacientes tratados nos cursos de Pós-graduação e Especialização do Departamento de Ortodontia da Faculdade de Odontologia de Bauru. Este estudo prévio ${ }^{22}$, com uma coincidência de $92 \%$ da amostra com o presente estudo, se caracterizou pela comparação dos resultados oclusais finais do grupo tratado com extrações de dois pré-molares superiores com outro grupo tratado com extrações de quatro pré-molares, baseados no Índice de Prioridade de Tratamento (IPT inicial e IPT final) proposto por GRAINGER $^{58}$.

Há de se ressaltar que a divisão da amostra, dividida inicialmente em apenas dois grupos, de acordo com o protocolo de extrações proposto ${ }^{22}$, teve que ser redividido para a criação de um terceiro grupo, visto que uma parte da amostra submetida a duas extrações de pré-molares superiores só foi conduzida à este protocolo após um replanejamento da mecânica ${ }^{3,95,123,136}$ (tabela 17), posterior a uma tentativa inicial de correção da Classe II sem extrações incluindo mecânicas distalizadoras com aparelho extrabucal e elásticos de Classe II ${ }^{8,10,53,64,76}$. Considerou-se que este período de tratamento inicial sem extrações levaria a uma distorção dos resultados da duração do tratamento para este grupo, tendendo a prolongá-los ${ }^{123,136}$. 
As idades médias dos pacientes dos três grupos apresentaram diferenças estatisticamente significantes entre o subgrupo 1 A e o grupo 2 (tabela 5). $\mathrm{O}$ subgrupo 1 A , com extrações de somente dois pré-molares superiores, apresentou idade média ligeiramente maior que o grupo submetido a quatro extrações e também ao subgrupo $1 \mathrm{~B}$, em que se tentou tratamento inicial sem extrações. Este fato é compreensível pois é sabido que, quanto maior a faixa etária, menores as perspectivas de crescimento e resposta mandibular ${ }^{42,88,143}$, assim como também maiores sãos os fatores complicadores do protocolo de extrações de quatro pré-molares, que demonstram uma maior exigência de controle mecânico $2,8,16,22,28,64,82,107$. Dentro desta perspectiva, o tratamento com extrações somente superiores é mais freqüentemente utilizada em pacientes com idade mais avançada $22,55,75,81,97$.

Quanto ao gênero, os grupos apresentavam distribuição semelhante, de forma que essa variável não provocasse nenhum tipo de influência nos resultados, relacionados a algum tipo de dimorfismo sexual, seja de maturação esquelética ou nos níveis de cooperação, que em algumas investigações ${ }^{33,49,128}$, apontam as meninas como mais cooperadoras.

Considerando-se o apinhamento inicial da região ântero-inferior entre os grupos (tabela 16), fica bastante evidente que a quantidade de apinhamento inicial pode influir decisivamente na decisão de se extrair ou não pré-molares inferiores. Observa-se que os subgrupos A e B, sem extrações inferiores, demonstraram mais de $70 \%$ de seus casos sem apinhamento inicial nenhum, com quantidade máxima de $4 \mathrm{~mm}$, o que facilitou a decisão de se evitar extrações inferiores ${ }^{55,75,81,118}$. O grupo 2 , submetido a extrações de quatro pré- 
molares, apresentou apinhamento inicial ântero-inferior variando de 0 a 10 $\mathrm{mm}$, porém observou-se que um pouco mais de $66 \%$ dos casos deste grupo apresentaram discrepância de modelo de até $4 \mathrm{~mm}$, que dentro de certos limites poderiam ter sido solucionada através de procedimentos de desgaste interproximal 106,121,122, embora alguns questionamentos sejam feitos em relação aos possíveis efeitos iatrogênicos deste procedimento ${ }^{25,98}$ ou mesmo através de pequena projeção dos incisivos inferiores ignorando-se dentro de certos limites os valores normativos da discrepância cefalométrica ${ }^{2,7,54,57,87,97,117}$.

\subsection{Metodologia}

A obtenção dos dados de interesse para este estudo basearam-se fundamentalmente na coleta de dados descritivos das pastas ortodônticas que se referem a todas as ocorrências de interesse durante o tratamento ortodôntico. Entre estes dados, o planejamento inicial determinou o protocolo inicial de extrações ${ }^{3,5,6,22,36,102,146}$, a indicação dos aparelhos extrabucais ${ }^{10,76}$, e o tipo de ancoragem (tabela 15), além da ocorrência de um replanejamento do protocolo inicial $^{3,95,123,136}$, após um início de tratamento que não se incluíam extrações ${ }^{8}$ (tabela 17).

A partir das fichas de procedimentos clínicos diários preenchidos pelos alunos da Pós-graduação ou Especialização, à cada consulta, foram coletados dados gerais dos pacientes, a data inicial e final de tratamento, determinou-se o tempo total de tratamento e de suas fases, o número de faltas, número de queda de peças, além do número de consultas 3,5,6,10,36,48,53,92,102,108,123,146. Em relação ao tempo de tratamento de cada fase, procurou-se identificar possíveis 
correlações das fases isoladamente com possíveis dificuldades da mecânica ${ }^{2,8,16,64,107}$, seja no nivelamento (Sobremordida) $)^{79,136,145}$, ou na retração anterior (Sobressalência) ${ }^{108}$.

Todos os casos tratados pelo Departamento de Ortodontia da Faculdade de Odontologia de Bauru (Especialização e Pós-graduação) são providos de um relatório final que inclue dados gerais sobre como o tratamento transcorreu , mudanças de planejamento, e o grau de cooperação e higiene apresentado pelos pacientes. Baseando-se neste relatório final, e no número de faltas e quebras do aparelho $^{10,36,48,50,108,123,128}$, coletadas anteriormente, efetuou-se uma classificação subjetiva do nível de cooperação apresentado pelos pacientes, estabelecida como Péssima (P), Regular (R) ou Boa (B), bastante similares aos critérios qualitativos usados por EL-MANGOURY ${ }^{44}$, em 1981. O nível de higiene bucal ${ }^{10,50,128}$ relatado no relatório final, também contribuiu para a classificação subjetiva dos escores de cooperação apresentados.

As variáveis relacionadas ao grau de severidade inicial dos casos, foram obtidas previamente ${ }^{22}$ através da avaliação dos modelos de gesso ${ }^{53}$ pré e póstratamento utilizando-se o Índice de Prioridade de Tratamento, elaborado por GRAINGER $^{58}$, em 1967. A quantidade de melhora oclusal proveniente do tratamento foi obtida através das diferenças entre os índices pré e póstratamento, de forma similar a outros estudos ${ }^{60,61}$.

Os valores da sobressaliência e sobremordida iniciais também foram mensuradas previamente ${ }^{22}$, e utilizados para que possíveis correlações pudessem ser encontradas entre a duração do tratamento e a sobressalência 
inicial, como os achados de ROOB, SADOWSKY, SCHNEIDER ${ }^{108}$, ou com a sobremordida inicial $^{79,136,145}$.

\subsection{Precisão da Metodologia}

Para a avaliação do erro intra-examinador, foram realizadas novas aferições sobre nove variáveis para métricas de 20 pacientes de ambos os grupos, selecionados aleatoriamente da amostra total (Tabela 2). Os resultados submetidos à formula proposta por DAHLBERG ${ }^{34}$, apresentaram as grandezas dos erros casuais bastante reduzidos. A obtenção dos erros sistemáticos procedeu-se pela aplicação do teste " $t$ " pareado, o qual demonstrou-se estatisticamente significante para a variável ANI (Duração da fase de alinhamento e nivelamento inferior). Os erros sistemáticos se manifestam quando um determinado parâmetro é persistentemente sub ou superestimado. A possível explicação para o erro de mensuração desta fase da mecânica deve-se principalmente à dificuldade de se identificar através das anotações de procedimentos diários, quando exatamente se procedeu o final da fase de alinhamento inferior e se iniciou a fase de finalização inferior, principalmente nos casos em que não houve retração da bateria ântero-inferior. 


\subsection{Resultados}

\subsubsection{Compatibilidade dos Grupos}

Embora tenha-se procurado estabelecer durante a seleção da amostra, critérios que a tornassem bastante homogênea, foram comparadas inicialmente a variáveis de cada grupo relacionadas à idade inicial e à severidade inicial da má oclusão, baseada no IPT, e na Sobressalência e Sobremordida iniciais.

Percebe-se que os resultados demonstrados na tabela 5, demonstraram um alto grau de compatibilidade entre os grupos estudados, principalmente no que se refere às severidades iniciais similares, visto que alguns estudos $^{2,48,70,79,108,123,127,136}$, relatam haver alguma correlação desta variável com a duração do tratamento ortodôntico, embora alguns trabalhos não admitam esta associação ${ }^{36,60,61}$.

\subsubsection{A duração do Tratamento Ortodôntico e sua variáveis}

No presente estudo, o tempo total de tratamento demonstrou diferenças estatisticamente entre os grupos, embora algumas considerações devam ser discutidas. Quando considerou-se exclusivamente o protocolo de duas ou de quatro extrações de pré-molares, o tempo total de tratamento não demonstrou 
diferenças estatisticamente signific antes (Tabela 4, Figura 1), resultados estes contrastantes com diversos trabalhos $3,6,36,48,92,102,145$ que demonstraram tempos de tratamento menores em protocolos envolvendo um menor número de extrações.

Porém, observou-se que um grande número de casos tratados com extrações de dois pré-molares (32,87\%) (Tabela 17), só as tinham realizado, após um replanejamento, realizado em média 8,4 meses depois do início do tratamento, sucedendo uma tentativa de tratamento sem extrações ${ }^{8}$. Desta forma, ficou evidente que a variável replanejamento ${ }^{3,95,123,136}$ estava distorcendo a avaliação do tempo de tratamento do grupo em questão. Por este motivo, dividiu-se o grupo com duas extrações superiores em dois subgrupos: o primeiro subgrupo, com extrações de dois pré-molares superiores imediatos, e o segundo subgrupo, com extrações de dois pré-molares superiores tardias, realizadas após o replanejamento. Com esta nova disposição da amostra, o subgrupo A, com duas extrações imediatas demonstrou claramente o menor tempo de tratamento entre os 3 grupos, 4,76 meses mais rápido que o grupo com quatro extrações, e 9,92 meses mais rápido que o grupo com duas extrações após o replanejamento tardio (Tabela 6, Figura 2). Estes resultados foram similares a outros achados ${ }^{92,102,145}$, assim como os de FINK; SMITH $^{48}$ e DE SATURNO ${ }^{36}$, embora estes dois últimos trabalhos tenham encontrado diferenças menores entre os mesmos protocolos aqui avaliados ${ }^{22}$. O primeiro deles $^{48}$, demonstrou um aumento de 0,9 meses para cada pré-molar extraído, e o segundo trabalho ${ }^{36}$, demonstrou uma diferença de 2 meses entre as diferentes condutas. 
A duração de um tratamento ortodôntico parece estar associada a uma gama de variáveis que podem influenciá-la positiva ou negativamente. $\mathrm{O}$ protocolo de tratamento, baseado primeiramente na presença ou ausência de extrações e no número destas extrações, parece ter grande influência sobre o tempo final de tratamento $2,3,5,6,28,36,48,79,92,102,127,136,145$.

Para SHIA, ${ }^{123}$, os principais fatores que contribuem para um maior ou menor tempo de tratamento são; a cooperação do paciente, o número de faltas, o número de quebras do aparelho, a necessidade de replanejamento, prognósticos equivocados, transferências e dentes impactados.

A severidade inicial da má oclusão é relevante para alguns autores $^{2,28,48,70,96,108,123}$, embora em outros estudos ${ }^{36,60,61}$ não tenham encontrado associação com a duração do tratamento. Como os grupos aqui definidos não demonstraram graus de severidade com diferenças significativas estatisticamente entre si (Tabelas 4 e 5), esta discussão torna-se irrelevante.

Para ALEXANDER; SINCLAIR; GOATES ${ }^{2}$, assim como CHIAPPONE $^{28}$ e LITT; NIELSEN ${ }^{79}$, o tratamento com quatro extrações de pré-molares, por criarem maiores dificuldades mecânicas, levam a um tempo maior de tratamento, com possíveis danos às raízes ${ }^{2,104}$. Já WRIGHT ${ }^{150}$, acredita que procedimentos de distalização de molares levam a tempos maiores de tratamento, enquanto que comparações ${ }^{10,123,144}$ entre tratamentos com e sem extrações indicam que as extrações dentárias tendem nitidamente a prolongar este tempo. 
Deve-se salientar nesta discussão , que a variável replanejamento $^{3,95,123,136}$, presente no subgrupo 1 B (Tabela 17), demonstrou-se decisiva no alongamento do tempo de tratamento deste grupo, que apresentouse a com o maior tempo de duração, similar aos relatos de $\mathrm{ALGER}^{3}$, e sendo segundo PECK; PECK $^{95}$, determinante para o aumento da incidência de extrações dentárias por falta de cooperação.

Com relação ao número de ativações, o subgrupo A apresentou o menor valor médio, com diferença estatisticamente significante em relação aos outros dois grupos(tabela 7). Estes resultados demonstraram um curto intervalo de ativações, de aproximadamente 18 dias, tempo este questionável sob alguns $\operatorname{aspectos}^{3}$, apesar de ter que se considerar ser este um tipo de tratamento realizado em um curso de pós-graduação, e por isso, com características diferenciadas.

O tempo de tratamento de cada fase mecânica, considerando-se basicamente as etapas de alinhamento/nivelamento, retração anterior, e finalização, considerados separadamente para cada arco, demonstrou diferenças estatisticamente significativas apenas para 0 alinhamento/nivelamento inferior do subgrupo $1 \mathrm{~B}$ (Replanejamento) e para ao finalização inferior para o mesmo grupo (Tabela 6). Este fato provavelmente esteja relacionado à variável replanejamento, associado à não realização de extrações inferiores para este grupo, ou seja, enquanto insistia-se inicialmente no tratamento sem extrações superiores, a fase de alinhamento e nivelamento inferior estendeu-se, aguardando um resolução para o arco superior, enquanto que o mesmo raciocínio pode ser considerado para um maior tempo da fase de finalização inferior, que provavelmente não fora mais demorada, mas sim 
tenha ficado pronta mais rápido, aguardando com os arcos ideais, a correção da Classe II no arco superior.

O número de faltas justificadas ou não às consultas e o número de quebras de peças ortodônticas, sejam braquetes ou bandas, além de poderem ser considerados indícios de cooperação ao tratamento, são muitas vezes associados a fatores que podem contribuir diretamente no tempo de tratamento ${ }^{10,29,36,48,92,103,108,123,128,148,150}$. Alguns destes, levam também em consideração o nível de higiene bucal ${ }^{10,50,128}$. Para DE SATURNO ${ }^{36}$, a regularidade às consultas demonstrou uma associação mais forte com o tempo de tratamento que as diferenças de protocolo quanto a extrações dentarias. Para FINK; SMITH ${ }^{48}$, após a variável extração, o número de faltas e quebras foi a que mais influenciou seus achados sobre o tempo de tratamento, e para ROOB; SADOWSKY; SCHNEIDER ${ }^{108}$, estas duas variáveis responderam por $46 \%$ da variabilidade do tempo de tratamento e por $24 \%$ da variabilidade da efetividade deste tratamento.

No presente estudo, o número de faltas não demonstrou diferenças estaticamente significantes entre os grupos, enquanto que o número de quebras teve a maior freqüência no subgrupo $1 \mathrm{~B}$, o mesmo que apresentou o maior tempo de tratamento, apesar do subgrupo $1 \mathrm{~A}$, que demonstrou o menor tempo de tratamento ter apresentado um número de quebras relativamente alto, não diferentes estatisticamente do subgrupo 1 B(Tabela 7, Figura 3).Há de se ressaltar que estas variáveis apresentaram desvios padrão acentuados, mascarando eventuais diferenças no teste " $t$ " e Anova, pois a curva apresentava uma curtose achatada. 
Há certa unanimidade na literatura ${ }^{9,46,48,49,50,56,109,115,130}$ em relação à importância da cooperação e motivação dos pacientes em tratamento para o resultado final, que tem seu sucesso baseado na qualidade final e no tempo que se levou para se atingir este resultado.

Estabelecida a importância deste fator, uma possível predição dos possíveis níveis de cooperação a se esperar de um determinado paciente seria de grande valia, seja para o estabelecimento do plano de tratamento, assim como do prognóstico de determinado caso. Muitos trabalhos, a maioria utilizando-se de testes psicológicos ${ }^{4,29,32,44,74,90,103,126,128,148}$ tentam quantificar o nível de cooperação dos pacientes, através da identificação de traços de personalidade, características comportamentais e também através de uma investigação familiar e do ambiente que circunda estes pacientes.

A relação interpessoal entre o profissional e o paciente deve se basear em uma relação de respeito mútuo, evitando-se um atendimento impessoal, frio ou de rivalidade ${ }^{12,46,48,109}$. Para GABRIEL ${ }^{50}$, a comunicação verbal é imprescindível para uma boa aceitação dos procedimentos e uma boa resposta ao uso de aparelhos extrabucais; já ALLAN; HODGSON ${ }^{4}$, definem o perfil de um paciente cooperador como amigável, atencioso, entusiástico, responsável, enquanto que os não cooperadores são, segundo eles, normalmente temperamentais, dominadores, impacientes e individualistas. Fatores como vaidade $^{44,130}$, otimismo e auto-estima ${ }^{33}$, além de amizade e confiança ${ }^{32}$, parecem ser fatores decisivos neste relacionamento. 
Embora existam métodos objetivos de mensuração do número de horas de uso de aparelhos extrabucais ou funcionais, baseados em sensores microeletrônicos ${ }^{13,112,113}$, a maioria das avaliações são subjetivas, baseadas em questionários e/ou relatos.

Neste estudo, baseados em relatos descritivos retrospectivos, qualificamos a variável cooperação, subjetivamente, como sendo P (Péssima), $\mathrm{R}$ (Regular) e B (Boa), similarmente à qualificação de cooperação usada por EL-MANGOURY ${ }^{44}$. Os resultados demonstraram que o grupo 2 apresentou os menores escores de cooperação, bastante próximos de $\mathrm{P}$, com diferenças estatisticamente significantes para os grupos 1 e 3, que apresentaram escores de cooperação bastante semelhantes, situando-se entre os escores de cooperação R (regular) e B (boa).(Tabela 8, Figura 4)

Desta forma, a falta de cooperação no subgrupo $1 \mathrm{~B}$ parece ter sido decisiva no insucesso do planejamento inicial, contribuindo ainda mais para que este grupo apresentasse o maior tempo de tratamento. Já para os subgrupos 1 A e grupo 2, as diferenças da duração dos tratamentos foram influenciadas pelos diferentes protocolos de tratamento, ndependentemente dos níveis de cooperação, embora o subgrupo $1 \mathrm{~A}$ tenha apresentado $63,27 \%$ dos pacientes com scores de cooperação ótimos, enquanto o grupo 2 só apresentou 45,83\% dos pacientes com este score máximo, apesar do menor número de quebras entre os 3 grupos.(Tabela 14, Figura 5)

Considerando-se algumas correlações entre as variáveis analisadas, foram encontradas para a amostra total correlações estatisticamente 
significantes entre o Tempo Total de tratamento com o IPT inicial e a Sobressalência inicial (Tabela 9), corroborando achados que vinculam à severidade inicial dos casos um maior tempo de tratamento $2,48,70,79,96,108,123,127,136$, embora contrastantes com outras investigações $^{36,60,61}$. Para ROBB; SADOWSKY; SCHNEIDER ${ }^{108}$, a correção da oclusão posteriore e da sobressalência, responderam por $46 \%$ da variabilidade da duração do tratamento.

O número de ativações, o número de quebras do aparelho e o número de faltas, para a amostra total (Tabela 9), também demonstraram correlação estatisticamente significantes, confirmando os achados de BECKWITH et al. ${ }^{10}$, de DE SATURNO ${ }^{36}$, FINK; SMITH ${ }^{48}$, O'BRIEN et al. $^{92}$ e outros ${ }^{108,123,150}$, além de GABRIEL ${ }^{50}$, que vincula características de assiduidade, higiene e cuidados gerais, com o nível de cooperação destes pacientes.

A variável cooperação demonstrou correlações negativas estatisticamente significantes (Tabela 10), para a amostra total e para o subgrupo $1 \mathrm{~A}$ isoladamente, com as variáveis Tempo Total, número de faltas e número de quebras, confirmando vários outros estudos que vinculam a falta de assiduidade $^{50,128}$ e os descuidos com o aparelho ${ }^{10,50,92,108,123,150}$ com falta de cooperação, e por conseguinte, com um maior tempo de tratamento ${ }^{83,90,123}$. Novamente para o grupo 2 isoladamente, a cooperação não se mostrou decisiva para o Tempo Total, mostrando-se mais dependente do protocolo de extrações, contrastando com os achados de DE SATURNO ${ }^{36}$, que encontrou 
uma maior correlação da duração do tratamento com a conduta dos pacientes, do que com as diferentes alternativas de extrações ${ }^{22}$.

Em relação à Sobremordida inicial, esta apresentou para a amostra total uma correlação positiva estatisticamente significante com o número de quebras, evidenciando maiores dificuldades no tratamento de casos com sobremordidas profunda ${ }^{16,30,79,107,151}$, confirmando os achados de FINK; $\mathrm{SMITH}^{48}$, que atribuíram a planos mandibulares mais divergentes, com mordidas menos profundas, um menor tempo de tratamento, causada segundo eles, por uma maior facilidade mecânica neste tipo de caso, estabelecendo uma proporção de 0,3 meses a menos no tratamento para cada grau de abertura deste plano, contrastando-se aos achados de ROBB, SADOWSKY; SCHNEIDER ${ }^{108}$, que não consideram a variável sobremordida significante para seus achados.(Tabela 11).

Evidências clínicas de uma maior tendência de quebras com sobremordidas mais acentuadas são confirmadas por estes resultados, confirmando a opinião de JANSON et al. $^{68}$, segundo o qual, o fator determinante do posicionamento vertical dos acessórios é a sobremordida profunda, sendo o dente chave para a determinação vertical dos demais, o dente posterior em que o acessório tiver que se colocado o mais cervicalmente, evitando-se interferências com a oclusão, e por consequiência a soltura das peças.

Há de se ressaltar, por fim, que possíveis mudanças de operador (transferências entre os alunos) durante o tratamento, que poderiam levar a um 
maior tempo de tratamento, conforme achados de McGUINESS; $\operatorname{McDONALD}^{85}$, não foram considerados. Além disso, todos os casos foram tratados com mecânica edgerwise simplificada, com braquetes sem prescrição e fios de aço inoxidável, fato este que deve ser considerado quando comparados estes resultados com outras investigações ${ }^{3,6,97,150}$, que consideram algumas evoluções técnicas como os aparelhos pré-ajustados ${ }^{1,3}$ e os fios superelásticos, de suma importância para uma maior dinâmica do tratamento e até mesmo para um menor tempo de tratamento.

\subsubsection{Resultados Oclusais}

Analisando os resultados obtidos em relação ao IPT (Tabela 5), verificou-se que houve uma diferença estatisticamente significante entre os grupos tratados com extrações de apenas dois pré-molares superiores e o grupo tratado com extrações de dois pré-molares superiores e dois inferiores . Essa diferença pode ser verificada tanto entre as médias do IPT final quanto nos valores do IPT(tto), que representa a quantidade de melhora oclusal conseguida pelo tratamento, entre os subgrupos 1 A e B comparados ao grupo 2. Estes valores demonstram que não houve diferença estatisticamente significante, em relação à melhora oclusal entre os subgrupos A e B , ou seja, a variável replanejamento não foi significante para o resultado oclusal final. Esses valores sugerem uma tendência de obtenção de um melhor resultado oclusal após o tratamento ortodôntico no grupo submetido ao protocolo de extrações somente no arco maxilar, quando comparado ao grupo 2 , com extrações de quatro prémolares. 
Ao considerarmos que o primeiro passo para se calcular o IPT consiste em classificar a oclusão no sentido ântero-posterior dos arcos dentários (Tabela 1), há de se suspeitar que os melhores índices de melhora oclusal junto ao protocolo de extração de dois pré-molares superiores deve-se, em grande parte, a um melhor desempenho da mecânica e da correção da Classe II no sentido ântero-posterior, reforçando a suspeita de uma maior dificuldade na correção das chaves no tratamento com extrações de 4 pré-molares ${ }^{2,8,16,28,48,64,82}$. Convém também acrescentar que o grupo 1 apresentou os melhores resultados oclusais, apesar de ser composto por pacientes apresentando a maior média etária, fato este que poderia ser prejudicial principalmente por uma menor resposta mandibular ${ }^{42,88,143}$.

Portanto fica claro que é a maior facilidade da correção da má oclusão de Classe II no sentido ântero-posterior, com apenas duas extrações, o fator decisivo para o estabelecimento destes resultados oclusais finais, confirmados também pela maior porcentagem de casos dos subgrupos A e B com IPT final igual a 0 , em relação ao grupo 2 (tabelas 12 e 13).

Ao considerarmos que uma má oclusão de Classe II completa independente do protocolo escolhido, necessitará do uso de reforço de ancoragem do seguimento posterior durante a retração anterior, e que este reforço de ancoragem, seja com aparelhos extrabucais ${ }^{8,10,53,64,76,88}$ ou elásticos de Classe II $^{42}$, exigirá algum tipo de cooperação dos pacientes, em maior ou menor intensidade, alguns aspectos devem ser discutidos. 
Em uma má oclusão de Classe II completa, a demanda de espaço é normalmente de cerca de $7 \mathrm{~mm}$. Ao considerarmos que esta seja a quantidade de espaço normalmente fornecida pela extração de um pré-molar, no protocolo com duas extrações superiores 3,6,36,54,55,57,75,81,102,118, o segmento posterior deveria ficar imutável, sem nenhum tipo de perda de ancoragem, para que a correção completa da Classe II nos caninos pudesse ser alcançada. Deste modo, mesmo no procedimento de extrações somente maxilares, o sucesso do tratamento dependerá de algum tipo de colaboração do paciente na manutenção desta unidade de ancoragem. Porém, quando a abordagem da Classe II completa é feita com quatro extrações de pré-molares ${ }^{2,28,36,54,57,79,127,135,146}$, os primeiros molares superiores não só deverão ser mantidos sem perda de ancoragem, mas também exigirão uma distalização de pelo menos $3,5 \mathrm{~mm}$ de cada lado, ainda se contarmos com uma mesialização dos molares inferiores de 3,5mm de cada lado $35,37,51,65,129,142,143$. Desta forma, teremos uma necessidade de retração ântero-superior de 7,0mm da sobressalência original, somadas a $3,5 \mathrm{~mm}$ de distalização adicional do seguimento posterior, somadas a mais $3,5 \mathrm{~mm}$ de retração provocada por uma mudança para distal de $3,5 \mathrm{~mm}$ dos caninos inferiores, totalizando $14 \mathrm{~mm}$. Conseqüentemente, a necessidade do reforço de ancoragem é o dobro e o sucesso dependerá enormemente da cooperação do paciente ${ }^{150}$.

A dependência da cooperação dos pacientes no uso destes sistemas de ancoragem convencionais, removíveis, torna o prognóstico deste protocolo bastante duvidoso, a menos que se lance mão de outras alternativas como os distalizadores intrabucais ${ }^{72,110,150}$, apesar dos seus efeitos indesejáveis, ou mesmo do uso dos sistemas de ancoragem chamados de absolutos, baseados em mini-implantes ósseos ${ }^{21,27,59,132}$ que têm se mostrado extremamente efetivos, eliminando completamente a necessidade de cooperação nesse aspecto. Assim, 
sobre outro ponto de vista, a diferença crucial entre estes dois protocolos é a de se manter a relação molar que se apresenta inicialmente ou a de modificá-la, por distalização, o que não há duvidas, dificulta enormemente a mecânica.

Todas essas considerações anteriores, em relação às extensões de movimentação dentária, sejam no arco superior e/ou inferior, não levaram em consideração possíveis potenciais de crescimento. Dessa forma o prognóstico da correção da má oclusão de classe II será tanto melhor quanto maior o potencial remanescente de crescimento, seja para uma resposta mandibular ${ }^{42,88,143}$, para anterior ou para um redirecionamento do crescimento maxilar ${ }^{8,10,76,143}$. Isto sem dúvidas torna o tratamento do paciente adulto menos favorável $^{2,28,42,153}$, apesar de normalmente este grupo de pacientes apresentar uma maior cooperação ${ }^{2}$.

A decisão por extrações inferiores passa quase que invariavelmente pela avaliação da quantidade de apinhamento inferior ${ }^{54,57,66}$ (Tabela 16), presença de discrepância cefalométrica ${ }^{141}$, e até mesmo pelo padrão de crescimento $^{16,82,107,151}$, seja mais horizontal ou mais vertical. Primeiramente quanto ao apinhamento inferior, se ele não está presente, e não há nenhum tipo

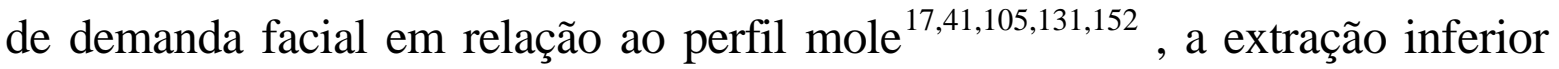
deveria ser de pronto desconsiderado ${ }^{51,142,143}$. Em situações em que haja um apinhamento suave a moderado, uma alternativa a ser considerada pode ser o desgaste interproximal ${ }^{25,98,106,121,122}$. Para SHERIDAN $^{121}$ e SHERIDAN;CRAIN ${ }^{122}$, é possível se conseguir até mesmo $6,4 \mathrm{~mm}$ na região posterior ( 8 faces de $0,8 \mathrm{~mm}$ ) e ate mesmo $2,5 \mathrm{~mm}$ na região anterior ( 5 faces de $0,5 \mathrm{~mm}$ ), perfazendo um total de $8,9 \mathrm{~mm}$, embora haja alguma resistência em relação aos efeitos iatrogênicos desta conduta, com uma provável maior 
tendência de acúmulo de placa bacteriana e incidência de cáries ${ }^{25,106}$. Com base em algumas investigações ${ }^{7,22,54,55,57,87}$, a indicação de extrações inferiores com o objetivo de realizar correções cefalométricas deveria ser revista e encarada com ressalvas. Para MILLS ${ }^{87}$, em 1966, algumas vezes, dentro de certos limites, até mesmo uma certa protrusão seria possível ${ }^{7}$.

Essa protrusão, não provocando efeitos desfavoráveis ao perfil mole, só seria questionável em relação a uma possível recidiva. Porém, a correção da sobressalência tende a remover o lábio inferior de sua interposição entre os incisivos superiores e inferiores, deixando-o até mesmo com um leve contato com a incisal dos incisivos superiores, fato este que diminuiria a recidiva ${ }^{7,87}$. Nos casos de Classe II divisão 2, esta solução é ainda mais oportuna ${ }^{30}$. Ainda com relação à estabilidade e recidiva, sejam em tratamentos com ou sem extrações, com ou sem correção cefalométrica, a literatura é praticamente unânime em afirmar que a região ântero-inferior se comporta de maneira imprevisível, independentemente do protocolo de tratamento, gênero, idade e tempo de contenção ${ }^{17,52,80,82,93,94,124}$, desmistificando a necessidade de extrações pela argumentação de se alcançar uma maior estabilidade pós-tratamento.

\section{Implicações Clínicas}

Foi possível observar entre os grupos, que o protocolo de extrações de dois pré-molares superiores, além de conseguir resultados oclusais finais mais satisfatórios $^{22}$, foram obtidos em um tempo de tratamento nitidamente mais rápido, fato este que segundo RIEDEL ${ }^{104}$ é de suma importância por levar a menores efeitos iatrogênicos radiculares ${ }^{2}$, além de proporcionar maiores 
benefícios pessoais e até mesmo financeiros aos pacientes e ao profissional. ${ }^{83,123}$. 
7 CONCLUSÕES 


\section{CONCLUSÕES}

1 A hipótese nula foi rejeitada porque o grupo inicialmente planejado e tratado com extrações de dois pré-molares apresentou um tempo de tratamento significantemente menor que o grupo tratado com extrações de quatro pré-molares,

2 Casos de extrações de dois pré-molares, que inicialmente haviam sido planejados para um tratamento sem extrações, apresentaram um tempo de tratamento significantemente maior do que aqueles planejados e tratados desde o início com duas extrações, apresentando valores bastante semelhantes ao grupo submetido à quatro extrações,

3 a O nível de cooperação apresentado pelos pacientes influenciou o cumprimento do planejamento inicial, e por conseguinte o tempo total de tratamento,

3 b Não foi possível estabelecer correlações confiáveis entre o número de faltas e de quebras do aparelho, com o tempo total de tratamento. 
REFERÊNCIAS BIBLIOGRÁFICAS 


\section{REFERÊNCIAS BIBLIOGRÁFICAS*}

1. ANDREWS, L. F. The straight wire appliance. Syllabus of philosophy and techniques. 2 ed.; 1975.

2. ALEXANDER, R. G.; SINCLAIR, P. M.; GOATES, L. J. Diagnosis and treatment planning for adult nonsurgical patient. Amer. J. Orthodont., v.89, n.2, p.95-112, Feb. 1986.

3. ALGER, D. W. Appointment frequency versus treatment time. Amer. J. Orthodont. Dentofac. Orthop., v.94, n.5, p.436-39, Nov. 1988.

4. ALLAN, T. K.; HODGSON, E. W. The use of personality measurements as a determinant of patient cooperation in an orthodontic pratice. Amer. J. Orthodont. , v.54, n.6, p.433-40, Jun. 1968.

5. ALTMAN, J. A.; ARNOLD, H.; SPECTOR, P. Substituting maxillary first premolars for maxillary impacted canines in cases requiring the extraction of dental units as part of orthodontic correction. Amer. J. Orthodont., v.75, n.6, p.618-29, Jun. 1979.

6. AMDITIS, C.; SMITH, L. F. The duration of fixed orthodontic treatment: a comparison of two groups of patients treated using Edgewise brackets with 0.018" and 0.022" slots. Aust. Orthodont. J., v.16, n.1, p.34-9, Mar. 2000.

7. ARTUN, J.; KROGSTAD, O.; LITTLE, R. M. Stability of mandibular incisor following excessive proclination: a study in adults with surgically treated mandibular prognathism. Angle Orthodont, n.2, p.99-106, 1990.

8. ARVYSTAS, M. G. Nonextraction treatment of Class II, division 1 malocclusions. Amer. J. Orthodont., v.88, n.5, p.380-95, Nov. 1985.

9. ASH, A. Psychology considerations in orthodontics. Amer. J. Orthodont., v.36, p.292, 1950

10. BECKWITH, F. R. et al. An evaluation of factors affecting duration of orthodontic treatment. Amer. J. Orthodont. Dentofac. Orthop., v.115, n.4, p.439-47, Apr. 1999.

11. BANKS, P. A.; READ, M. J. F. An investigation into the reliability of the timing headgear. Brit. J. Orthodont. v.14, p.263-7, 1987.

\footnotetext{
* Normas recomendadas para o uso no âmbito da Universidade de São Paulo, com base no documento "Referências Bibliográficas: Exemplos", emanado do Conselho Supervisor do Sistema Integrado de Bibliotecas da USP, em reunião de 20 de setembro de 1990.
} 
12. BARBOUR, A.; CALLENDER, R. S. Understanding patient compliance. J. Clin. Orthodont., v.12, p.803-9, 1981.

13. BARTSCH, A. et al. Correlates of objective patient compliance with removable appliance wear. Amer. J. Orthodont. Dentofac. Orthop., v.104, n.4, p.37886, Octob.1993.

14. BAUMIRIND, S. et. al. The decision to extract: Part II. Analysis of clinician's stated reasons for extraction. Amer. J. Orthodont. Dentofac. Orthop., v.109, n.4, p.393-402, Apr.1996.

15. BEATtiE, J. R.; PAQUETTE, D. E.; JOHNSTON JR., L. E. The functional impact of extraction and nonextraction treatments: a long term comparision in patients with "borderline" equally susceptible Class II malocclusions. Amer. J. Orthodont. Dentofac. Orthop., v.185, n.5, p.444-9, May.1994.

16. BELL, W. H.; JACOBS, J. D.; LEGAN, H. L. Treatment of Class II deep bite by orthodontic and surgical means. Amer. J. Orthodont., v.85, n.1, p.1-20, Jan. 1984.

17. BISHARA, S. E. et al. Comparisions of the dental arch changes in patients with Class II, division 1 malocclusions: extraction versus nonextraction treatment. Angle Orthodont., v.64, n.5, p.351-8, 1994.

18. BISHARA, S. E. et al. Dentofacial and soft tissue changes in Class II, division 1 cases treated with and without extractions. Amer. J. Orthodont. Dentofac. Orthop., v.107, n.1, p.28-37, Jan. 1995.

19. BISHARA, S. E.; CUMMINS, D. M.; JAKOBSEN, J. R. The morphologic bases for the extraction decision. Amer. J. Orthodont. Dentofac. Orthop., v.107, n.2, p.129-35, Feb. 1995.

20. BISHARA, S. E.; CUMMINS, D. M.; ZAHER, A. R. Treatment and post treatment changes in patients with Class II, division 1 malocclusion after extraction and nonextraction treatment. Amer. J. Orthodont. Dentofac. Orthop., v.111, n.1, p.18-27, Jan.1997.

21. BLOCK, M. S.; HOFFMAN, D. R. A new device for absolute anchorage for orthodontics. Amer. J. Orthodont. Dentofac. Orthop., v.107, n.3, p.251-8, Mar.1995.

22. BRAMBILLA, A. C. Comparação dos resultados oclusais do tratamento de Classe II realizado com extrações de dois pré-molares, com a terapêutica utilizando as extrações de quatro pré-molares. Bauru, 2002, 94p. Dissertação (mestrado), Faculdade de Odontologia de Bauru, Universidade de São Paulo. 
23. BRATTSTROM, V.; INGELSSON, M.; ABERG, E. Treatment cooperation in orthodontic patients. Brit. J. Orthodont., v.18, n.1, p.37-42, Feb. 1991.

24. BRUSOLA, J. A. C. et al. Ortodoncia clinica. Barcelona, Salvat Editores, 1989, 509p.

25. CAPELli JR. J.; CARDOSO, M.; ROSEMBACH, G. Tratamento do apinhamento ântero-inferior por meio de desgaste interproximal. Rev. Bras. Odont., v.56, n.4, p.170-3, Jul-Ago. 1999.

26. CASE, C. S. The question of extraction in orthodontic. Amer. J. Orthodont., v.50, n.9, p.660-91, Sept. 1964.

27. CELENZA, F.; HOCHMAN, M. N. Absolute anchorage in orthodontics: direct and indirect implant - assisted modalities. J. Clin. Orthodont., v.34, n.7, p.397-402, July 2000.

28. CHIAPPONE, R. C. Special considerations for adult orthodontics. J. Clin. Orthodont., v.10, p.535-545, 1976.

29. CLARK, J. R. Oral hygiene in the orthodontic practice, motivation, responsibilities and concepts. Amer. J. Orthodont., v.69, n.1, p.72-82, Jan. 1976.

30. ClEAll, J.; BEGOlE, E. A. Diagnosis and treatment of Class II division 2 malocclusion. Angle Orthodont., v.52, n.1, p.38-60, Jan. 1982.

31. CLEMMER, E. J.; HAYES, E. W. Patient cooperation in wearing orthodontic heardgear. Amer. J. Orthodont., v.75, n.5, p.517-24, May 1979.

32. COLENATY, C.; GABRIEL, H. F. Predicting patient cooperation. J. Clin. Orthodont., v.11, n.12, p.814-19, Dec. 1977.

33. CUCALON, A.; SMITH, R. J. Relationship between compliance by adolescent orthodontic patients and performance on psychological tests. Angle Orthodont., v.60, n.2, p.107-14, 1990.

34. DAHLBERG, G. Statistical methods for medical and biological students. New York, Intercience, 1940.

35. DE CASTRO, N. Second premolar extracting in clinical practice. Amer. J. Orthodont., v.65, p.115-37, 1974.

36. DE SATURNO, L. D. La duracion del tratamiento ortodoncico y sus condicionantes. Caracas (1994) tese (prof. titular), 100p. Universidad de Caracas. 
37. DEWEL, B. F. Second premolar extraction in orthodontics: Principles, procedures and case analysis. Amer. J. Orthodont., v.41, p.107-120, 1955.

38. DEWEL, B. F. The clinical application of the edgewise appliance in orthodontic treatment. Amer. J. Orthodont., v.42, p.4-28, Jan.1956.

39. DOLL, G. M. et al. Relationship between patient discomfort, appliance acceptance and compliance in orthodontic therapy. J. Orofac. Orthop., v.61, n.6, p.398-413, 2000.

40. DORSEY, J.; KORABIK, K. Social and psychological motivations of orthodontic treatment. Amer. J. Orthodont., v.72, p.460-5, 1977.

41. DROBOCKY, O. B.; SMITH, R. J. Changes in facial profile during orthodontic treatment with extraction of four first premolars. Amer. J. Orthodont. Dentofac. Orthop., v.95, n.3, p.220-30, Mar. 1989.

42. DYER, G. S.; HARRIS, E. F.; VADEN, J. L. Age effects on orthodontic treatment: adolescents contrasted with adults. Amer. J. Orthodont. Dentofac. Orthop., v.100, n.6, p.523-30, Dec. 1991.

43. EGOLF, R. J.; BEGOLE, E. A.; UPSHAW, H. S. Factors associated with orthodontic patient compliance with intraoral elastic and headgear wear. Amer. J. Orthodont. Dentofac. Orthop., v.97, p.336-48, 1990.

44. El-MANGOURY, N. H. Orthodontic cooperation. Amer. J. Orthodont. Dentofac. Orthop., v.80, n.6, p.604-22, Dec. 1981.

45. FANNING, R. J. The role of extractions in orthodontic treatment. Int. J. Orthodont., v.2, n.1, p.17-26, Jan. 1964.

46. FELDSTEIN, L. Problems of orthodontics in treating adolescents. Amer. J. Orthodont., v.45, n.2, p.131-40, Feb.1959.

47. FIELDS, R. S. Influencing patient cooperation. J. Clin. Orthodont., v.11, p.417-21, Jun. 1980.

48. FINK, D. F.; SMITH, R. J. The duration of orthodontic treatment. Amer. J. Orthodont. Dentofac. Orthop., v.102, n.1, p.45-51, July 1992.

49. GABRIEL, H. F. Psychology of the use of the headgear. Angle Orthodont., v.35, p.320, 1965.

50. GABRIEL, H. F. Motivation of the headgear patient. Angle Orthodont., v.38, n.2, p.129-35, Apr 1968. 
51. GEBECK, T. R.; MERRIFIELD, L. L. Orthodontic diagnosis and treatment analysis concepts and values: Part I Special article. Amer. J. Orthodont. Dentofac. Orthop., v.107, n.4, p.434-43, Apr. 1995.

52. GLEN, G.; SAINTCLAIR, P. M.; ALEXANDER, R. G. Nonextraction orthodontic therapy postreatment dental and skeletal stability. Amer. J. Orthodont. Dentofac. Orthop., v.92, p.321-8, Oct. 1987.

53. GOTTLIEB, E. L. Grading your orthodontic treatment results. J. Clin. Orthodont., v.9, p.155-61, Mar.1975.

54. GRABER, T. M. Current orthodontic concepts and techniques. Philadelphia, W. B. Saunders Company, 1969, v.1, 998p.

55. GRABER, T. M. Maxillary second molar extraction in Class II malocclusion. Amer. J. Orthodont., v.56, n.4, p.331-53, Oct. 1969.

56. GRABER, T. M. Patient motivation. J. Clin. Orthodont., v.5, n.12, p.670-88, Dec. 1971.

57. GRABER, T. M.; VANARSDALL JR.; R. L. Orthodontics: current principles and techniques. 2 nd ed. St. Lowis: Mosby, 1994, p.37-40.

58. GRAINGER, R. M. Orthodontic treatment Priority Index, Public health service publication n.1000, serie 2, n.25. Washington, D. C., National Center for health Statistics, Education and Welfare, 1967.

59. GRAY, J. B.; SMITH, R. Transitional implants for orthodontic anchorage. J. Clin. Orthodont., v.34, n.11, p.659-66, Nov. 2000.

60. GREWE, J. M. Occlusal and skeletal disharmonies, cooperation and duration of orthodontic therapy. Amer. J. Orthodont., v.62, n.4, p.427-8, Oct. 1972.

61. GREWE, J. M.; HERMANSON, P. C. Influence of severity of malocclusion and the duration of orthodontic treatment. Amer. J. Orthodont., v.63, n.5, p.5336, May 1973.

62. GRIEVE, G. W. Anatomical and clinical problems involved where extraction is indicated in orthodontic treatment. Amer. J. Orthodont., v.30, p.437-43, July/Dec. 1944.

63. GROSS, A. M.; SAMSON, G.; DIERKES, M. Patient cooperation in treatment with removable appliances: a model of patient non-compliance with treatment implications. Amer. J. Orthodont., v.87, p.392-7, 1985. 
64. HARRIS, E. F.; DYER, G. S.; VADEN, J. L. Age effects on orthodontic treatment: skeletodental assessments from the Johnston analysis. Amer. J. Orthodont. Dentofac. Orthop., v.100, n.6, p.531-6, Dec. 1991.

65. HENRY, R. G. The extraction of the four second premolars in orthodontic treatment. Aust. Orthop. J., v.1, n.2, p.28-32, Oct. 1967.

66. HOWE, R. P.; MC NAMARA JR., J. A.; O'CONNOR, K. A. An examination of dental crowding and its relationship to tooth size and arch dimension. Amer. J. Orthodont., v.83, n.5, p.363-73, May 1983.

67. JANSON, G. Estudo tridimensional das assimetrias dentárias e esqueléticas na má oclusão de Classe II, subdivisão. Bauru, 1998, 271p. tese (Livre Docência) - Faculdade de Odontologia de Bauru, Universidade de São Paulo.

68. JANSON, G. et al. Considerações clínicas sobre o posicionamento vertical dos acessórios. Rev. Dental Press Ortodont. Ortop. Facial , v.5, n.3, p.45-51, maio/jun. 2000.

69. JARABAK, J. R. Development of a treatment plan in the light of one's concept of treatment objectives. Amer. J. Orthodont., v.46, n.7, p.481-514, July 1960.

70. JOHN, W.;KERR, S.; BUCHANAN, I. B. Factors influencing the outcome and duration of removable appliance treatment. Europ. J. Orthodont., v.16, n.3, p.181-6, June 1994.

71. JOHNSON, D. K.; SMITH, R. J. Smile esthetics after orthodontic treatment with and without extraction of four first premolars. Amer. J. Orthodont. Dentofac. Orthop., v.108, n.2, p.162-17, Aug. 1995.

72. KELES, A.; SAYINSU, K. A new approach in maxillary molar distalization: intraoral bodily molar distalizer. Amer. J. Orthodont. Dentofac. Orthop., v.177, n.1, p.39-48, Jan. 2000.

73. KESLING, P. C. Improving the final occlusion through selective premolar extractions. J. Clin. Orthodont., v.28, n.2, p.84-92, Feb. 1994.

74. KLAGES, V.; SERGL, H. G.; BURUCKER, I. Relations between verbal behavior of the orthodontist and communicative cooperation of the patient in regular orthodontic visits. Amer. J. Orthodont. Dentofac. Orthop., v.102, n.3, p.265-9, Sept. 1992.

75. KLAPPER, L. et al. The influence of extraction and nonextraction orthodontic treatment on brachyfacial and dolichofacial growth patterns. Amer. J. 
Orthodont. Dentofac. Orthop., v.101, p.425-30, 1992.

76. KLOEHN, S. J. Guiding alveolar growth and eruption of teeth to reduce treatment time and produce a more balanced denture and face. Angle Orthodont, v.17, n.1-2, p.10-33, Jan/Apr.1947.

77. LANDIS,J.R. ; KOCH,G.G. The measurement of observer agreement for categorical data. Biometrics, v.33, p.159-74, Mar.1977.

78. LIDDLE, D. W. Second molar extraction in orthodontic treatment. Amer. J. Orthodont., v.72, n.6, p.599-616, Dec. 1977.

79. LITT, R. A.; NIELSEN, I. L. Class II, division 2 malocclusion - to extract or not extract? Angle Orthodont., v.54, n.2, p.123-38, Apr. 1984.

80. LiTTLE, R. M.; WALLEN, T. R.; RIEDEL, R. A. Stability and relapse of mandibular anterior alignment-first premolar extraction cases treated by traditional Edgewise orthodontics. Amer. J. Orthodont., v.80, n.4, p.34965, Octob. 1981.

81. LUECKE III, P. E.; JOHNSTON JR., L. E. The effect of maxillary first premolar extraction and incisor retraction on mandibular position: testing the central dogma of "functional orthodontics". Amer. J. Orthodont. Dentofac. Orthop., v.101, n.1, p.4-12, Jan. 1992.

82. LUPPANAPORNLARP, S.; JOHNSTON, L. The effects of premolar extraction: a long term comparision of outcomes in "clearcut" extraction and nonextraction Class II patients. Angle Orthodont., v.63, p.257-72, 1993.

83. MACHEN, D. E. Risk management. Additional fee in case of non-cooperation in orthodontics. J. Clin. Orthodont., v.29, n.1, p.23-30, Jan. 1995.

84. MC GREGOR, F. C. Social and psychological implications of dentofacial desfigurement. Amer. J. Orthodont., v.40, p.213, 1970.

85. McGUINESS, N. J.; McDONALD, J. P. The influence of operator changes on orthodontic treatment time and results in a postgraduate teaching environme nt. Eur. J. Orthodont., v.20, n.2, p.159-67, Apr. 1998.

86. MC LAUGHLIN, R. P.; BENNET, J. C. The extraction - nonextraction dilemma as it relates to TMD. Angle Orthodont., v.65, p.175-86, 1995.

87. MILLS, J. R. E. Long-term results of the proclination of lower incisors. Brit. Dent. J., v.120, n.8, p.355-63, Apr. 1966.

88. MOORE, A. W. Orthodontic treatment factors in Class II malocclusion. Amer. J. Orthodont., v.45, n.5, p.323-52, May 1959. 
89. MYRBERG, N.; THILANDER, B. An evaluation of the duration and the results of orthodontic treatment. Scand. J. Dent. Res., v.81, n.2, p.85-91, 1973.

90. NANDA, R. S.; KIERL, M. J. Prediction of cooperation in orthodontic treatment. Amer. J. Orthodont. Dentofac. Orthop., v.102, n.1, p.15-21, Jul. 1992.

91. NORTHCUTT, M. E. The timing headgear. J. Clin. Orthodont., v.8, p.321-4, 1974.

92. O'BRIEN, K. D. et al. The effectiveness of Class II, division 1 treatment. Amer. J. Orthodont. Dentofac. Orthop., v.107, p.329-34, 1995.

93. OLIVEIRA JUNIOR, G. et al. Estudo da recidiva do apinhamento ânteroinferior de casos tratados com extrações de quatro primeiros pré-molares e mecânica de arco de canto. Ortodontia, v.24, n.1, p.24-30, Jan/Abr. 1991.

94. PAQUETTE, D. E.; BEATTIE, J. R.; JOHNSTON JR, L. E. A long-term comparision of nonextraction and premolar extraction Edgewise therapy in "borderline" Class II patients. Amer. J. Orthodont. Dentofac. Orthop., v.102, n.1, p.1-14, July 1992.

95. PECK, S.; PECK, H. Frequency of tooth extraction in orthodontic treatment. Amer. J. Orthodont. Dentofac. Orthop., v.76, n.5, p.491-6, Nov. 1979.

96. PLATZER, K. M. Considerations related to the duration of orthodontic treatment. Angle Orthodont., v.38, n.2, p.170-3, Apr.1968.

97. PROFFIT, W. R. Forty-year review of extraction frequencies at a university orthodontic clinic. Angle Orthodont., v.64, n.6, p.407-14, 1994.

98. RADLANSK, R. J.; JAGER, A. Plaque accumulation caused by interdental stripping. Amer. J. Orthodont. Dentofac. Orthop., v.94, n.5, p.416-20, 1988.

99. RIBAREVSKI, R et al. Consistency of orthodontic extraction decisions. Europ. J. Orthodont., v.18, n.1, p.77-80, Feb. 1996.

100. RICHARDSON, M. E. Late lower arch crowding: the role of the transverse dimension. Amer. J. Orthodont. Dentofac. Orthop., v.107, n.6, p.613-7, June 1995.

101. RICHMOND, S.; STEPHENS, C. D. Orthodontics in the general Dental services in England and Wales: the provision of treatment. Brit. Dent. J., v.172, p.150-2, Feb 1992. 
102. RICHMOND, S.; ANDREWS, M.; ROBERTS, C. T. The provision of orthodontic care in the general Dental service of England and Wales: extraction patterns, treatment duration, appliance types and standards. Brit. J. Orthodont., v.20, n.4, p.345-50, 1993.

103. RICHTER, D. D. et al. Effect of behavior modification on patient compliance in orthodontics. Angle Orthodont., v.68, n.2, p.123-32, Apr. 1998.

104. RIEDEL, R. A. On retention and relapse. J. Clin. Orthodont., v.10, n.6, p.45472, June 1976.

105. ROBISON, J. M.; RINCHUSE, D. J.; ZULLO, T. G. Relationship of skeletal pattern and nasal form. Amer. J. Orthodont., v.89, n.6, p.499-506, Jun. 1986.

106. ROCCO, T. D. Thoughts on stripping of anterior teeth. J. Clin. Orthodont., v.5, n.9, p.510-11, 1971 .

107. ROCK, W. P. Treatment of Class II malocclusions with removable appliances. Part 4. Class II division 2 treatment. Brit. Dent. J., v.168, n.7, p.298-302, Apr. 1990.

108. ROOB, S. I.; SADOWSKY, C.; SCHNEIDER, B. J. Effectiveness and duration of orthodontic treatment in adults and adolescents. Amer. J. Orthodont. Dentofac. Orthop., v.114, n.4, p.383-6, Octob.1998.

109. RUBIN, R. M. The uncooperative patient. J. Clin. Orthodont., v.14, n.3, p.1767, Mar. 1980.

110. RUNGE, M. E.; MARTIN, J. T.; BUKAI, F. Analysis of rapid maxillary molar distal movement without patient cooperation. Amer. J. Orthodont. Dentofac. Orthop., v.115, n.2, p.153-7, Feb. 1999.

111. SAATÇI, P.; YUKAY, F. The effect of premolar extractions on tooth-size discrepancy. Amer. J. Orthodont. Dentofac. Orthop., v.111, n.4, p.428-34, Apr. 1997.

112. SAHM, G.; BARTSCH, A.; WITT, E. Micro-electronic monitoring of functional appliance wear. Europ. J. Orthodont., v.12, n.3, p.297-301, Aug 1990.

113. SAHM, G.; BARTSCH, A.; WITT, E. Reliability of patient reports on compliance. Europ. J. Orthodont., v.12, n.4, p.438-46, Nov.1990.

114. SAIN, A. J. Concept and commentary: the extraction - nonextraction decision. J. Clin. Orthodont., v.7, n.70, p.621-36, 1973. 
115. SALZMANN, J. A. Factors in successful orthodontic therapy before and after using appliances. Amer. J. Orthodont., v.49, n.2, p.581-87, Aug.1963.

116. SALZMAN, J. A. An evaluation of retention and relapse following orthodontic therapy. Amer. J. Orthodont., v.51, n.10, p.779-81, Oct. 1965.

117. SAlZMANN, J. A. Practice of orthodontics. Philadelphia, J. B. Lippincott Company, 1966, v.2, p.701-24.

118. SCHUTZ-FRANSSON, V.; BJERKLIN, K.; KURD, J. Mandibular incisor stability after bimaxillary orthodontic treatment with premolar extraction in the upper arch. J. Orofac. Orthop., v.59, n.1, p.47-58, 1998.

119. SHEIHAM, A. et al. Orthodontic treatment in the general dental service in England and Wales; a study. Brit. Dent. J. , v.131, n.6, p.535-8, Sept.1971.

120. SHERIDAN, J. J. Air-rotor stripping. J. Clin. Orthodont., v.19, n.1, p.43-59, Jan. 1985.

121. SHERIDAN, J. J. Air-rotor stripping update. J. Clin. Orthodont., v.21, n.11, p.781-8, Nov. 1987.

122. SHERIDAN, J. J.; CRAIN, G. Susceptibility to caries and periodontal disease after posterior air-rotor stripping. J. Clin. Orthodont., v.24, n.24, p.84-5, 1990.

123. SHIA, G. J. Treatment overruns. J. Clin. Orthodont., v.20, n.9, p.602-4, Sept.1986.

124. SHIELDS, T. E.; LITTLE, R. M.; CHAPKO, M. K. Stability and relapse of mandibular anterior alignment: a cephalometric appraisal of first premolar extraction cases treated by traditional edgewise orthodontics. Amer. J. Orthodont., v.87, p.27-38, 1985.

125. SHUBICH, I Cuanto tiempo requiere un tratamiento ortodoncico? Pract. Odontol., v.9, n.2, p.10, Jun. 1988.

126. SLAKTER, M. J. et al. Reliability and stability of the orthodontic patient cooperation scale. Amer. J. Orthodont., v.78, n.5, p.559-63, Nov. 1980.

127. STAGGERS, J. A. A comparision of results of second molar and first premolar extraction treatment. Amer. J. Orthodont. Dentofac. Orthop., v.98, n.5, p.430-6, Nov. 1990.

128. STARNBACH, H. K.; KAPLAN, A. Profile of an excellent orthodontic patient. Angle Orthodont., v.45, n.2, p.141-5, Apr.1975. 
129. STEYN, C. L.; PREEZDU, R. J.; HARRIS, A. M. P. Differential premolar extraction. Amer. J. Orthodont. Dentofac. Orthop., v.112, n.5, p.480-6, Nov. 1997.

130. STORY, I. Psychological issues in orthodontic practice. Amer. J. Orthodont., v.52, n.8, p.584-97, Aug.1966.

131. STROMBONI, Y. Facial aesthetics in orthodontic treatment with and without extractions. Eur. J. Orthodont., v.1, n.3, p.201-6, Mar. 1979.

132. SUGAWARA, J. The skeletal anchorage system. J. Clin. Orthodont., v.33, n.12, p.689-96, Dec. 1999.

133. SWAIN, B. F. Borderline extraction cases. J. Clin. Orthodont., v.5, n.10, p.539-647, Oct. 1971.

134. SWETLIK, W. P. A behavioral evaluation of patient cooperation in the use of extraoral elastic and coil spring traction devices. Amer. J. Orthodont., v.74, p.687, 1978.

135. TANER-SANSOY, L.; DARENDELILER, N. The influence of extraction orthodontic treatment on cranio facial structures: Evaluation according to two different factors. Amer. J. Orthodont. Dentofac. Orthop., v.115, n.5, p.50814, May 1999.

136. TAYLOR, P. J. S.; KERR, W. I. S. Factors associated with the standard and duration of orthodontic treatment. Brit. J. Orthodont., v.23, p.335-41, Nov. 1996.

137. TULLEY, W. J.; CAMPBELL, A. C. A manual of practical orthodontics. John Wright and sons, 1965, p.203-10, 218-21.

138. TURBILL, E. A.; RICHMOND, S.; WRIGHT, J. L. The time-factor in orthodontics what influences the duration of treatments in national Health service practices? Community Dent. Oral Epidemiol, v.29, n.1, p.62-72, Feb. 2001.

139. TWEED, C. H. The application of the principles of the Edgewise arch in the treatment of Class II, division 1 malocclusion: part 2. Angle Orthodont., v.11, n.1, p.12-67, Jan. 1941.

140. TWEED, C. H. Indications for the extractions of teeth in orthodontic procedures. Amer. J. Orthodont. Oral Surg., v.30, p.405-28, Jul/Dec. 1944.

141. TWEED, C. H. The Frankfort mandibular incisor angle (FMIA) in orthodontic 
diagnosis, treatment planning and prognosis. Angle Orthodont., v.24, n.3 p.121-69, Jul. 1954.

142. VADEN, J. L. Sequential directional forces treatment: two Class II case reports. Amer. J. Orthodont. Dentofac. Orthop., v.99, n.6, p.491-504, June 1991.

143. VADEN, J. L.; HARRIS, E. F.; BEHRENTS, R. G. Adult versus adolescent Class II correction: a comparision - case report. Amer. J. Orthodont. Dentofac. Orthop., v.107, n.6, p.651-61, June 1995.

144. VADEN, J. L.; KISER, H. E. Straight talk about extraction and nonextraction: a differential diagnostic decision. Amer. J. Orthodont. Dentofac. Orthop., v.109, n.4, p.445-52, Apr. 1996.

145. VIG, P. S. et al. The duration of orthodontic treatment with and without extractions : a pilot study of five selected practices. Amer. J. Orthodont. Dentofac. Orthop., v.97, n.1, p.45-51, Jan. 1990.

146. WAGNER, M.; BERG, R. Serial extraction or premolar extraction in the permanent dentition? Comparision of duration and outcome of orthodontic treatment. J. Orofac. Orthop., v.61, n.3, p.207-16, 2000.

147. WEINTRAUB, J. A. et al. The prevalence of orthodontic extractions. Amer. J. Orthodont. Dentofac. Orthop., v.96, n.6, p.462-6, Dec. 1989.

148. WHITE, L. W. A behavioristc approach to oral hygiene. Amer. J. Orthodont., v.72, p.406-13, 1977.

149. WHITE, L. W. Pain and cooperation in orthodontic treatment. J. Clin. Orthodont., v.18, n.8, p.572-5, Aug. 1984.

150. WRIGHT, D. M. Getting orthodontic cases done on time. J. Gen. Orthodont., v.6, n.1, p.26-8, Jun. 1995.

151. YAMAGUCHI, K.; NANDA, R. S. The effects of extraction and nonextraction treatment on the mandibular position. Amer. J. Orthodont. Dentofac. Orthop., v.100, n.5, p.443-52, Nov. 1991.

152. YOUNG, T. M.; SMITH, R. J. Effects of orthodontics on the facial profile: a comparision of changes during nonextraction and four premolar extraction treatment. Amer. J. Orthodont. Dentofac. Orthop., v.103, n.5, p.452-457, May 1993. 
ABSTRACT 


\section{ABSTRACT}

The purpose of this investigation was to compare orthodontic treatment duration between two different protocols concerning extraction of either two or four premolars during the therapy. The sample consisted of 121 patients showing a complete Class II malocclusion, divided in group 1 and group 2, treated with two or four premolar extraction, respectively. The initial mean age of group 1 and group 2 was respectively, 13,73 and 13,03 years old. It was observed that many patients into group 1 had been submitted to extractions after a initial effort to treat the Class II malocclusion without extractions. So this group was divided again in subgroups $\mathrm{A}$ and $\mathrm{B}$, respecting if the decision to extract had been done since the beginning or only after a new treatment planning. Results demonstrated a statistically significant difference between the treatment duration in the groups, with subgroup 1 A presenting a shorter treatment duration when compared with group 2, treated with four premolar extractions. Besides that, subgroup $1 \mathrm{~B}$, which was submitted to a replanning, demonstrated the longest treatment time, presenting a mean treatment duration vary similar to group 2. In addition, factors associated with cooperation, regularity in appointments and appliance breakage seemed to influenciate treatment time. Therefore it was concluded that treatment of Class II malocclusion with two premolar extractions provides a shorter treatment time than treatment with four premolar extraction. 
APÊNDICE 


\section{APÊNDICE}

As tabelas A-1 e A-2 referem-se aos valores reais individuais de cada variável, para cada um dos 121 pacientes avaliados, dos grupos 1A, 1B e grupo 2.

A figura A-1 representa o modelo de ficha utilizada para a coleta dos dados nas pastas ortodônticas investigadas.

Tabela A-1

\begin{tabular}{|c|c|c|c|c|c|c|c|c|c|}
\hline Pacientes & $\mathbf{N}^{\mathbf{o}}$ & Arq. & Grupo & Gênero & Idade & IPT (i) & IPT (tto) & SS (i) & SM(i) \\
\hline Maksuel M.Buscariolo & 01 & E/A & 1 & $\mathrm{M}$ & 12.33 & 6.07 & 4.57 & 5.00 & 2.00 \\
\hline Luiz A.M.dos Reis & 02 & $\mathrm{E} / \mathrm{A}$ & 1 & $\mathrm{M}$ & 15.83 & 5.97 & 5.70 & 3.00 & 4.00 \\
\hline Talita D. da Silva & 03 & E/A & 1 & $\mathrm{~F}$ & 13.17 & 8.67 & 8.10 & 7.00 & 5.00 \\
\hline Luiz G. dos Reis & 04 & E/A & 1 & $\mathrm{M}$ & 12.83 & 10.77 & 10.40 & 3.00 & -6.00 \\
\hline José Augusto Ticianelli & 05 & $\mathrm{E} / \mathrm{A}$ & 1 & $\bar{M}$ & 11.42 & 7.37 & 7.10 & 3.00 & 6.00 \\
\hline Luciane Ap. B. Pereira & 06 & $\mathrm{E} / \mathrm{A}$ & 1 & $\mathrm{~F}$ & 14.00 & 7.17 & 5.40 & 6.00 & 3.00 \\
\hline Geovana Ap. Silveira & 07 & E/A & 1 & $\mathrm{~F}$ & 16.50 & 7.67 & 6.17 & 10.00 & 4.00 \\
\hline Érika Cristina Duarte & 08 & E/A & 1 & $\mathrm{~F}$ & 14.33 & 5.57 & 5.57 & 5.50 & 1.50 \\
\hline Dimas Horne de Deus & 09 & E/A & 1 & $\mathrm{M}$ & 15.25 & 6.37 & 6.37 & 2.00 & 4.00 \\
\hline Alexandre Bianospino & 10 & PG & 1 & $\mathrm{M}$ & 13.75 & 10.47 & 8.97 & 9.00 & 1.00 \\
\hline Marcelo P. Pinto & 11 & PG & 1 & M & 19.33 & 6.87 & 5.60 & 3.00 & 2.00 \\
\hline Luis Carlos O. JR & 12 & PG & 1 & $\mathrm{M}$ & 13.92 & 7.67 & 5.90 & 12.00 & 1.00 \\
\hline William Biral & 13 & PG & 1 & M & 13.00 & 10.07 & 10.07 & 11.00 & 9.00 \\
\hline Willians César Ferraz & 14 & $\overline{P G}$ & 1 & $\bar{M}$ & 15.25 & 8.87 & 8.60 & 12.00 & 5.00 \\
\hline Aline O . Rosa & 15 & $\mathrm{E}$ & 1 & $\mathrm{~F}$ & 11.58 & 10.27 & 10.27 & 4.00 & 3.00 \\
\hline Carlos Roberto M. Filho & 16 & $\mathrm{E}$ & 1 & $\mathrm{M}$ & 13.67 & 7.57 & 7.30 & 8.00 & 4.50 \\
\hline Brisa B. Angelice & 17 & $\mathrm{E}$ & 1 & $\mathrm{~F}$ & 18.50 & 8.77 & 8.77 & 7.00 & 5.50 \\
\hline André Luis Bastasini & 18 & $\mathrm{E}$ & 1 & $\mathrm{M}$ & 11.50 & 6.37 & 6.10 & 4.00 & 3.00 \\
\hline André G. Bertone & 19 & $\mathrm{E}$ & 1 & $\mathrm{M}$ & 14.67 & 7.27 & 5.50 & 5.00 & 6.00 \\
\hline Alessandro Martinelli & 20 & $\mathrm{E}$ & 1 & $\mathrm{M}$ & 14.33 & 8.67 & 7.17 & 12.00 & 5.00 \\
\hline Alessandro M. Gomes & 21 & $\mathrm{E}$ & 1 & $\mathrm{M}$ & 13.00 & 5.67 & 5.40 & 5.00 & 1.50 \\
\hline Lissandra M. Medina & 22 & $\mathrm{E}$ & 1 & $\mathrm{~F}$ & 17.50 & 5.77 & 5.50 & 3.00 & 2.50 \\
\hline Licínia Carreira & 23 & $\mathrm{E}$ & 1 & $\mathrm{~F}$ & 14.00 & 8.27 & 6.77 & 6.00 & 3.50 \\
\hline Leonardo J.P. Passos & 24 & $\mathrm{E}$ & 1 & $\mathrm{M}$ & 13.50 & 9.27 & 8.90 & 14.00 & 7.00 \\
\hline Leandro F. Dias & 25 & $\mathrm{E}$ & 1 & $\mathrm{M}$ & 13.33 & 7.57 & 7.57 & 7.00 & 4.50 \\
\hline Leandro G.C. Silva & 26 & $\bar{E}$ & 1 & $\bar{M}$ & 15.33 & 8.97 & 6.70 & 6.00 & 3.50 \\
\hline Juliana de Oliveira & 27 & $\bar{E}$ & 1 & $\mathrm{~F}$ & 15.08 & 6.97 & 6.70 & 5.00 & -1.00 \\
\hline Ivan A.F. de Marche & 28 & $\mathrm{E}$ & 1 & M & 14.67 & 8.47 & 6.97 & 3.00 & 7.00 \\
\hline Helida de Souza Sanches & 29 & $\mathrm{E}$ & 1 & $\mathrm{~F}$ & 12.42 & 7.77 & 7.50 & 6.00 & 3.50 \\
\hline Irma Elisa B. Carneiro & 30 & $\mathrm{E}$ & 1 & $\mathrm{~F}$ & 27.08 & 8.87 & 7.07 & 3.00 & 6.50 \\
\hline Heder A. J. Santos & 31 & $\mathrm{E}$ & 1 & $\mathrm{M}$ & 12.67 & 7.57 & 6.07 & 7.00 & 3.50 \\
\hline Emerson A . Montanhini & 32 & $\mathrm{E}$ & 1 & $\mathrm{M}$ & 14.67 & 8.07 & 7.80 & 9.00 & 4.50 \\
\hline Eduardo S. Penitente & 33 & $\mathrm{E}$ & 1 & $\mathrm{M}$ & 15.08 & 7.07 & 6.80 & 5.00 & 4.50 \\
\hline Eduardo Cavacami & 34 & $\bar{E}$ & 1 & $\bar{M}$ & 13.75 & 7.37 & 7.10 & 1.00 & 4.00 \\
\hline Ederton José Davilla & 35 & $\mathrm{E}$ & 1 & $\mathrm{M}$ & 13.67 & 7.37 & 6.10 & 3.00 & 4.50 \\
\hline Marcelo Escobar Branco & 36 & $\mathrm{E}$ & 1 & $\mathrm{M}$ & 19.00 & 8.47 & 6.97 & 6.00 & -4.00 \\
\hline Marlon Pelizario & 37 & $\mathrm{E}$ & 1 & $\mathrm{M}$ & 15.00 & 8.37 & 8.37 & 9.00 & 4.00 \\
\hline Mayra Carrero Muniz & 38 & $\mathrm{E}$ & 1 & $\mathrm{~F}$ & 15.00 & 8.77 & 8.77 & 11.00 & 4.00 \\
\hline Priscila G. de Oliveira & 39 & $\mathrm{E}$ & 1 & $\mathrm{~F}$ & 12.92 & 8.47 & 6.70 & 9.00 & 9.00 \\
\hline
\end{tabular}




\begin{tabular}{|c|c|c|c|c|c|c|c|c|c|}
\hline Rafaela O.T. Pitta & 40 & $\mathrm{E}$ & 1 & $\mathrm{~F}$ & 13.33 & 6.97 & 6.60 & 3.00 & 4.00 \\
\hline Renata Carla Ferrari & 41 & $\bar{E}$ & 1 & $\mathrm{~F}$ & 9.42 & 7.77 & 6.27 & 9.00 & 6.00 \\
\hline Renata Carreira Castro & 42 & $\mathrm{E}$ & 1 & $\mathrm{~F}$ & 14.00 & 7.37 & 5.87 & 9.00 & 3.00 \\
\hline Rosimeire Neto da Silva & 43 & $\mathrm{E}$ & 1 & $\mathrm{~F}$ & 11.67 & 8.87 & 8.60 & 10.00 & 8.00 \\
\hline Samuel Abrahão & 44 & $\mathrm{E}$ & 1 & $\mathrm{M}$ & 12.33 & 6.07 & 6.07 & 7.00 & 4.00 \\
\hline Sidnei N. Leite & 45 & $\mathrm{E}$ & 1 & $\mathrm{M}$ & 19.25 & 8.37 & 8.37 & 6.00 & 6.00 \\
\hline Wesley S. Tertuliano & 46 & $\bar{E}$ & 1 & $\bar{M}$ & 11.83 & 10.37 & 10.10 & 12.00 & 7.00 \\
\hline Tatiane T. Ferrari & 47 & $\mathrm{E}$ & 1 & $\mathrm{~F}$ & 11.08 & 9.47 & 9.47 & 8.00 & -4.00 \\
\hline Vanessa Regina Melges & 48 & $\mathrm{E}$ & 1 & $\mathrm{~F}$ & 14.25 & 8.67 & 8.67 & 9.00 & 4.00 \\
\hline Willian A . Villas Boas & 49 & $\mathrm{E}$ & 1 & $\bar{M}$ & 13.00 & 7.77 & 7.50 & 10.00 & 3.00 \\
\hline Danilo Bertone Prado & 50 & $\mathrm{E} / \mathrm{A}$ & $1 \mathrm{R}$ & $\mathrm{M}$ & 15.17 & 8.07 & 6.57 & 9.00 & 6.00 \\
\hline Raphael Rondon Monji & 51 & $\mathrm{E} / \mathrm{A}$ & $1 \mathrm{R}$ & $\mathrm{M}$ & 9.42 & 5.87 & 5.87 & 5.00 & 5.00 \\
\hline Bruno Tavera & 52 & $\mathrm{E} / \mathrm{A}$ & $\overline{1 R}$ & $\mathrm{M}$ & 14.08 & 10.07 & 8.57 & 11.00 & -5.00 \\
\hline Ana Laura R. Daher & 53 & $\mathrm{E} / \mathrm{A}$ & $1 \mathrm{R}$ & $\mathrm{F}$ & 11.42 & 8.27 & 7.90 & 8.00 & 5.50 \\
\hline Josë Terto Junior & 54 & $\mathrm{E} / \mathrm{A}$ & $1 \mathrm{R}$ & $\mathrm{M}$ & 14.00 & 8.57 & 8.57 & 3.00 & 8.00 \\
\hline Adriana C. Luchesi & 55 & $\mathrm{E} / \mathrm{A}$ & $1 \mathrm{R}$ & $\mathrm{F}$ & 14.58 & 7.77 & 6.27 & 8.00 & 5.00 \\
\hline Ana Paula Laranjeira & 56 & PG & $1 \mathrm{R}$ & $\mathrm{F}$ & 12.83 & 8.37 & 5.77 & 11.00 & 5.00 \\
\hline Camilla dos S. Zanatta & 57 & PG & $1 \mathrm{R}$ & $\mathrm{F}$ & 11.33 & 7.67 & 7.67 & 4.00 & 5.00 \\
\hline Ricardo H. Coneglian & 58 & $\mathrm{PG}$ & $1 \mathrm{R}$ & $\mathrm{M}$ & 10.67 & 9.97 & 9.97 & 12.00 & 4.00 \\
\hline Maria Eliza A . Paes & 59 & PG & $1 \mathrm{R}$ & $\mathrm{F}$ & 21.50 & 8.27 & 6.50 & 7.00 & 5.00 \\
\hline Elaine Barbosa & 60 & $\mathrm{PG}$ & $\overline{1 R}$ & $\mathrm{~F}$ & 13.75 & 17.77 & 17.77 & 6.00 & -1.00 \\
\hline Bruno Loureiro Luz & 61 & $\mathrm{E}$ & $1 \mathrm{R}$ & $\bar{M}$ & 11.50 & 7.17 & 6.90 & 3.00 & 7.00 \\
\hline Alessandra Marques & 62 & $\mathrm{E}$ & $1 \mathrm{R}$ & $\mathrm{F}$ & 11.92 & 7.37 & 5.87 & 3.00 & 5.50 \\
\hline Alceu Borges Junior & 63 & $\bar{E}$ & $1 \mathrm{R}$ & $\bar{M}$ & 15.00 & 7.47 & 7.47 & 8.00 & 6.00 \\
\hline Luiz Eduardo Borgo & 64 & $\mathrm{E}$ & $1 \mathrm{R}$ & $\bar{M}$ & 12.33 & 6.87 & 5.37 & 5.00 & 5.00 \\
\hline Luis Ângelo Schio & 65 & $\bar{E}$ & $\overline{1 R}$ & $\bar{M}$ & 17.25 & 7.17 & 6.90 & 3.00 & 7.50 \\
\hline Ludymilla F. Terto & 66 & $\mathrm{E}$ & $1 \mathrm{R}$ & $\mathrm{F}$ & 13.08 & 7.67 & 6.17 & 8.00 & 6.00 \\
\hline Luciana F. Rufino & 67 & $\mathrm{E}$ & $1 \mathrm{R}$ & $\mathrm{F}$ & 11.92 & 7.87 & 7.60 & 5.00 & 3.00 \\
\hline Marcus Vinicius Souza & 68 & $\mathrm{E}$ & $\overline{1 R}$ & $\bar{M}$ & 12.75 & 7.47 & 7.47 & 3.00 & 5.00 \\
\hline Marcos Roberto Vieira & 69 & $\mathrm{E}$ & $1 \mathrm{R}$ & $\mathrm{M}$ & 11.50 & 8.07 & 6.57 & 9.00 & 5.00 \\
\hline Mayra F. Z. Crepaldi & 70 & $\mathrm{E}$ & $1 \mathrm{R}$ & $\mathrm{F}$ & 12.00 & 8.07 & 6.57 & 9.00 & 7.00 \\
\hline Paula Cristina Picoli & 71 & $\mathrm{E}$ & $1 \mathrm{R}$ & $\mathrm{M}$ & 13.33 & 6.87 & 6.87 & 5.00 & 5.00 \\
\hline Ricardo P. de Oliveira & 72 & $\mathrm{E}$ & $1 \mathrm{R}$ & $\mathrm{M}$ & 12.00 & 7.27 & 7.00 & 6.00 & 6.00 \\
\hline Romina Lindolfo Prieto & 73 & $\mathrm{E}$ & $1 \mathrm{R}$ & $\mathrm{F}$ & 11.42 & 9.17 & 9.17 & 12.00 & 7.00 \\
\hline Thiago Barbosa Ramalho & 74 & E/A & 2 & $\bar{M}$ & 14.00 & 7.17 & 4.45 & 5.00 & 5.00 \\
\hline Rafael P. de Camargo & 75 & E/A & 2 & $\mathrm{M}$ & 14.00 & 8.37 & 6.87 & 11.00 & 3.00 \\
\hline Edílson N. Medeiros & 76 & $\mathrm{E}$ & 2 & $\bar{M}$ & 13.17 & 9.67 & 7.90 & 8.50 & 5.00 \\
\hline Ednaldo Alves Costa & 77 & $\mathrm{E} / \mathrm{A}$ & 2 & $\mathrm{M}$ & 15.50 & 8.47 & 4.85 & 10.00 & 3.00 \\
\hline Vânia Maria Pinheiro & 78 & PG & 2 & $\mathrm{~F}$ & 12.25 & 6.97 & 6.97 & 8.00 & 3.00 \\
\hline Maria Cândida C.Andrade & 79 & $\mathrm{PG}$ & 2 & $\mathrm{~F}$ & 12.42 & 7.77 & 6.00 & 8.00 & 5.00 \\
\hline Celso A . Chermont & 80 & $\mathrm{PG}$ & 2 & $\bar{M}$ & 12.17 & 9.47 & 6.57 & 15.00 & 6.00 \\
\hline Cristiane R. Minorello & 81 & $\mathrm{PG}$ & 2 & $\mathrm{~F}$ & 11.33 & 9.17 & 6.57 & 13.00 & 5.00 \\
\hline Carlos Alberto G. Brito & 82 & $\overline{P G}$ & 2 & $\bar{M}$ & 18.33 & 7.97 & 2.30 & 7.00 & 4.00 \\
\hline Ana Lucia P. Leite & 83 & $\mathrm{PG}$ & 2 & $\mathrm{~F}$ & 12.25 & 8.17 & 6.57 & 7.00 & 3.00 \\
\hline Bernardete T. Napolitano & 84 & PG & 2 & $\mathrm{~F}$ & 12.33 & 8.77 & 7.00 & 7.00 & 5.00 \\
\hline Cristiani P. de Moraes & 85 & PG & 2 & $\mathrm{~F}$ & 12.50 & 9.67 & 9.67 & 12.00 & 1.00 \\
\hline Gláucia V. Souza & 86 & PG & 2 & $\mathrm{~F}$ & 13.00 & 7.57 & 5.80 & 7.00 & 3.00 \\
\hline Márcia Cristina Peregini & 87 & $\mathrm{PG}$ & 2 & $\mathrm{~F}$ & 14.50 & 9.47 & 6.87 & 12.00 & 3.00 \\
\hline Ricardo N. Mesquita & 88 & $\mathrm{PG}$ & 2 & $\mathrm{M}$ & 12.08 & 9.77 & 9.77 & 11.00 & 7.00 \\
\hline Maria G. Mondelli & 89 & $\mathrm{PG}$ & 2 & $\mathrm{~F}$ & 13.67 & 7.17 & 5.40 & 10.00 & 4.00 \\
\hline João L. Carvalho & 90 & PG & 2 & $\mathrm{M}$ & 18.25 & 7.17 & 4.57 & 12.00 & 2.00 \\
\hline José Issa Junior & 91 & PG & 2 & $\mathrm{M}$ & 15.08 & 8.17 & 8.17 & 8.00 & 4.50 \\
\hline Kátia de S. Christofaro & 92 & $\mathrm{PG}$ & 2 & $\mathrm{~F}$ & 13.92 & 8.17 & 8.17 & 6.00 & 4.00 \\
\hline Hilton C. Guimarães & 93 & PG & 2 & $\mathrm{M}$ & 12.83 & 7.07 & 6.80 & 6.00 & 3.00 \\
\hline Paulo Sergio Medeiros & 94 & $\mathrm{PG}$ & 2 & $\mathrm{M}$ & 14.33 & 8.27 & 8.00 & 3.00 & 4.00 \\
\hline Marcos Ricardo Atayde & 95 & $\mathrm{PG}$ & 2 & $\bar{M}$ & 11.17 & 6.17 & 4.40 & 1.00 & 3.00 \\
\hline Vilma Galvão & 96 & $\mathrm{PG}$ & 2 & $\mathrm{~F}$ & 14.33 & 6.67 & 4.90 & 6.00 & 1.50 \\
\hline Débora R. M. Baldani & 97 & PG & 2 & $\mathrm{~F}$ & 14.17 & 8.67 & 6.90 & 8.00 & 4.00 \\
\hline Viviane M. Bonfim & 98 & $\mathrm{PG}$ & 2 & $\mathrm{~F}$ & 11.25 & 7.37 & 7.37 & 2.00 & 4.00 \\
\hline Lidiane da Silva & 99 & $\mathrm{E}$ & 2 & $\mathrm{~F}$ & 12.08 & 8.77 & 5.65 & 10.00 & 6.00 \\
\hline Juliano P. Loureiro & 100 & $\mathrm{E}$ & 2 & $\bar{M}$ & 13.25 & 7.07 & 7.07 & 6.00 & 5.00 \\
\hline
\end{tabular}




\begin{tabular}{llllllllll}
\hline Joao Carlos N. Luiz & 101 & $\mathrm{E}$ & 2 & $\mathrm{M}$ & 10.67 & 7.37 & 3.12 & 4.50 & 4.00 \\
\hline Janaina R. O . Santos & 102 & $\mathrm{E}$ & 2 & $\mathrm{~F}$ & 11.92 & 8.17 & 6.67 & 5.00 & 3.00 \\
\hline Halphen Delie Berbert & 103 & $\mathrm{E}$ & 2 & $\mathrm{M}$ & 14.42 & 9.57 & 4.15 & 6.00 & 3.00 \\
\hline Heder E. T. Cavalheri & 104 & $\mathrm{E}$ & 2 & $\mathrm{M}$ & 11.33 & 7.57 & 5.80 & 8.00 & 4.00 \\
\hline Fernando L. Neto & 105 & $\mathrm{E}$ & 2 & $\mathrm{M}$ & 11.33 & 6.67 & 6.40 & 2.00 & 3.00 \\
\hline Fabrício Santos & 106 & $\mathrm{E}$ & 2 & $\mathrm{M}$ & 11.33 & 9.37 & 7.87 & 9.00 & 3.00 \\
\hline Fabio R. P. Luciano & 107 & $\mathrm{E}$ & 2 & $\mathrm{M}$ & 14.67 & 6.27 & 4.77 & 7.00 & 1.00 \\
\hline Danny M. da Silva & 108 & $\mathrm{E}$ & 2 & $\mathrm{~F}$ & 12.08 & 8.47 & -0.20 & 9.00 & 4.00 \\
\hline Daniel F. de Oliveira & 109 & $\mathrm{E}$ & 2 & $\mathrm{M}$ & 11.92 & 8.67 & 8.40 & 4.00 & 4.00 \\
\hline Clariana A. S. Pinto & 110 & $\mathrm{E}$ & 2 & $\mathrm{~F}$ & 11.58 & 8.87 & 7.37 & 5.00 & 5.00 \\
\hline César Caetano de Oliveira & 111 & $\mathrm{E}$ & 2 & $\mathrm{M}$ & 14.17 & 6.77 & 5.27 & 8.00 & 3.00 \\
\hline Ana Emilio Pio & 112 & $\mathrm{E}$ & 2 & $\mathrm{~F}$ & 11.08 & 9.27 & 9.00 & 7.00 & 5.00 \\
\hline Marcelo C. Silva & 113 & $\mathrm{E}$ & 2 & $\mathrm{M}$ & 11.25 & 8.97 & 8.70 & 8.00 & 6.00 \\
\hline Marcos S. Yamakawa & 114 & $\mathrm{E}$ & 2 & $\mathrm{M}$ & 14.50 & 8.97 & 7.47 & 11.00 & 6.00 \\
\hline Micael F. O. Mateus & 115 & $\mathrm{E}$ & 2 & $\mathrm{M}$ & 13.17 & 6.87 & 5.37 & 5.00 & 4.00 \\
\hline Mirian Cavalcante & 116 & $\mathrm{E}$ & 2 & $\mathrm{~F}$ & 11.17 & 10.47 & 5.42 & 11.00 & 5.00 \\
\hline Rangel Soares Silva & 117 & $\mathrm{E}$ & 2 & $\mathrm{M}$ & 15.00 & 10.67 & 9.17 & 10.00 & 5.00 \\
\hline Vanessa M. Biroli & 118 & $\mathrm{E}$ & 2 & $\mathrm{~F}$ & 13.00 & 8.17 & 5.45 & 7.00 & 4.00 \\
\hline Vinicius Cardoso Rossi & 119 & $\mathrm{E}$ & 2 & $\mathrm{M}$ & 12.83 & 7.97 & 7.70 & 7.00 & 5.00 \\
\hline Viviane Koch Barbosa & 120 & $\mathrm{E}$ & 2 & $\mathrm{~F}$ & 11.50 & 7.87 & 5.27 & 6.00 & 4.00 \\
\hline Waderson D. Petelinkar & 121 & $\mathrm{E}$ & 2 & $\mathrm{M}$ & 12.17 & 8.17 & 4.55 & 5.00 & 4.00 \\
\hline
\end{tabular}

Tabela A-2

\begin{tabular}{|c|c|c|c|c|c|c|c|c|c|c|c|c|c|}
\hline $\mathbf{N}^{0}$ & Grup & $\mathbf{T} / \mathbf{T}$ & RP & $\mathbf{A} / \mathbf{N}-\mathbf{S}$ & $\mathbf{A} / \mathbf{N}-\mathbf{I}$ & R-S & R-I & F-S & F-I & Ativ. & Faltas & Queb. & Coop. \\
\hline 1 & 1 & 24.73 & 0.00 & 6.90 & 13.67 & 9.10 & 0.00 & 6.00 & 7.00 & 29 & 0 & 4 & 1 \\
\hline 2 & 1 & 29.60 & 0.00 & 14.20 & 3.43 & 10.83 & 0.00 & 1.80 & 12.63 & 38 & 2 & 4 & 1 \\
\hline 3 & 1 & 33.00 & 0.00 & 10.83 & 19.27 & 10.50 & 0.00 & 4.53 & 4.53 & 41 & 1 & 44 & 0 \\
\hline 4 & 1 & 21.57 & 0.00 & 15.17 & 14.00 & 0.00 & 0.00 & 3.43 & 3.43 & 27 & 3 & 0 & 1 \\
\hline 5 & 1 & 21.00 & 0.00 & 8.17 & 16.13 & 9.00 & 0.00 & 2.77 & 2.77 & 18 & 3 & 9 & 1 \\
\hline 6 & 1 & 18.20 & 0.00 & 8.47 & 7.10 & 0.00 & 0.00 & 5.57 & 5.57 & 26 & 01 & 04 & 2 \\
\hline 7 & 1 & 20.00 & 0.00 & 13.13 & 3.00 & 10.13 & 0.00 & 3.00 & 3.00 & 25 & 0 & 0 & 2 \\
\hline 8 & 1 & 20.53 & 0.00 & 7.13 & 13.33 & 7.33 & 0.00 & 4.63 & 4.63 & 30 & 0 & 0 & 2 \\
\hline 9 & 1 & 13.00 & 0.00 & 3.63 & 6.67 & 3.00 & 0.00 & 4.53 & 4.53 & 15 & 2 & 3 & 2 \\
\hline 10 & 1 & 30.37 & 0.00 & 9.60 & 19.53 & 5.00 & 0.00 & 9.00 & 9.00 & 44 & 3 & 4 & 1 \\
\hline 11 & 1 & 16.40 & 0.00 & 9.30 & 9.30 & 4.60 & 0.00 & 1.83 & 1.83 & 17 & 0 & 0 & 2 \\
\hline 12 & 1 & 24.67 & 0.00 & 7.10 & 6.63 & 6.17 & 0.00 & 9.00 & 9.00 & 34 & 5 & 3 & 1 \\
\hline 13 & 1 & 31.00 & 0.00 & 10.57 & 9.10 & 16.57 & 0.00 & 1.30 & 12.17 & 64 & 13 & 0 & 1 \\
\hline 14 & 1 & 30.07 & 0.00 & 8.47 & 9.73 & 18.53 & 0.00 & 2.13 & 19.27 & 42 & 2 & 12 & 1 \\
\hline 15 & 1 & 19.23 & 0.00 & 6.60 & 15.60 & 7.07 & 0.00 & 1.17 & 1.17 & 30 & 1 & 2 & 2 \\
\hline 16 & 1 & 23.00 & $\overline{0.00}$ & 8.63 & 8.63 & 7.43 & 0.00 & 3.70 & 3.70 & 42 & 3 & 13 & 0 \\
\hline 17 & 1 & 33.23 & 0.00 & 6.40 & 5.40 & 4.93 & 0.00 & 8.50 & 8.50 & 32 & 4 & 0 & 2 \\
\hline 18 & 1 & 24.40 & 0.00 & 11.10 & 7.10 & 7.17 & 0.00 & 4.20 & 4.20 & 33 & 0 & 7 & 2 \\
\hline 19 & 1 & 26.67 & 0.00 & 6.67 & 6.67 & 14.00 & 0.00 & 4.00 & 4.00 & 49 & 3 & 16 & 2 \\
\hline 20 & 1 & 21.73 & 0.00 & 8.23 & 8.23 & 11.5 & 0.00 & 2.00 & 2.00 & 38 & 1 & 14 & 2 \\
\hline 21 & 1 & 14.23 & 0.00 & 5.27 & 4.40 & 0.00 & 0.00 & 7.13 & 7.13 & 28 & 0 & 1 & 2 \\
\hline 22 & 1 & 26.20 & 0.00 & 5.60 & 4.00 & 16.33 & 0.00 & 2.73 & 2.73 & 51 & 1 & 0 & 2 \\
\hline 23 & 1 & 23.60 & 0.00 & 14.00 & 12.00 & 4.20 & 0.00 & 2.60 & 2.60 & 38 & 0 & 5 & 1 \\
\hline 24 & 1 & 24.80 & 0.00 & 9.17 & 9.17 & 9.00 & 0.00 & 1.00 & 1.00 & 38 & 2 & 24 & 0 \\
\hline 25 & 1 & 23.23 & 0.00 & 6.13 & 5.13 & 10.33 & 0.00 & 3.67 & 3.67 & 43 & 1 & 0 & 2 \\
\hline 26 & 1 & 25.93 & 0.00 & 6.60 & 6.60 & 16.60 & 0.00 & 1.17 & 1.17 & 47 & 2 & 21 & 0 \\
\hline 27 & 1 & 37.50 & 0.00 & 6.20 & 5.77 & 27.23 & 0.00 & 2.43 & 2.43 & 49 & 3 & 0 & 2 \\
\hline 28 & 1 & 15.83 & 0.00 & 6.50 & 5.50 & 5.70 & 0.00 & 1.60 & 1.60 & 24 & 0 & 0 & 2 \\
\hline 29 & 1 & 15.53 & 0.00 & 5.47 & 4.87 & 2.53 & 0.00 & 5.00 & 5.00 & 25 & 1 & 0 & 2 \\
\hline 30 & 1 & 27.53 & 0.00 & 11.60 & 10.60 & 13.80 & 0.00 & 1.13 & 1.13 & 44 & 1 & 2 & 1 \\
\hline 31 & 1 & 21.20 & 0.00 & 6.80 & 2.00 & 8.23 & 0.00 & 1.00 & 1.00 & 17 & 3 & 0 & 1 \\
\hline
\end{tabular}




\begin{tabular}{|c|c|c|c|c|c|c|c|c|c|c|c|c|c|}
\hline 32 & 1 & 24.77 & 0.00 & 6.00 & 6.00 & 16.33 & 0.00 & 1.13 & 1.13 & 44 & 0 & 0 & 2 \\
\hline 33 & 1 & 22.10 & 0.00 & 5.47 & 5.47 & 13.20 & 0.00 & 1.00 & 1.00 & 28 & 1 & 2 & 2 \\
\hline 34 & 1 & 18.60 & 0.00 & 6.00 & 4.00 & 6.40 & 0.00 & 4.90 & 4.90 & 28 & 0 & 0 & 2 \\
\hline 35 & 1 & 16.77 & 0.00 & 6.27 & 5.77 & 10.50 & 0.00 & 0.00 & 0.00 & 16 & 0 & 1 & 2 \\
\hline 36 & 1 & 24.00 & 0.00 & 3.47 & 7.00 & 17.50 & 0.00 & 1.00 & 15.37 & 47 & 1 & 0 & 2 \\
\hline 37 & 1 & 20.37 & 0.00 & 4.17 & 4.63 & 5.73 & 0.00 & 8.43 & 13.70 & 32 & 0 & 2 & 2 \\
\hline 38 & 1 & 32.10 & 0.00 & 6.00 & 12.80 & 23.13 & 0.00 & 1.00 & 17.17 & 51 & 4 & 8 & 1 \\
\hline 39 & 1 & 19.27 & 0.00 & 6.93 & 11.53 & 5.67 & 0.00 & 5.00 & 5.00 & 38 & 1 & 6 & 2 \\
\hline 40 & 1 & 20.50 & $\overline{0.00}$ & 11.23 & 8.00 & 4.20 & 0.00 & 0.50 & 11.30 & 35 & 2 & 1 & 2 \\
\hline 41 & 1 & 22.47 & 0.00 & 7.23 & 18.63 & 12.40 & 0.00 & 1.30 & 1.30 & 41 & 2 & 0 & 2 \\
\hline 42 & 1 & 23.57 & 0.00 & 5.30 & 16.10 & 10.80 & 0.00 & 4.47 & 4.47 & 44 & 0 & 2 & 2 \\
\hline 43 & 1 & 41.03 & 0.00 & 17.00 & 35.23 & 19.00 & 0.00 & 4.13 & 4.13 & 62 & 2 & 36 & 0 \\
\hline 44 & 1 & 22.53 & 0.00 & 6.43 & 5.50 & 9.60 & 0.00 & 4.43 & 14.47 & 28 & 1 & 5 & 2 \\
\hline 45 & 1 & 15.80 & 0.00 & 1.37 & 10.07 & 8.70 & 0.00 & 5.00 & 5.00 & 18 & 4 & 2 & 1 \\
\hline 46 & 1 & 19.80 & 0.00 & 5.00 & 9.00 & 12.70 & 0.00 & 1.00 & 9.67 & 32 & 1 & 6 & 2 \\
\hline 47 & 1 & 21.63 & 0.00 & 6.00 & 5.50 & 12.80 & 0.00 & 0.70 & 0.47 & 40 & 0 & 0 & 2 \\
\hline 48 & 1 & 22.03 & 0.00 & 5.57 & 5.33 & 9.00 & 0.00 & 3.67 & 10.77 & 36 & 1 & 1 & 2 \\
\hline 49 & 1 & 27.07 & 0.00 & 7.80 & 14.00 & 9.70 & 0.00 & 5.23 & 9.00 & 53 & 3 & 0 & 2 \\
\hline 50 & $1 \mathrm{R}$ & 43.73 & 29.50 & 7.53 & 17.43 & 10.60 & 0.00 & 1.60 & 1.60 & 31 & 1 & 0 & 0 \\
\hline 51 & $1 \mathrm{R}$ & 23.87 & 5.20 & 6.27 & 6.87 & 5.23 & 0.00 & 6.20 & 6.20 & 31 & 0 & 14 & 1 \\
\hline 52 & $1 \mathrm{R}$ & 28.03 & 7.37 & 6.20 & 6.20 & 10.13 & 0.00 & 6.43 & 6.43 & 37 & 2 & 4 & 1 \\
\hline 53 & $1 \mathrm{R}$ & 28.20 & 8.47 & 4.13 & 5.23 & 12.00 & 0.00 & 2.00 & 12.43 & 38 & 1 & 6 & 0 \\
\hline 54 & $1 \mathrm{R}$ & 46.90 & 12.27 & 10.00 & 21.73 & 23.80 & 0.00 & 10.13 & 10.13 & 59 & 3 & 33 & 0 \\
\hline 55 & $1 \mathrm{R}$ & 22.50 & 12.27 & 10.00 & 21.73 & 23.80 & 0.00 & 10.13 & 10.13 & 59 & 3 & 33 & 0 \\
\hline 56 & $1 \mathrm{R}$ & 33.07 & 10.80 & 7.40 & 20.17 & 14.07 & 0.00 & 1.37 & 1.37 & 67 & 1 & 0 & 1 \\
\hline 57 & $1 \mathrm{R}$ & 19.17 & 5.33 & 12.00 & 16.40 & 4.40 & 0.00 & 2.80 & 2.80 & 27 & 0 & 2 & 1 \\
\hline 58 & $1 \mathrm{R}$ & 40.00 & 4.57 & 8.63 & 16.80 & 7.60 & 0.00 & 16.30 & 16.30 & 45 & 0 & 12 & 1 \\
\hline 59 & $1 \mathrm{R}$ & 21.87 & 12.00 & 12.17 & 12.17 & 6.27 & 0.00 & 1.40 & 1.40 & 18 & 0 & 0 & 2 \\
\hline 60 & $1 \mathrm{R}$ & 52.80 & 8.63 & 1.00 & 9.67 & 19.80 & 0.00 & 22.73 & 38.63 & 71 & 9 & 2 & 0 \\
\hline 61 & $1 \mathrm{R}$ & 45.00 & 4.00 & 14.23 & 4.77 & 21.67 & 0.00 & 4.87 & 4.87 & 52 & 2 & 8 & 1 \\
\hline 62 & $1 \mathrm{R}$ & 26.17 & 12.00 & 13.90 & 13.90 & 6.83 & 0.00 & 0.47 & 0.47 & 48 & 2 & 8 & 0 \\
\hline 63 & $1 \mathrm{R}$ & 49.63 & 8.70 & 20.67 & 20.67 & 14.40 & 0.00 & 6.00 & 6.00 & 65 & 4 & 12 & 1 \\
\hline 64 & $1 \mathrm{R}$ & 20.27 & 3.00 & 4.43 & 4.43 & 14.73 & 0.00 & 1.00 & 12.00 & 35 & 0 & 5 & 1 \\
\hline 65 & $1 \mathrm{R}$ & 40.73 & 4.73 & 13.57 & 13.57 & 17.50 & 0.00 & 3.60 & 21.00 & 56 & 4 & 11 & 0 \\
\hline 66 & $1 \mathrm{R}$ & 60.70 & 17.20 & 22.00 & 22.00 & 19.77 & 0.00 & 2.00 & 24.50 & 52 & 5 & 18 & 0 \\
\hline 67 & $1 \mathrm{R}$ & 29.17 & 8.07 & 9.80 & 6.13 & 7.37 & 0.00 & 3.47 & 3.47 & 44 & 7 & 21 & 0 \\
\hline 68 & $1 \mathrm{R}$ & 27.83 & 8.00 & 9.13 & 10.73 & 8.07 & 0.00 & 2.53 & 8.57 & 42 & 4 & 11 & 1 \\
\hline 69 & $1 \mathrm{R}$ & 23.17 & 4.00 & 10.33 & 8.03 & 10.33 & 0.00 & 0.47 & 11.73 & 40 & 0 & 9 & 1 \\
\hline 70 & $1 \mathrm{R}$ & 20.53 & 5.33 & 1.93 & 9.93 & 9.77 & 0.00 & 3.00 & 4.63 & 35 & 1 & 8 & 1 \\
\hline 71 & $1 \mathrm{R}$ & 33.40 & 4.00 & 6.43 & 11.23 & 10.63 & 0.00 & 14.70 & 20.53 & 62 & 1 & 10 & 0 \\
\hline 72 & $1 \mathrm{R}$ & 34.57 & 3.67 & 7.40 & 19.00 & 13.73 & 0.00 & 9.37 & 10.27 & 49 & 3 & 11 & 0 \\
\hline 73 & $1 \mathrm{R}$ & 31.20 & 10.17 & 4.13 & 10.00 & 13.67 & 0.00 & 1.43 & 9.20 & 54 & 2 & 5 & 0 \\
\hline 74 & 2 & 22.17 & 0.00 & 4.77 & 4.77 & 11.17 & 11.17 & 2.27 & 2.27 & 25 & 1 & 1 & 2 \\
\hline 75 & 2 & 40.87 & 0.00 & 5.00 & 3.00 & 31.90 & 31.90 & 1.00 & 1.00 & 53 & 0 & 3 & 1 \\
\hline 76 & 2 & 28.50 & 0.00 & 13.13 & 14.43 & 9.70 & 9.70 & 4.00 & 4.00 & 57 & 9 & 0 & 0 \\
\hline 77 & 2 & 22.70 & 0.00 & 9.43 & 9.00 & 10.00 & 10.00 & 1.13 & 1.13 & 31 & 0 & 0 & 2 \\
\hline 78 & 2 & 24.17 & 0.00 & 6.87 & 6.40 & 8.00 & 8.00 & 8.03 & 8.03 & 62 & 0 & 0 & 2 \\
\hline 79 & 2 & 15.33 & 0.00 & 1.73 & 1.73 & 13.53 & 13.53 & 0.07 & 0.07 & 18 & 0 & 0 & 2 \\
\hline 80 & 2 & 44.08 & 0.00 & 3.27 & 3.27 & 19.53 & 12.70 & 19.80 & 19.80 & 74 & $\overline{19}$ & 8 & 0 \\
\hline 81 & 2 & 25.47 & 0.00 & 5.07 & 13.10 & 11.70 & 3.60 & 8.63 & 8.63 & 57 & 0 & 0 & 2 \\
\hline 82 & 2 & 38.43 & 0.00 & 7.37 & 7.37 & 26.13 & 7.13 & 5.00 & 5.00 & 55 & 1 & 1 & 2 \\
\hline 83 & 2 & 33.93 & 0.00 & 13.00 & 11.17 & 14.57 & 11.53 & 3.30 & 13.67 & 60 & 1 & 4 & 2 \\
\hline 84 & 2 & 26.23 & 0.00 & 13.23 & 11.00 & 8.60 & 10.83 & 1.67 & 1.67 & 39 & 4 & 0 & 0 \\
\hline 85 & 2 & 36.13 & 0.00 & 10.67 & 10.67 & 14.50 & 21.63 & 8.57 & 1.43 & 52 & 3 & 5 & 1 \\
\hline 86 & 2 & 25.03 & 0.00 & 12.47 & 6.00 & 9.00 & 14.13 & 2.00 & 2.00 & 64 & 0 & 2 & 0 \\
\hline 87 & 2 & 22.83 & 0.00 & 11.50 & 9.80 & 6.53 & 8.17 & 1.67 & 1.67 & 56 & 0 & 0 & 1 \\
\hline 88 & 2 & 19.87 & 0.00 & 8.30 & 13.60 & 10.60 & 9.47 & 2.70 & 4.53 & 53 & 3 & 2 & 2 \\
\hline 89 & 2 & 34.60 & 0.00 & 1.57 & 1.57 & 20.40 & 20.40 & 10.10 & 10.10 & 43 & 3 & 0 & 0 \\
\hline 90 & 2 & 33.83 & 0.00 & 7.40 & 6.30 & 23.23 & 8.00 & 2.23 & 17.47 & 72 & 1 & 0 & 1 \\
\hline 91 & 2 & 26.07 & 0.00 & 4.07 & 4.07 & 7.10 & 7.70 & 12.60 & 12.00 & 35 & 0 & 0 & 2 \\
\hline 92 & 2 & 23.30 & 0.00 & 5.30 & 3.87 & 6.67 & 5.10 & 9.00 & 12.27 & 67 & 0 & 0 & 1 \\
\hline
\end{tabular}




\begin{tabular}{|c|c|c|c|c|c|c|c|c|c|c|c|c|c|}
\hline 93 & 2 & 31.23 & 0.00 & 19.00 & 14.53 & 1.27 & 5.13 & 8.77 & 10.03 & 20 & 1 & 0 & 1 \\
\hline 94 & 2 & 30.60 & 0.00 & 8.77 & 8.50 & 6.43 & 13.57 & 13.10 & 6.33 & 84 & 3 & 2 & $\overline{0}$ \\
\hline 95 & 2 & 20.30 & 0.00 & 7.80 & 7.30 & 8.47 & 8.47 & 2.40 & 2.40 & 59 & 1 & 8 & 2 \\
\hline 96 & 2 & 32.50 & 0.00 & 7.57 & 8.80 & 7.57 & 7.57 & 4.47 & 4.47 & 47 & 8 & 0 & 1 \\
\hline 97 & 2 & 29.77 & 0.00 & 13.20 & 13.20 & 12.37 & 12.37 & 2.40 & 2.40 & 33 & 0 & 3 & 2 \\
\hline 98 & 2 & 36.10 & 0.00 & 12.90 & 15.80 & 4.37 & 4.37 & 15.63 & 15.63 & 64 & 0 & 1 & 2 \\
\hline 99 & 2 & 34.77 & 0.00 & 8.40 & 11.67 & 23.60 & 5.00 & 1.63 & 16.10 & 61 & 1 & 3 & 1 \\
\hline 100 & 2 & 19.00 & 0.00 & 5.53 & 5.53 & 12.00 & 12.00 & 1.00 & 1.00 & 25 & 0 & 0 & 2 \\
\hline 101 & 2 & 31.43 & 0.00 & 6.90 & 6.90 & 18.17 & 18.17 & 3.20 & 3.20 & 38 & 4 & 5 & 1 \\
\hline 102 & 2 & 20.93 & 0.00 & 9.30 & 8.30 & 6.17 & 6.17 & 4.40 & 4.40 & 53 & 0 & 5 & 2 \\
\hline 103 & 2 & 21.53 & 0.00 & 12.40 & 12.40 & 4.33 & 4.33 & 2.80 & 2.80 & 34 & 4 & 0 & 1 \\
\hline 104 & 2 & 38.93 & 0.00 & 10.10 & 9.20 & 22.93 & 22.93 & 3.83 & 3.83 & 29 & 3 & 23 & 0 \\
\hline 105 & 2 & 24.63 & $\overline{0.00}$ & 14.23 & 9.40 & 5.17 & 10.00 & 2.73 & 2.73 & 42 & 1 & 0 & 2 \\
\hline 106 & 2 & 24.40 & 0.00 & 9.17 & 9.17 & 9.27 & 9.27 & 3.43 & 3.43 & 46 & 0 & 0 & 2 \\
\hline 107 & 2 & 22.27 & 0.00 & 5.23 & 5.70 & 14.57 & 14.57 & 1.00 & 1.00 & 18 & 0 & 2 & 2 \\
\hline 108 & 2 & 23.00 & 0.00 & 10.37 & 10.37 & 7.30 & 7.30 & 3.30 & 3.30 & 43 & 5 & 0 & 1 \\
\hline 109 & 2 & 28.20 & 0.00 & 7.60 & 8.07 & 9.67 & 9.67 & 8.00 & 8.00 & 48 & 3 & 0 & 2 \\
\hline 110 & 2 & 43.83 & 0.00 & 10.37 & 9.73 & 30.77 & 30.77 & 1.40 & 1.40 & 52 & 8 & 5 & 0 \\
\hline 111 & 2 & 36.10 & 0.00 & 10.80 & 10.80 & 6.73 & 6.73 & 4.50 & 4.50 & 46 & 2 & 0 & 2 \\
\hline 112 & 2 & 26.17 & 0.00 & 8.53 & 8.53 & 7.17 & 7.17 & 6.83 & 6.83 & 52 & 1 & 1 & 2 \\
\hline 113 & 2 & 15.63 & $\overline{0.00}$ & 4.80 & 4.80 & 7.00 & 7.00 & 4.13 & 4.13 & 26 & 5 & 0 & 1 \\
\hline 114 & 2 & 31.27 & 0.00 & 15.23 & 15.23 & 23.23 & 23.23 & 3.30 & 3.30 & 70 & 1 & 0 & 2 \\
\hline 115 & 2 & 19.30 & 0.00 & 6.33 & 6.33 & 7.47 & 7.47 & 4.00 & 4.00 & 40 & 1 & 45 & 0 \\
\hline 116 & 2 & 37.37 & 0.00 & 10.57 & 10.57 & 10.50 & 10.50 & 12.00 & 12.00 & 57 & 4 & 3 & 0 \\
\hline 117 & 2 & 33.43 & 0.00 & 11.70 & 11.70 & 17.30 & 17.30 & 3.23 & 3.23 & 51 & 5 & 3 & 1 \\
\hline 118 & 2 & 37.20 & 0.00 & 6.90 & 6.90 & 19.63 & 19.63 & 8.47 & 8.47 & 49 & 3 & 2 & 1 \\
\hline 119 & 2 & 20.20 & 0.00 & 5.50 & 5.50 & 9.43 & 9.43 & 2.63 & 2.63 & 37 & 5 & 2 & $\overline{0}$ \\
\hline 120 & 2 & 15.80 & 0.00 & 6.93 & 6.93 & 6.87 & 6.87 & 1.00 & 1.00 & 27 & 2 & 0 & 1 \\
\hline 121 & 2 & 27.53 & $\overline{0.00}$ & 12.13 & 12.13 & 8.10 & 8.10 & 1.37 & 1.37 & 50 & 0 & 0 & 2 \\
\hline
\end{tabular}


Figura A-1

\section{FICHA DE LEVANTAMENTO DE DADOS (PESQUISA)}

1. NOME DO PACIENTE: GRUPO:

2. $\mathrm{N}^{\mathrm{o}}$ : PG ( ) E ( )

3. GÊNERO: MASCULINO（） FEMININO（）

4. DATA NASCIMENTO:

5.1 EXTRAÇÕES PRÉ -MOLARES: $2(\quad) \quad 4(\quad)$ imediatas ( ) tardias ( ) intervalo:

5.2 AEB : $\quad$ SIM ( ) NÃO ( ) TRAÇÃO :

5.3 DATA INICIO : _________ IDADE INICIO :

5.4 DATA TÉRMINO:

DURAÇÃO TRATAMENTO FIXO : RETRAÇÃO INICIAL CANINOS:_S/ MESES DIAS ALINHAMENTO/NIVELAMENTO:S/ I/

RETRAÇÃO: S/ I/

ARCOS IDEAIS + FINALIZAÇÃO: S/ I/

NÚMERO DE CONSULTAS :

NÚMERO DE FALTAS :

NÚMERO DE QUEBRAS:

COOPERAÇÃO:

QUANTIDADE DE OVERJET INICIAL : $\mathrm{mm}$.

QUANTIDADE DE OVERBITE INICIAL : - $\mathrm{mm}$. OBSERVAÇÕES ADICIONAIS: 